\title{
Are there consistent abnormalities in event-related EEG oscillations in patients with Alzheimer's disease compared to other diseases belonging to dementia?
}

\author{
Bahar Güntekin $^{1,2}$ (D) | Tuba Aktürk ${ }^{1,3,4}$ (D) | Xianghong Arakaki ${ }^{5}$ | Laura Bonanni' ${ }^{6}$ | \\ Claudio Del Percio $^{7}$ | Rebecca Edelmayer $^{8}$ | Francesca Farina, ${ }^{9,10}$ | Raffaele Ferri ${ }^{11}$ | \\ Lütfü Hanoğlu $^{12}$ | Sanjeev Kumar ${ }^{13,14}$ | Roberta Lizio ${ }^{15}$ | Susanna Lopez ${ }^{7}$ \\ Brian Murphy $^{16}$ | Giuseppe Noce ${ }^{15}$ | Fiona Randall $^{17}$ | Alexander T. Sack ${ }^{4}$ | \\ Fabrizio Stocchi $^{18}$ | Görsev Yener ${ }^{19}$ | Ebru Yıldırım ${ }^{1,3}$ (i) | Claudio Babiloni ${ }^{8,20}$
}

\footnotetext{
${ }^{1}$ Research Institute for Health Sciences and Technologies (SABITA), Regenerative and Restorative Medicine Research Center (REMER), Clinical Electrophysiology, Neuroimaging and Neuromodulation Lab, Istanbul Medipol University, Istanbul, Turkey

${ }^{2}$ Department of Biophysics, School of Medicine, Istanbul Medipol University, Istanbul, Turkey

${ }^{3}$ Vocational School, Program of Electroneurophysiology, Istanbul Medipol University, Istanbul, Turkey

${ }^{4}$ Department of Cognitive Neuroscience, Faculty of Psychology and Neuroscience, Maastricht University, Maastricht, Netherlands

${ }^{5}$ Huntington Medical Research Institutes, Pasadena, California, USA

${ }^{6}$ Department of Neuroscience Imaging and Clinical Sciences and CESI, University G d'Annunzio of Chieti-Pescara, Chieti, Italy

${ }^{7}$ Department of Physiology and Pharmacology “Vittorio Erspamer”, Sapienza University of Rome, Rome, Italy

${ }^{8}$ Alzheimer's Association, Chicago, Illinois, USA

${ }^{9}$ School of Psychology, Trinity College Dublin, Dublin, Ireland

${ }^{10}$ Trinity College Institute of Neuroscience, Trinity College Dublin, Dublin, Ireland

${ }^{11}$ Oasi Research Institute - IRCCS, Troina, Italy

${ }^{12}$ Department of Neurology, School of Medicine, Istanbul Medipol University, Istanbul, Turkey

${ }^{13}$ Adult Neurodevelopmental and Geriatric Psychiatry Division, Centre for Addiction and Mental Health, Toronto, Ontario, Canada

${ }^{14}$ Faculty of Medicine, University of Toronto, Toronto, Ontario, Canada

${ }^{15}$ IRCCS SDN, Napoli, Italy

${ }^{16}$ BrainWaveBank Ltd, Dublin, Ireland

${ }^{17}$ Vertex Pharmaceuticals Incorporated, Boston, Massachusetts, USA

${ }^{18}$ Institute for Research and Medical Care, IRCCS San Raffaele Pisana, Rome, Italy

${ }^{19}$ Izmir Biomedicine and Genome Center, Dokuz Eylul University Health Campus, Izmir, Turkey

${ }^{20}$ Institute for Research and Medical Care, Hospital San Raffaele of Cassino, Cassino, Italy
}

\section{Correspondence}

Bahar Güntekin, Department of Biophysics,

School of Medicine, Istanbul Medipol

University, Istanbul, Turkey.

Email: bguntekin@medipol.edu.tr

Funding information

Dr. Claudio Babiloni is supported

by European Committee (H2020-

\begin{abstract}
Cerebrospinal and structural-molecular neuroimaging in-vivo biomarkers are recommended for diagnostic purposes in Alzheimer's disease (AD) and other dementias; however, they do not explain the effects of AD neuropathology on neurophysiological mechanisms underpinning cognitive processes. Here, an Expert Panel from the Electrophysiology Professional Interest Area of the Alzheimer's Association
\end{abstract}


EU.1.3.1.H2020-MSCA-ITN-ETN-2016 project with short title "BBDiag") reviewed the field literature and reached consensus on the event-related electroencephalographic oscillations (EROs) that show consistent abnormalities in patients with significant cognitive deficits due to Alzheimer's, Parkinson's (PD), Lewy body (LBD), and cerebrovascular diseases. Converging evidence from oddball paradigms showed that, as compared to cognitively unimpaired (CU) older adults, AD patients had lower amplitude in widespread delta $(>4 \mathrm{~Hz})$ and theta $(4-7 \mathrm{~Hz})$ phase-locked EROs as a function of disease severity. Similar effects were also observed in PD, LBD, and/or cerebrovascular cognitive impairment patients. Non-phase-locked alpha $(8-12 \mathrm{~Hz})$ and beta $(13-30 \mathrm{~Hz})$ oscillations were abnormally reduced (event-related desynchronization, ERD) in AD patients relative to CU. However, studies on patients with other dementias remain lacking. Delta and theta phase-locked EROs during oddball tasks may be useful neurophysiological biomarkers of cognitive systems at work in heuristic and intervention clinical trials performed in AD patients, but more research is needed regarding their potential role for other dementias.

\section{K E Y W O R D S}

Alzheimer's disease mild cognitive impairment (ADMCI), Alzheimer's disease (AD), event-related desynchronization, event-related oscillations (EROs), event-related potentials (ERPs), eventrelated synchronization, lewy body dementia (LBD), Parkinson's disease (PD), vascular cognitive impairment (VCI)

\section{1 | BACKGROUND}

\section{1 | The gap in Alzheimer's disease (AD) biomarkers}

Alzheimer's disease (AD) is one of the most diffuse neurodegenerative disorders characterized by a progressive cognitive decline to dementia. Several biomarkers of AD are currently used in clinical research. According to the US National Institute on Aging-Alzheimer's Association (NIA-AA), in-vivo cerebrospinal fluid (CSF) measures of Abeta and phoshpo tau and amyloid/tau positron emission tomography (PET) maps allow the diagnosis of $\mathrm{AD}$ at the preclinical, prodromal (with objective mild cognitive impairment, MCI), and overt dementia stages for clinical trials (Albert et al., 2011; Jack et al., 2018; McKhann et al., 2011). Furthermore, AD progression may be monitored by biomarkers derived from 18Fluorodeoxyglucose PET (FDG-PET), total tau in CSF, and magnetic resonance imaging (MRI) of brain atrophy in temporoparietal cortex and the medial temporal lobes (including the hippocampi).

Apart from the indirect role played by FDG-PET as a sensitive marker of neural and synaptic integrity, none of the above biomarkers reflects effects of AD neuropathology on neurophysiological mechanisms underpinning cognitive processes. To fill this gap, measures of scalp-recorded electroencephalographic (EEG) rhythms are promising as they are non-invasive, cost-effective, and based on recording techniques largely available worldwide, including lowerand middle-income countries (Babiloni, Barry, et al., 2020; Babiloni, Blinowska, et al., 2020; Rossini et al., 2020). These EEG measures may probe the effects of AD on ascending activating systems and reciprocal thalamus-cortical circuits in which oscillatory (de)synchronizing signals underpin cortical arousal during quiet vigilance and sensory processing in cognitive-motor tasks (Babiloni, Barry, et al., 2020; Babiloni, Blinowska, et al., 2020; Pfurtscheller and Lopes da Silva, 1999; Rossini et al., 2020).

In $\mathrm{AD}$ patients, abnormalities in event-related EEG rhythms may reflect the effect of $\mathrm{AD}$ neuropathology on (1) the synchronous conduction of action potentials along neural networks in multiple cortical areas and (2) synaptic transmissions, thus affecting spatial and temporal summation of post-synaptic potentials in cortical pyramidal neurons and, consequently, scalp-recorded EEG activity (de Haan et al., 2009; Pfurtscheller and Lopes da Silva, 1999; Pievani et al., 2011; Stam et al., 2007; Teipel et al., 2016). Animal studies have elucidated the cellular and molecular basis of these effects at cortical and subcortical levels as loss of myelinated axons possibly associated with cortical neural hyperexcitability and hypersychronization as well as reduced neurotransmission, neural signaling, and synaptic activity (Crunelli et al., 2015; Steriade, 1993).

Resting state eyes-closed EEG rhythms in quiet vigilance have been repeatedly investigated in $\mathrm{AD}$ patients as candidate biomarkers in clinical trials (for reviews, see Babiloni et al., 
2021; Babiloni, Blinowska, et al., 2020; Rossini et al., 2020). The most consistent findings from this research indicates that $\mathrm{AD}$ patients with $\mathrm{MCI}$ and dementia show abnormalities in peak frequency, power, and "interrelatedness" at posterior alpha $(8-12 \mathrm{~Hz})$ and widespread delta $(<4 \mathrm{~Hz})$ and theta $(4-8 \mathrm{~Hz})$ rhythms according to disease progression (Babiloni et al., 2021).

\section{2 | Phase- and non-phase-locked event- related EEG oscillations}

Another well-known application of the EEG technique in AD patients allows for the study of EEG activity phase-locked to sensory stimuli or participant responses during cognitive tasks, the so-called event-related potentials or ERPs (Babiloni, Blinowska, et al., 2020). It is well known that ERPs are obtained by averaging voltages across artifact free EEG epochs related to all sensory stimuli or participant responses using the stimulus or response onset as a zerotime. This method allows for the removal of neural processes that are not phase-locked to sensory stimuli during the EEG recording.

The cognitive task most commonly used to elicit eventrelated EEG activity is that of the active oddball paradigm (Donchin et al., 1973; O'connell et al., 2012; Polich \& Kok, 1995). In this paradigm, a series of frequent $(70 \%-$ $80 \%)$ and rare $(30 \%-20 \%)$ auditory or visual stimuli are presented to the participant. The participant must immediately respond to the rare (target) stimuli by button-press or other motor action, or by mental-counting the number of the stimuli (which are then reported to the experimenter at the end of the task) (Donchin et al., 1973; Horvath et al., 2018; O'connell et al., 2012; Polich \& Kok, 1995). As compared to ERPs computed by averaging the EEG epochs related to frequent stimuli, ERPs for the target stimuli are characterized by a large parietal late positive potential peaking at $\sim 300$ 400 ms post-stimulus, the so called $\mathrm{P} 300$ or $\mathrm{P} 3 \mathrm{~b}$ component, reflecting focused attention, decision making, and working memory (Donchin et al., 1973; O'connell et al., 2012; Polich \& Kok, 1995).

Delayed latency and lower amplitude in the oddball P300 have repeatedly been observed in patients with $\mathrm{AD}$ at different clinical stages (Golob et al., 2007; Polich \& CoreyBloom, 2005). Effects have also been reported (though with less large-scale replication) for early sensory and sub-conscious attention components, such as the auditory steady-state, P50 and Mismatch Negativity (MMN), and later cognitive components, such as the N400, Late Positive Potential (LPP), P600 and Error Related Negativity (ERN) (Bobes et al., 2010; Olichney et al., 2002, 2006, 2011; Quiroz et al., 2011). Some of these early components have demonstrated translational equivalence to EEG work with rodents (Drinkenburg et al., 2015).
EEG activity recorded during cognitive tasks of episodic memory, language processing and executive function can provide further neurophysiological information in the frequency domain to enhance our understanding of the effects of $\mathrm{AD}$ on brain functions (Babiloni, Blinowska, et al., 2020). In this line, ERPs can be analyzed by decomposing the phase-locked EEG oscillatory impulses at delta, theta, alpha, beta, and gamma frequency bands that linearly compose them, the so-called event-related EEG oscillations (EROs; Herrmann \& Knight, 2001; Lejko et al., 2020; Neuper et al., 2006; Yener \& Başar, 2010; Yener \& Başar, 2013).

The ongoing EEG activity recorded during cognitive tasks can also be linearly analyzed to exploit event-related increase or decrease in amplitude (power) of the ongoing oscillatory responses non-phase locked to the stimulus or response onset at delta, theta, alpha, beta, and gamma frequency bands, the so-called event-related desynchronization/synchronization (ERD/ERS) (Pfurtscheller and Lopes da Silva, 1999).

Such EROs and ERD/ERS measures have significant potential for understanding the abnormal cognitive neurophysiological systems that occur in AD relative to other dementias such as Parkinson's (PD), Lewy Body (LBD), and vascular cognitive impairment (VCI).

\section{AIMS AND METHODOLOGY}

The Steering Committee of the Electrophysiology Professional Interest Area (EPIA) of The Alzheimer's Association International Society to Advance Alzheimer's Research and Treatment (ISTAART), Alzheimer's Association (AA; https://www.alz.org/), formed a large Expert Panel to review the literature and provide recommendations on candidate ERO and ERD/ERS measures for characterizing neurophysiological oscillatory mechanisms in AD, PD, LBD, and VCI dementias. The Expert Panel was multidisciplinary and included expertize from the fields of neurology, psychiatry, and neuroimaging of dementias, clinical neurophysiology and quantitative EEG of dementias and cognitive and systems neurosciences. The Panel addressed the following specific question: What are the ERO and ERD/S measures that most consistently reveal abnormalities in brain neurophysiological oscillatory mechanisms in $\mathrm{AD}$ patients relative to age-matched cognitively unimpaired (CU) people and patients with PD, LBD, and cerebrovascular diseases?

To address to this question, the Panel pursued the following objectives: (1) identification of abnormal ERO and $\mathrm{ERD} / \mathrm{S}$ measures in AD patients, (2) assessment of how these measures are affected by the progression of the cognitive impairment, and (3) the extent to which these measures can differentiate patient sub-groups. 
A comprehensive literature search was completed on EROs and ERD/S in Alzheimer's disease patients with MCI (ADMCI) and dementia (ADD), Parkinson's disease patients with MCI (PDMCI) and dementia (PDD), LB disease with MCI (LBMCI), and dementia (LBD), and cerebrovascular disease with MCI and dementia (major and minor VCI).

The literature review was performed using the Scopus and PubMed databases, which were carefully searched by the authors (TA, EY, and BG) until November 4, 2020. Searches were performed under "Title, abstract and keywords" in Scopus, and "Title, abstract" in PubMed.

Keywords for the AD patients were as follows: "Dementia" OR "Mild Cognitive Impairment" AND "Brain Oscillation" OR "Event-Related Oscillation"; OR "Event-Related Desynchronization"; OR "Event-Related Synchronization"; OR "Induced Oscillation"; OR "Evoked Oscillation." Identical literature searches were carried out for patients with $\mathrm{PD}, \mathrm{LBD}$, and cerebrovascular disease with MCI and dementia (major and minor VCI).

All selected papers were critically reviewed by three members of the Expert Panel (BG, EY, and TA). Only eventrelated EEG studies were included. Studies using long stimuli (several hundreds of milliseconds) or where the analysis was not finely time-locked to the event onset, and those that used EEG measurements in patients in the resting state condition were excluded. Afterward, four members of the Expert Panel (BG, EY, TA, and CB) produced a first draft of the manuscript. This draft was sent to the co-Authors for amendments. Following revisions, the Panel reached a unanimous consensus about the findings and recommendations. The manuscript was finalized in mid-February and revised in July 2021.

It should be noted that the terms and methodological procedures discussed in this manuscript may not correspond to those used in daily medical practice, and we do not recommend that neurologists and psychiatrists use the present terms and procedures in their practice for diagnostic, prognostic, or monitoring purposes. Indeed, this manuscript is not a collection of guidelines for the application of techniques of clinical neurophysiology in daily medical practice. Similarly, the manuscript was not designed to suggest revisions to diagnostic criteria. Rather, it was designed to reach consensus recommendations on the optimal ERO and ERD/S measures to be used in clinical trials enrolling AD patients. Notably, the present review of the literature was not based on standard procedures typically adopted by international biomedical societies for the review of the medical intervention and practice (e.g., among them, see the GRADE Handbook to address the so-called PICO health care questions, https://gdt.gradepro. org/app/handbook/handbook.html). The authors hope that the field will soon reach maturity for involvement of international biomedical societies for that purpose.

Significant caveats and intrinsic limitations of this article include (i) the potentially restrictive criteria used for the literature review and classification; (ii) the inclusion of studies that have applied the heterogeneous diagnostic criteria for $\mathrm{AD}$, which been used for decades, and therefore may not exclude AD patients with moderate cerebrovascular, non-AD hippocampal impairment (TDP-43), and Lewy body co-pathology, especially in older groups; (iii) the use of the term ADMCI to denote patients with amnesic MCI, thus suggesting possible prodromal ADMCI without a diagnosis based on in-vivo biomarkers of $\mathrm{AD}$; (iv) the blurring effects of the head as a volume conductor spreading scalp EEG activity, and (v) heterogeneous procedures for the detection of artifacts in preliminary EEG data analysis.

\section{3 | PROCEDURES FOR THE ANALYSIS OF EVENT- RELATED OSCILLATIONS (EROS) AND EVENT-RELATED DESYNCHRONIZATION/ SYNCHRONIZATION (ERD/ERS)}

In event-related EEG paradigms, many epochs (typically $>20$ ), each keyed to a time-locking stimulus or response event, are recorded in sequence to reach a sufficient signalto-noise ratio. In any EEG epoch, event-related EEG potentials within $\sim 1 \mathrm{~s}$ post-stimulus are embedded in greater non-phase locked ongoing EEG rhythms that are unrelated to the stimulus. After the averaging of all artifact-free EEG epochs related to the event onset, these potentials become visible in the ERPs and can be studied in terms of peak amplitude, latency, and topography (distribution over the scalp). Thanks to the averaging procedure, non-phase locked EEG rhythms unrelated to the event-onset are markedly reduced (Güntekin \& Emek-Savaş, 2019; Luck, 2014).

Many measures can be derived from event-related EEG epochs as illustrated in Figure 1. In the following sections, we briefly review these and report main findings in understanding the pathophysiological oscillatory mechanisms generating abnormal EROs and ERD/ERS in patients with $\mathrm{AD}$ compared to other dementias.

\section{1 | Event-related digital filtering of ERP}

There is ongoing discussion about the optimal procedures to analyze and interpret scalp-recorded event-related EEG activity in time and frequency domains (Helfrich \& Knight, 2019; Sauseng et al., 2007). From an analytical point of view, EEG activity can be decomposed as several overlapping oscillations of the voltage (i.e., waveforms), each characterized by: (i) a phase related to stimulus or response onset, (ii) a time evolution within 1s post-stimulus at frequency bands, and (iii) a scalp (source) topography of the maximum amplitude 


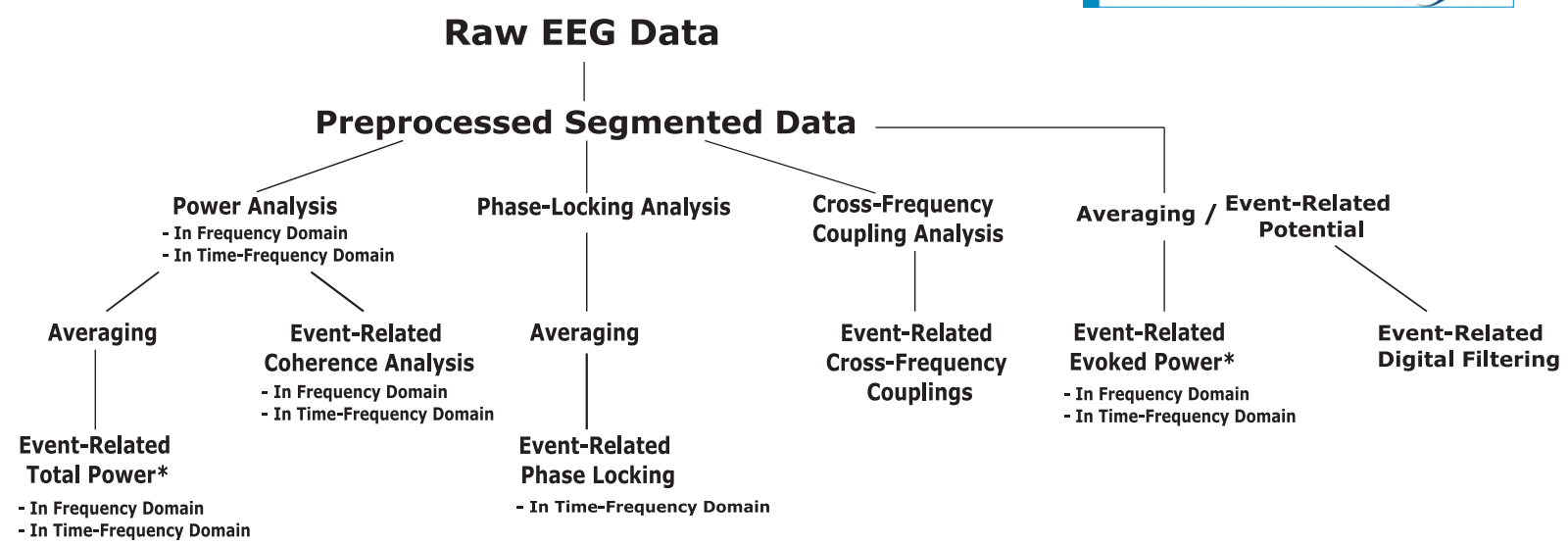

*(Event-Related Total Power) - (Event-Related Evoked Power) = Event-Related Induced Power

F I G U RE 1 Common methodologies used in event-related oscillation studies

(Başar et al., 1992, 1999). Signal processing methods can be used to derive these oscillations from the original eventrelated EEG activity and analyze them separately (Başar, Gölbaşı, et al., 2016).

Decades ago, Erol Başar (1972) and colleagues proposed that averaged ERPs can be conceived as the superimposition of EEG oscillatory impulses (i.e., EROs), which are induced by sensory stimulus processing and be analyzed by spectral analysis techniques. Digital bandpass filtering is widely used to separate band frequency components forming ERPs such as delta $(0.5-3.5 \mathrm{~Hz})$, theta $(4-7 \mathrm{~Hz})$, alpha $(8-13 \mathrm{~Hz})$, beta $(15-30 \mathrm{~Hz})$, and gamma $(28-48 \mathrm{~Hz})$. The band passed ERPs at each frequency band (i.e., EROs) can be analyzed as peakto-peak amplitude within 1s post-stimulus and topography (Güntekin \& Emek-Savaş, 2019).

EROs can also be derived by the calculation of phase and power density from the averaged ERPs at frequency bands from delta to gamma (Başar, Gölbaş1, et al., 2016). In the analysis of EROs, the combination of results from digital filtering and power density analysis provides an enriched view of the underlying neurophysiological mechanisms generating event-related and phase-locked EEG activity (Başar, Gölbaşı, et al., 2016).

\section{2 | Event-related power spectrum of EEG epochs}

Spectral analysis can be applied on epochs at scalp electrodes or source estimates to derive other interesting measures of event-related EEG activity. This analysis can be performed by time-frequency procedures that take into account the intrinsic non-stationary nature of event-related EEG signals (Cohen, 2014; Güntekin \& Emek-Savaş, 2019). Specifically, time-frequency analysis provides estimates of the power of event-related EEG epochs at frequency bands in relatively short time periods ( 1 s post-stimulus). Short-time Fourier transform (STFT) and wavelet transform (WT) methods have gained in popularity for this purpose (Başar, Gölbaş1, et al., 2016).

The power of EEG activity in post-stimulus periods can be corrected for the pre-stimulus values as a type of "baseline correction". A popular procedure for baseline correction is ERD/S (Pfurtscheller \& Andrew, 1999). For each EEG epoch, electrode, and frequency band of interest, ERD/S computes the time course of the percentage of power changes after a stimulus (or before the onset of a voluntary movement) relative to a previous period of background EEG activity. For any given period, a percentual decrease of EEG power at that frequency band (relative to baseline values) is called ERD, while a percentual increase is called ERS. Notably, this procedure investigates the event-related and non-phase-locked EEG oscillatory activity, so a model of ERPs is removed from any event-related EEG epoch before the computation of ERD/ERS (Pfurtscheller and Lopes da Silva, 1999).

Another methodological approach to investigate the timeand non-phase-locked component of event-related EEG activity is the computation of the so-called "induced" EEG power, as opposed to "evoked" EEG power computed applying spectral analysis on ERPs (Herrmann et al., 2004, 2014). The induced EEG power represents the time- and non-phaselocked component of event-related EEG activity. To compute this, EEG power is calculated by averaging the power of the single EEG epochs. Induced EEG power is then obtained by subtracting evoked power from total power (Herrmann et al., 2004, 2014).

\section{3 | Event-related phase locking analysis of EEG epochs}

Phase-locking analysis of event-related EEG activity at each electrode and frequency band of interest measures the consistency of the spectral phase values across all EEG epochs 
related to single events. It is independent of EEG power computed in those epochs and reflects the stability in the phase-locking reactivity of underlying neurophysiological oscillatory mechanisms during the course of the experiment (Delorme \& Makeig, 2004; Herrmann et al., 2004, 2014). Phase locking values are normalized between 0 and 1. For each electrode and frequency band of interest, a phaselocking value of 1 indicates that within the period of interest, the phase of the event-related EEG oscillatory impulse is equal across EEG epochs. In contrast, a phase-locking value of 0 represents random values of the phases of that oscillatory impulse across EEG epochs. A popular method to compute phase information is the Wavelet Transform, also termed as inter-trial coherence (Delorme \& Makeig, 2004).

\subsection{Event-related coherence analysis of EEG epochs}

Spectral coherence analysis of event-related EEG activity at a given frequency band measures the linear and bivariate interdependence of that activity at an electrode or source pair. This analysis is challenging due to issues of volume conduction, spatial blurring of EEG signals by the skull, and the indeterminacy of EEG source reconstruction techniques (Haufe et al., 2013; Mahjoory et al., 2017). Many other linear and non-linear procedures can be applied with the same purpose (Babiloni, Blinowska, et al., 2020). Caveats with the use of these techniques have recently been discussed by an International Federation of Clinical Neurophysiology Workgroup (Babiloni, Barry, et al., 2020). Simulated and empirical comparisons have shown sensor-based phase-lag approaches to be effective (Ruiz-Gómez et al., 2019).

\section{5 | Event-related cross-frequency couplings of epochs}

For each electrode, the cross-frequency coupling of eventrelated EEG activity measures the dependence of that activity at a frequency band on the activity computed at another frequency band. This analysis is based on previous evidence that EEG rhythms at low frequency bands (i.e., delta and theta) may trigger and frame operative EEG rhythms at higher frequency bands (i.e., beta and gamma; Canolty \& Knight, 2010).

There are several different approaches to cross-frequency coupling analysis. Commonly used approaches include the computation of multiple coupled charateristics of eventrelated EEG activity, such as amplitude (of a frequency band)-amplitude (of another frequency band), powerpower, phase-amplitude and phase-phase. Several mathematical methods can be used to test each cross-frequency coupling approach (Bruns et al., 2000; Canolty et al., 2006; Cohen, 2008, 2014; Friston, 1997; Martínez-Cancino et al., 2019; Penny et al., 2008; Tort et al., 2010; Voytek et al., 2013).

The event-related cross-frequency coupling analysis is used to evaluate the interdependence of the event-related EEG activity for an electrode (source) pair. In this analysis, the procedure computes the interrelatedness between a given spectral characteristic of the EEG activity at one electrode (source) with that computed at another electrode (source; Cohen, 2014). Therefore, it can be considered as an additional approach to the study of brain neural newtorks with EEG techniques.

\section{4 | EVENT-RELATED OSCILLATION STUDIES IN ADMCI AND ADD PATIENTS}

\section{1 | Event-related delta responses in ADMCI and ADD patients}

In wakefulness, scalp-recorded EEG oscillatory activity at delta frequencies occurs at $\sim 0.5-3.5 \mathrm{~Hz}$ and may be generated mainly by cycles of hyperpolarization and depolarization in large populations of cortical pyramidal neurons via thalamic inputs (Steriade and Buzsaki, 1990; Steriade et al., 1990; Steriade, 1993). However, delta activity can also be recorded in several locations in the human brain, including the nucleus accumbens (Leung \& Yim, 1993), ventral tegmental area (Grace, 1995), ventral pallidum (Lavin \& Grace, 1996), and the brain stem (Lambertz \& Langhorst, 1998).

Başar and Stampfer (1985) and Stampfer and Başar (1985) revealed the essential role of an event-related transient increase in EEG delta oscillations (i.e., hundreds of milliseconds) in CU adults during cognitive tasks including decision making and working memory. A similar transient increase in EEG delta responses was also found during the processing of emotional stimuli (Karamacoska et al., 2018; Maffei, 2020; Venturella et al., 2019). A typical experimental condition eliciting these delta oscillations is the "oddball" paradigm. In this task, widespread delta oscillations have been shown to increase in amplitude during rare auditory or visual "target" stimuli requiring a cognitive response, compared to frequent stimuli to be ignored (Bachman \& Bernat, 2018; Basar \& Stampfer, 1985; Demiralp et al., 2001; Güntekin \& Başar, 2016; Stampfer \& Başar, 1985). The topology of these delta responses varies according to stimulus modality. While visual and auditory oddball paradigms elicit higher frontal, central, and parietal delta responses, more complex visual stimuli with emotional contents elicit greater parietal and occipital delta responses (Güntekin \& Başar, 2009, 2016; Güntekin et al., 2008; Venturella et al., 2019). 
Evidence shows that physiological and pathological brain aging reduces the amplitude of event-related EEG delta responses (Emek-Savaş et al., 2016; Kurt et al., 2014; Michalopoulos et al., 2012; Schmiedt-Fehr and BaşarEroğlu, 2011; Yener et al., 2013, 2014, 2016). For example, two studies by Emek-Savaş et al. (2016) and Schmiedt-Fehr and Başar-Eroğlu (2011) found lower delta responses to visual stimuli in older adults relative to younger adults during visual oddball and go/no-go tasks, respectively.

Similarly, Liu et al. (2012) analyzed event-related crossmutual information between different electrodes in ADMCI patients, possibly due to $\mathrm{AD}$, young adults, and $\mathrm{CU}$ older adults during auditory oddball paradigms. These authors reported reductions in event-related delta responses across multiple scalp regions in the older $\mathrm{CU}$ and ADMCI groups compared to the young group, and reductions in delta at parietal-occipital electrodes in ADMCI patients relative to CU groups (Liu et al., 2012). Furthermore, Michalopoulos et al. (2012) showed that progressive ADMCI patients had lower delta phase-locking compared to $\mathrm{CU}$ participants, but found no group differences in event-related delta power. Similarly, Başar's group showed that ADMCI patients had lower delta responses during auditory (Kurt et al., 2014) and visual oddball paradigms, compared to CU participants (Yener et al., 2013, 2014, 2016). Furthermore, Yener and Başar (2013) reported that delta responses to oddball target stimuli were less affected in ADMCI than ADD patients.

The effect of pathological brain aging on event-related EEG delta responses was even more pronounced in ADD patients. Yener et al. (2008), Yener et al. (2012) found marked decreases in topographically widespread delta EROs to auditory and visual oddball target stimuli in ADD patients compared to CU adults. Notably, delta responses of ADMCI patients and CU controls were positively correlated with frontal cortical gray matter volume (Yener et al., 2016). Similarly, event-related delta coherence over frontal-parietal electrode pairs was lower in ADD patients when compared to CU controls during the visual oddball paradigm (Başar et al., 2010; Güntekin et al., 2008). Caravaglios et al. (2008) and Tülay et al. (2020) confirmed the above effects, with some minor methodological differences.

As the successful processing of and reaction to oddball target stimuli requires selective attention and limited working memory load, it can be speculated that abnormal phase-locked delta EROs in ADMCI and ADD patients may reveal a dysfunction in those processes of executive function (Miyake et al., 2000). This dysfunction may be specific to the oddball, as Fraga et al. (2017) did not find any significant effect on delta EROs in ADMCI and ADD patients during the so-called N-back working memory task. In this task, the participant has must respond to the stimulus that appeared some (i.e., N) events before. As compared to the oddball paradigm, the N-back task imposes a larger load on working memory and cognitive control to mitigate interference effects. Thus, the relatively high background brain arousal occurring during the N-back task may reduce differences in phase-locked delta EROs between CU adults and ADD patients. Notably, a reanalysis of the same EEG datasets revealed that ADMCI patients had lower delta non-phase-locked ERD relative to CU persons. These results highlight the complex interrelatedness between parallel phase- and non-phase-locked neural synchronization mechanisms, brain arousal, stimulus information and cognitive-motor information processing.

Table 1 summarizes the studies on event-related delta responses in ADMCI and ADD patients in chronological order.

\section{2 | Event-related delta responses in non- AD dementias}

Caution is needed when considering reduced event-related delta responses as an electrophysiological biomarker for $\mathrm{AD}$, as the effect may simply be a non-specific indicator of brain disorders.

Along this line, cognitively intact PD patients have shown lower delta EROs relative to CU adults during cognitive tasks (Emek Savaş et al., 2017), but not during emotional processing (Yuvaraj et al., 2016) or lateralization tasks (Schmiedt-Fehr et al., 2007). In a separate study, delta EROs during oddball target detection were lower as a function of cognitive decline in PD patients compared with CU participants (Güntekin et al., 2018), but no difference was found in delta evoked by auditory stimuli not associated with cognitive demands (Güntekin et al., 2018). In another study, Yener et al. (2019) compared event-related delta power and phase-locking responses during a visual oddball task between ADMCI, PDMCI, and CU groups. Results showed reduced event-related delta power in the PDMCI group compared to the $\mathrm{CU}$ group and reduced delta phase locking in the PDMCI group compared to the ADMCI group (Yener et al., 2019). Furthermore, Rosenblum et al. (2020) analyzed event-related power and phase-locking during visual and auditory oddball tasks in LBD and CU groups. Delta power responses were lower in the LBD than in the CU group during both visual and auditory versions of the task. In contrast, only delta phase-locking responses during the auditory oddball task were lower in the LBD than in the CU group (Rosenblum et al., 2020). These authors also showed that LBD patients' scores on the motor Movement Disorder Society Unified Parkinson's Disease Rating Scale (MDS- UPDRS) were negatively correlated with delta power responses to visual stimuli (Rosenblum et al., 2020).

Abnormalities in event-related delta responses have also been found in major VCI patients. Xu et al. (2011) reported reduced delta ERS during a visual oddball task in major VCI patients compared to $\mathrm{CU}$ controls over frontal, central, and 


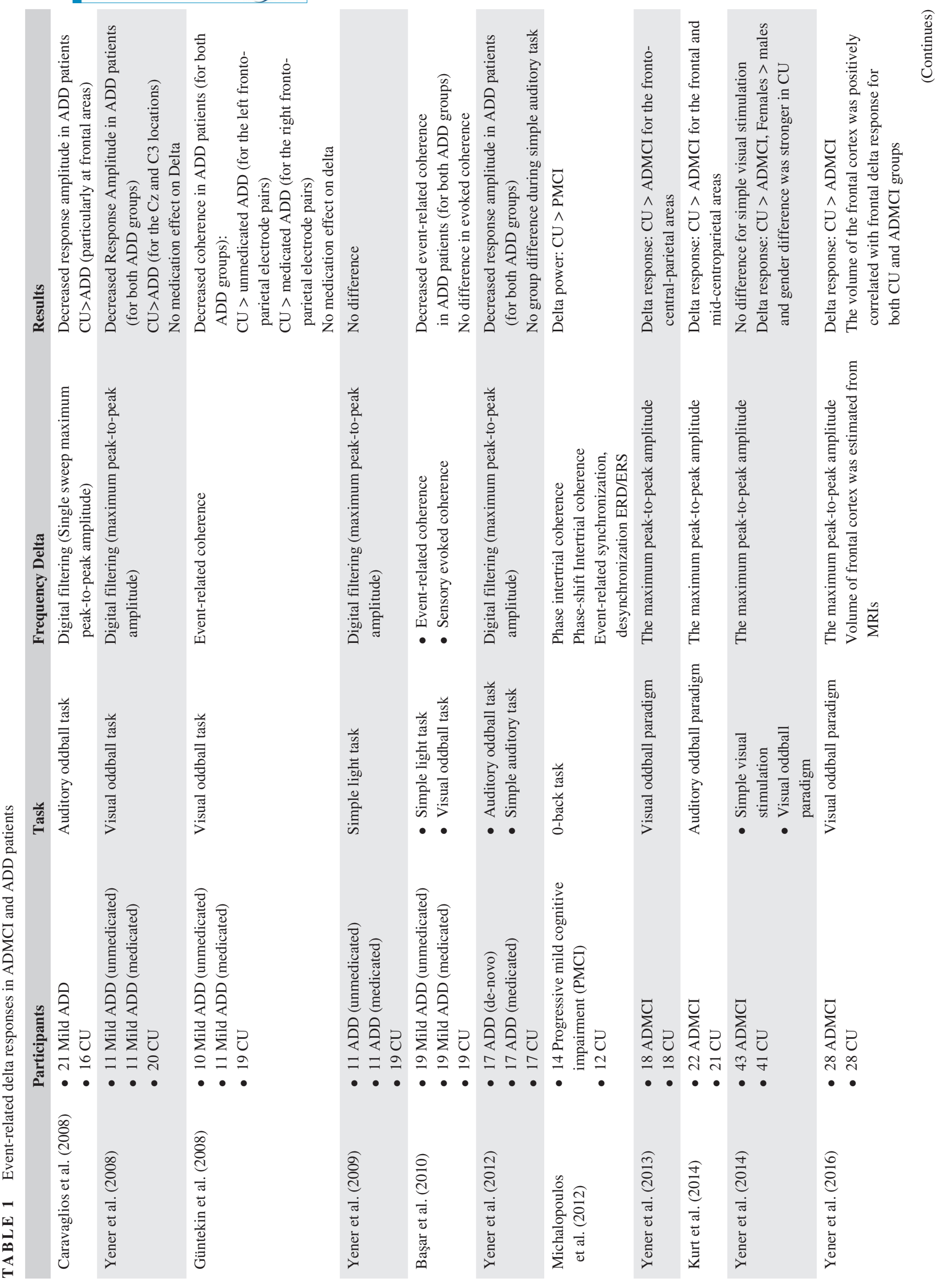


parietal electrodes. Furthermore, Xu et al. (2015) reported a decrease in the pre- and post-stimulus interdependence of delta responses at electrode pairs in VCI patients. In similar experimental conditions, Lou et al. (2011) found reduced event-related delta synchronization in VCI patients, while Wang et al. (2016) identified an abnormal topology (i.e., clustering coefficient) in the event-related delta responses (graph-theory markers) in these patients, relative to controls (Wang et al., 2014, 2016).

Notably, the above abnormalities in event-related delta responses may not be specific to patients with dementia. Indeed, similar reductions in delta responses have been found in patients with schizophrenia (Bates et al., 2009; Doege, Jansen, et al., 2010; Doege, Kumar, et al., 2010; Ergen et al., 2008; Ford et al., 2008; Roschke and Fell, 1997) and bipolar disease (Atagün et al., 2014; Lundin et al., 2018). Moreover, patients with alcohol use disorder have been shown to exhibit lower event-related delta responses as compared to CU participants during go/no go (Kamarajan et al., 2004) and visual oddball tasks (Jones et al., 2006). Reduced eventrelated delta responses during the visual oddball tasks have also been observed in the adolescent children of parents with alcohol use disorder as compared to controls (Rangaswamy et al., 2007). Therefore, event-related delta responses during cognitive tasks may characterize impairments in brain disorders more broadly, rather than being a signature of $\mathrm{AD}$ or other dementias.

Table 2 summarizes the results of event-related oscillatory responses in all frequency bands in other types of ADMCI and dementia patients.

\section{3 | Event-related theta responses in ADMCI and ADD patients}

Similar to delta responses, previous studies have demonstrated transient event-related magnitude increases in EEG theta oscillations (i.e., hundreds of milliseconds) in CU participants during cognitive tasks. Studies also highlight lower event-related theta power in older relative to younger $\mathrm{CU}$ participants across various tasks. These include the Sternberg (Hogan et al., 2003), verbal working memory (Cummins \& Finnigan, 2007), go/no-go (Schmiedt-Fehr and Başar-Eroglu, 2011), probabilistic learning (van de Vijver et al., 2014), Stroop (Tafuro et al., 2019), visual delayed match-to-sample, visual oddball (Kardos et al., 2014) and auditory oddball tasks (Müller et al., 2009). Similarly, the peak frequency of theta responses was lower in older adults $($ mean $=4.1 \mathrm{~Hz})$ compared to the young adults (mean $=5.2 \mathrm{~Hz}$; van de Vijver et al., 2014). Findings with other measures of event-related thetas responses, such as phase-locking and phase synchronization, were less robust (Aktürk et al., 2020; Kolev et al., 2009; Müller et al., 2009). 

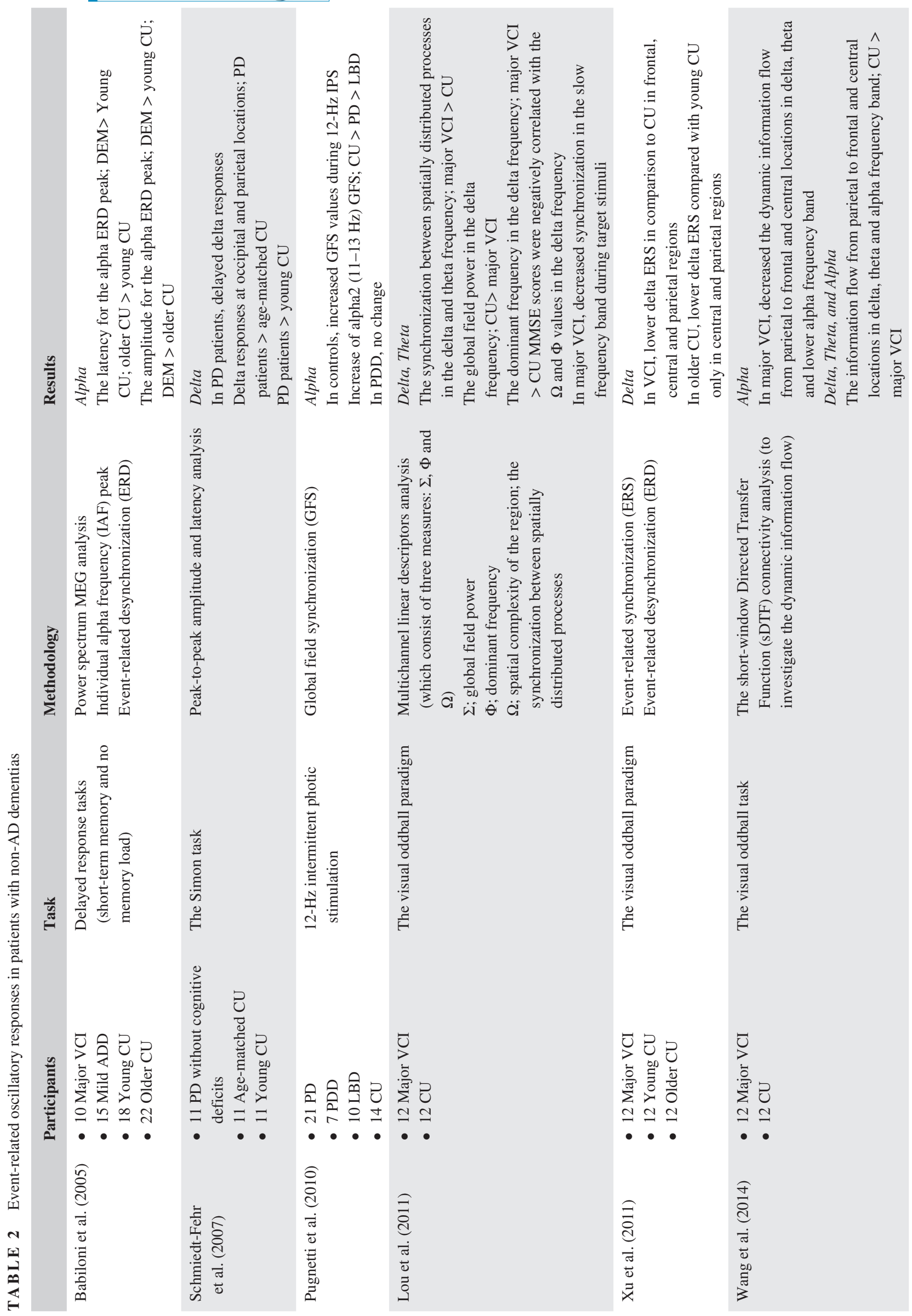

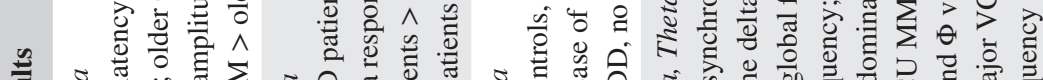



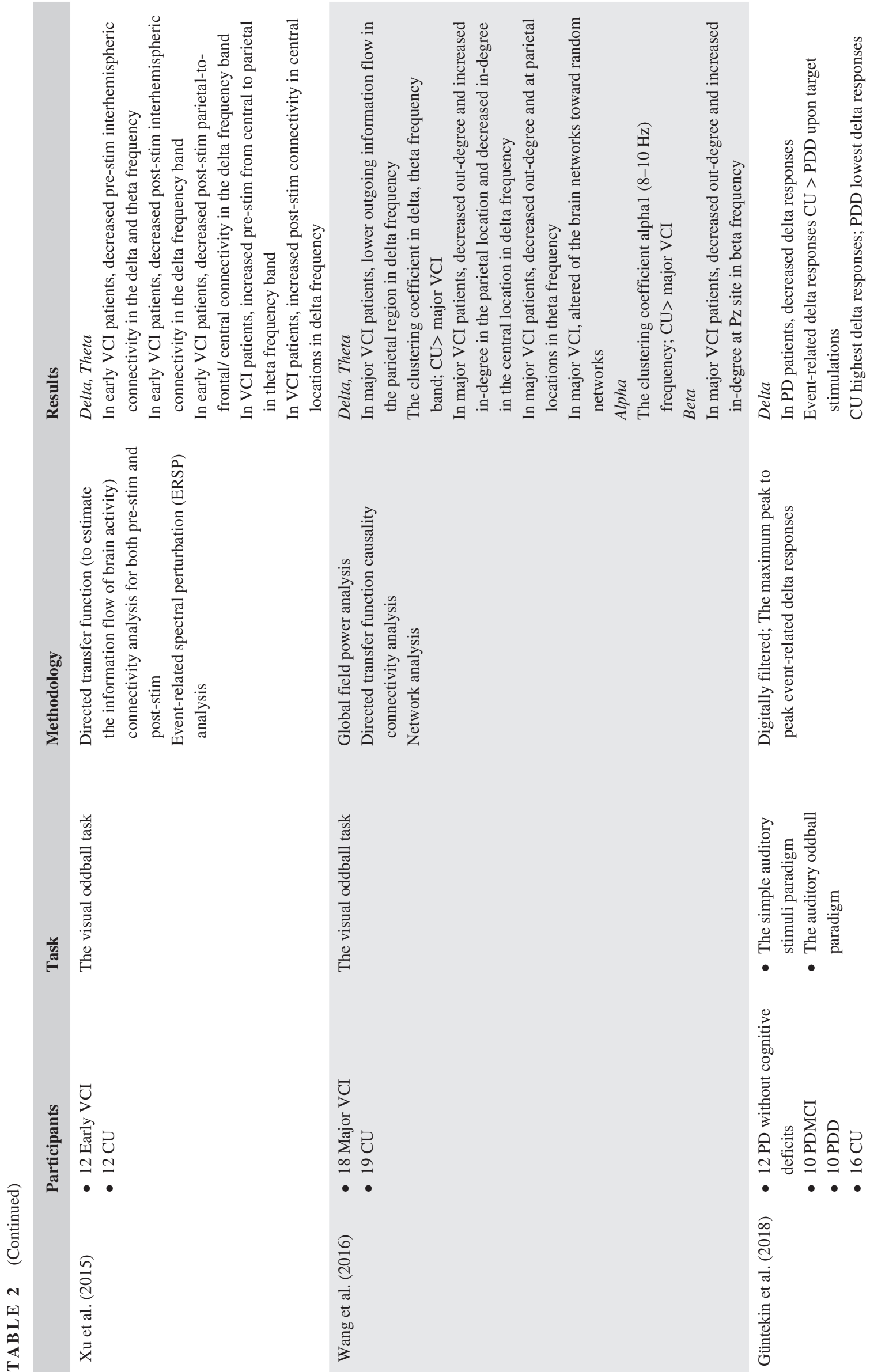
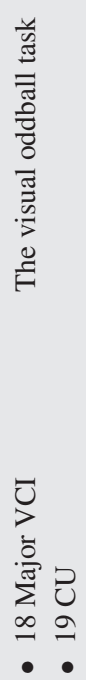

0
0
0
0
1
5
0
0
5
5
3
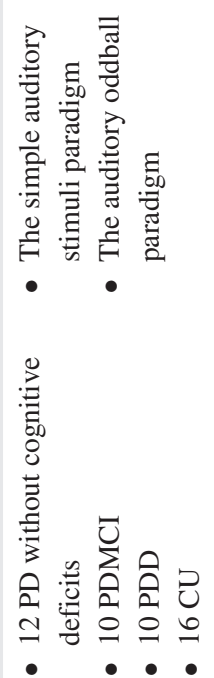

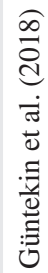




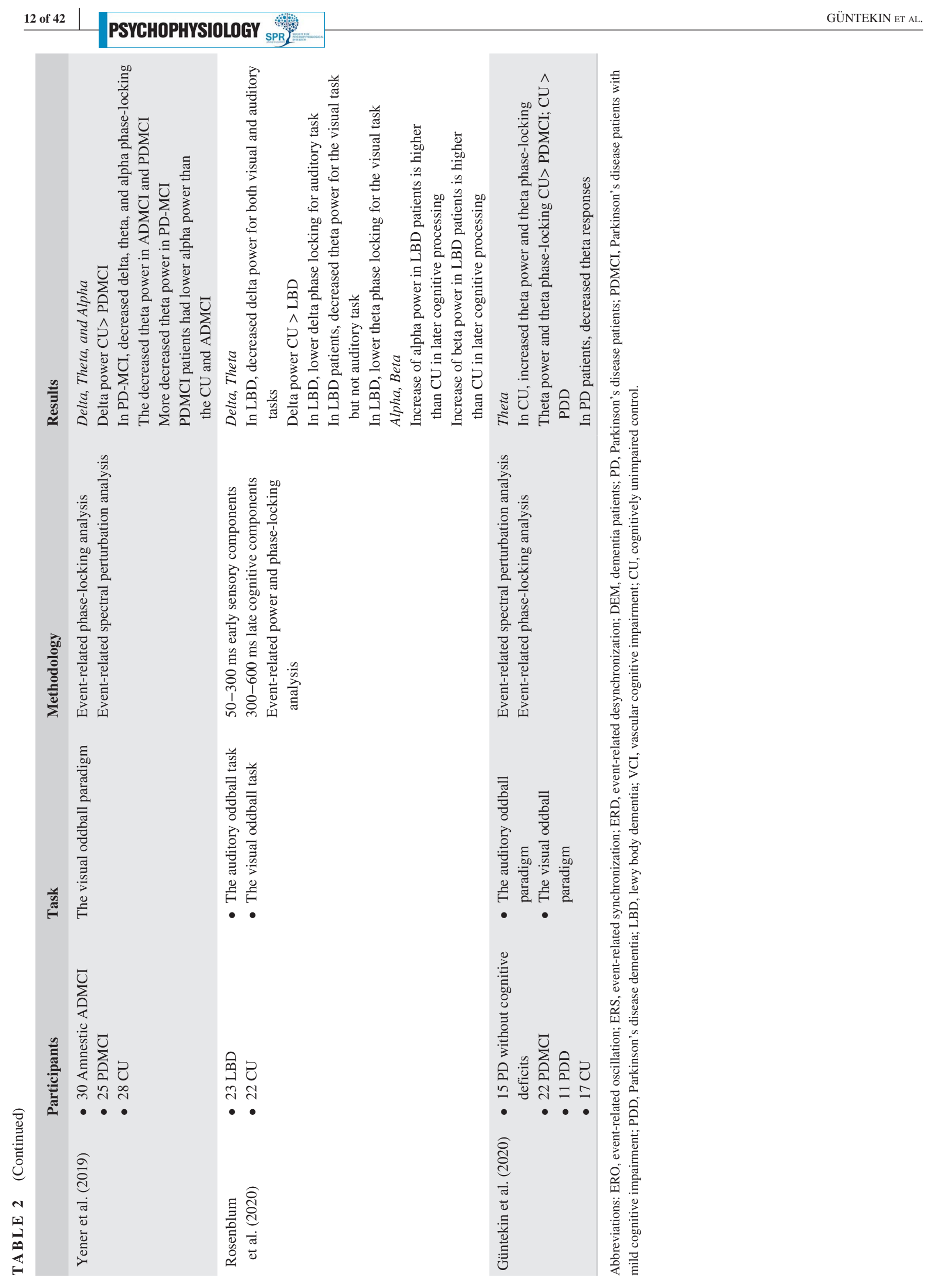


Concerning pathological brain aging, most studies showed a reduction of event-related theta power during memory tasks in ADMCI and ADD patients over CU participants. Karrasch et al. (2006) showed abnormal theta ERD (instead of ERS) in ADMCI patients during the short-term memory encoding phase of a Sternberg task, as well as an abnormal absence of theta ERS in ADD patients during the retrieval phase. Deiber et al. (2015) showed reduced event-related theta power and phase-locking in ADMCI patients relative to $\mathrm{CU}$ participants during a 2-back working memory task. Moreover, Cummins et al. (2008) found lower theta power during a modified Sternberg word recognition task in ADMCI patients compared to CU participants; ADMCI patients also showed lower theta power under high versus low memory load. In retrospective studies, ADMCI patients who converted to ADD (ADMCI converter) were found to have previously exhibited reduced event-related theta responses during an N-back task, relative to ADMCI non-converters and controls (Deiber et al., 2009, 2015; Missonnier et al., 2006). ADMCI converters were also characterized by lower event-related theta responses at the baseline recording session than at one-year follow-up (Deiber et al., 2009). Analogously, event-related theta responses during a word processing task were lower in ADMCI converters relative to $\mathrm{CU}$ participants and ADMCI non-converters (Mazaheri et al., 2018).

Similar effects were observed in non-memory cognitive tasks. Michalopoulos et al. (2012) found lower event-related theta power and theta phase-locking during a simple visual response task in ADMCI patients when compared to CU controls. Furthermore, Caravaglios et al. (2013) showed theta ERS lower in ADMCI patients relative to controls during temporal orienting of attention paradigm. Similarly, Yener et al. (2007) showed lower frontal theta phase-locking during a visual oddball task in non-medicated ADD patients as compared to CU participants. Tülay et al. (2020) also reported that event-related theta responses were lower in ADMCI and ADD patients relative to controls during a visual oddball task. In a separate study, Liu et al. (2012) showed that theta coherence at electrode pairs during an auditory oddball task was lower in ADMCI patients compared to CU participants. Finally, Güntekin et al. (2019) showed reduced event-related theta power during the recognition of facial expressions in ADD patients.

The impaired event-related theta responses in ADMCI and ADD patients may be strictly related to the pre-stimulus theta rhythms. Indeed, Caravaglios et al. (2010) and Goodman et al. (2019) reported greater pre-stimulus theta power and lower post-stimulus event-related theta responses in ADD patients when compared to CU adults.

Furthermore, these event-related theta responses may be sensitive to interventions for neuromodulation. Along this line, Mudar et al. (2019) showed that theta ERS during a go/no-go task increased in ADMCI patients as a function of cognitive training. Similarly, Cespón et al. (2019) investigated the effects of transcranial direct current stimulation (TDCs) over left dorsolateral prefrontal cortex in ADD patients and CU controls. The authors found that event-related theta responses (but not other frequency bands) during an N-back task were greater after the cathodal tDCS neuromodulation in ADD (but not controls) (Cespón et al., 2019). However, the impaired event-related dynamics were not unique for the theta responses in $\mathrm{AD}$; therefore, more research is needed to find the right modulation for normalizing event-related delta, theta, alpha, beta, and gamma responses in these patients. In another study, Koch et al. (2018) studied the effect of noninvasive repetitive transcranial magnetic stimulations (rTMS) over the precuneus for two weeks on EEG activity evoked by a single pulse TMS on that cortical area in ADD patients. Results showed that rTMS intervention only modulated beta responses to the single pulseTMS (Koch et al., 2018).

In relation to the study of event-related theta power responses, other measures have shown mixed results in ADD patients, possibly due to the intrinsic features of spectral markers, task difficulty, and sample size differences. Sweeney-Reed et al. (2012) analyzed the event-related theta phase-locking in ADMCI patients and $\mathrm{CU}$ participants during a Deese-Roediger-MacDermott paradigm used to analyze neurophysiological mechanisms underlying false memory. In their study, ADMCI patients showed greater frontal theta event-related phase-locking as compared to $\mathrm{CU}$ participants (Sweeney-Reed et al., 2012). Furthermore, Yener and colleagues digitally filtered theta responses of ADMCI patients and controls during a visual oddball task and found no significant group differences (Yener et al., 2007, 2013). Later the same group showed that during simple visual stimulation, ADD patients without drugs had overexcited occipital regions that were represented with greater theta responses (Yener et al., 2009). Moreover, Fraga et al. (2017) found no significant effects on theta rhythms during the N-back visual task in ADD patients. Similarly, Kurimoto et al. (2012) reported no significant effects on theta rhythms during the Sternberg task when comparing ADD patients and CU participants. In a later study, Fraga et al. (2018) pointed to more theta ERD during an N-back task in ADMCI patients than ADD patients.

Table 3 summarizes the results of the event-related theta responses during cognitive tasks in ADMCI and ADD patients.

\subsection{Event-related theta responses in patients with non-AD dementias}

Concerning non-AD dementias, the study of event-related theta responses have shown interesting findings. Yener et al. (2019) showed that event-related theta power during a 

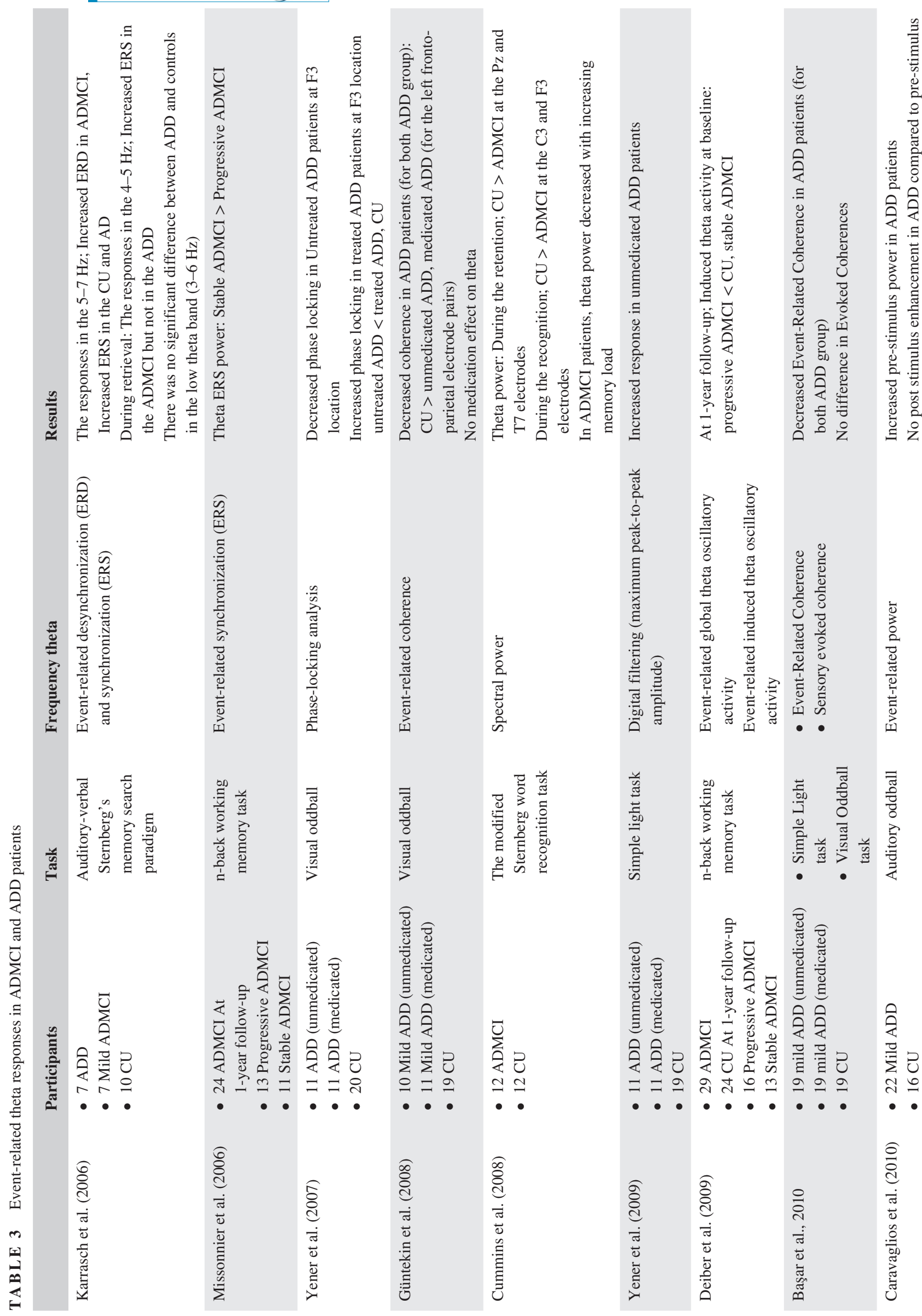

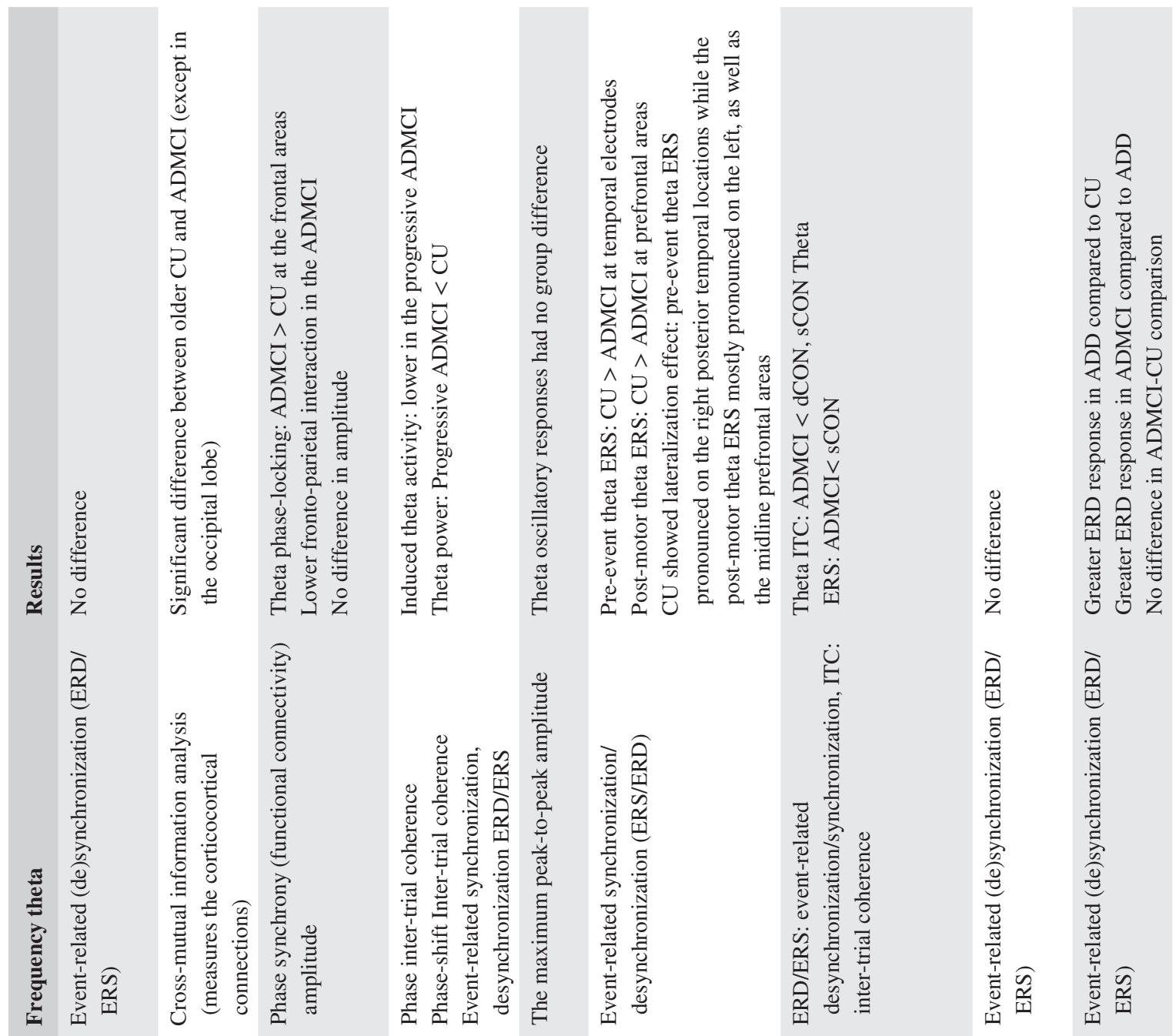

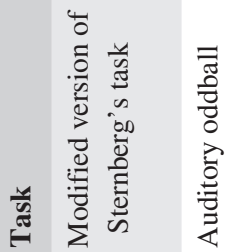
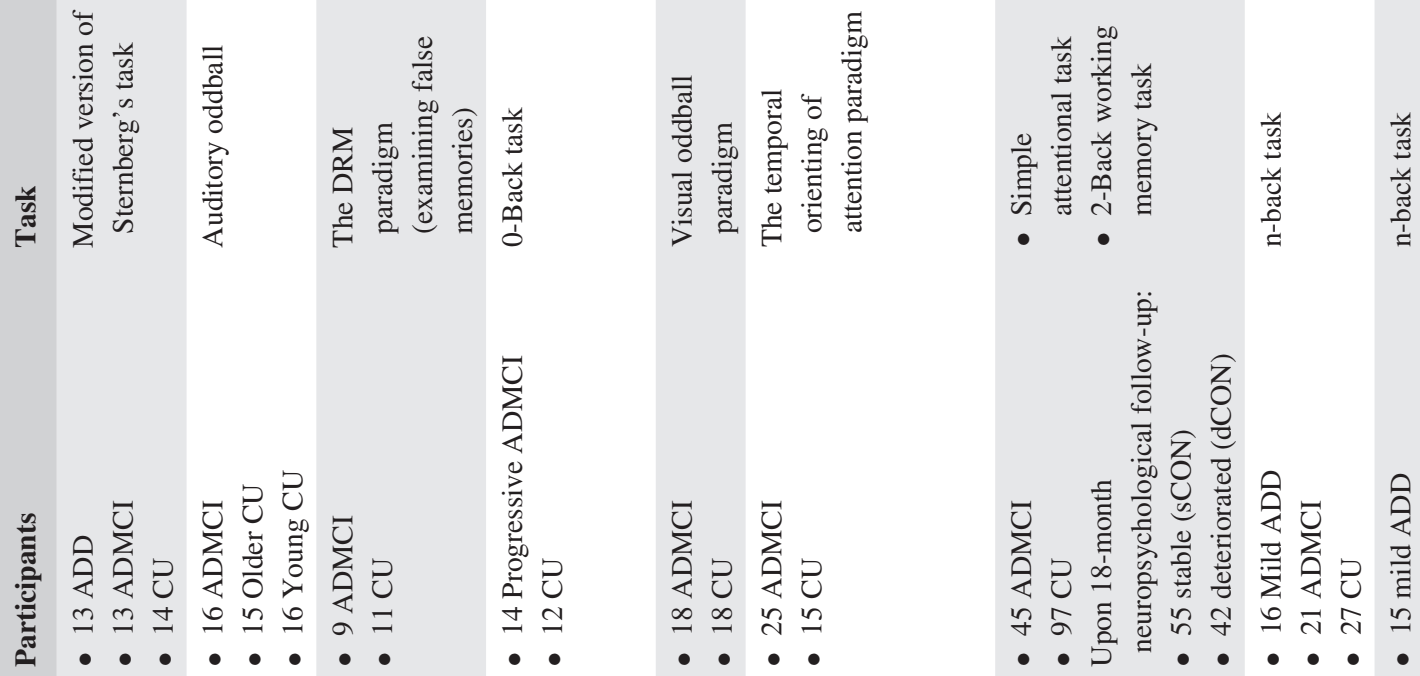

ن류

行
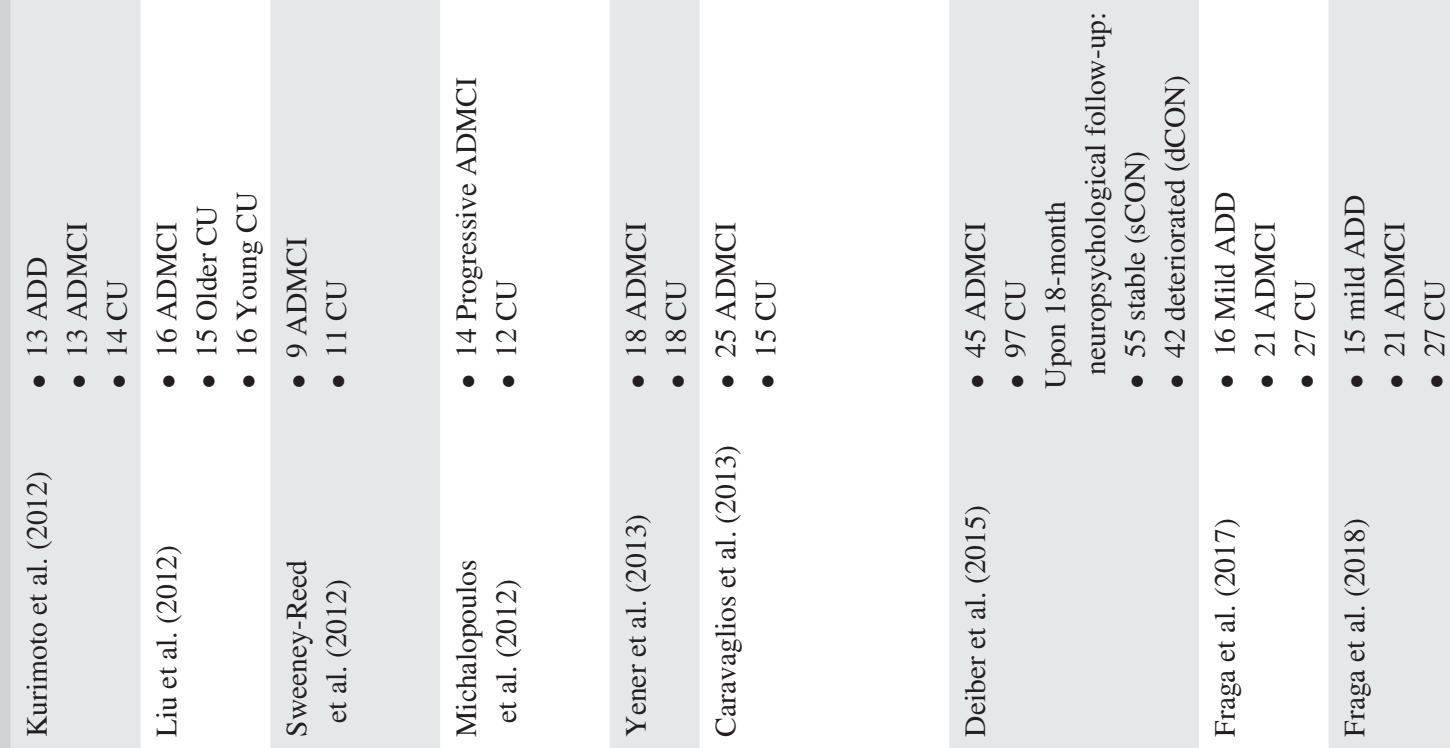

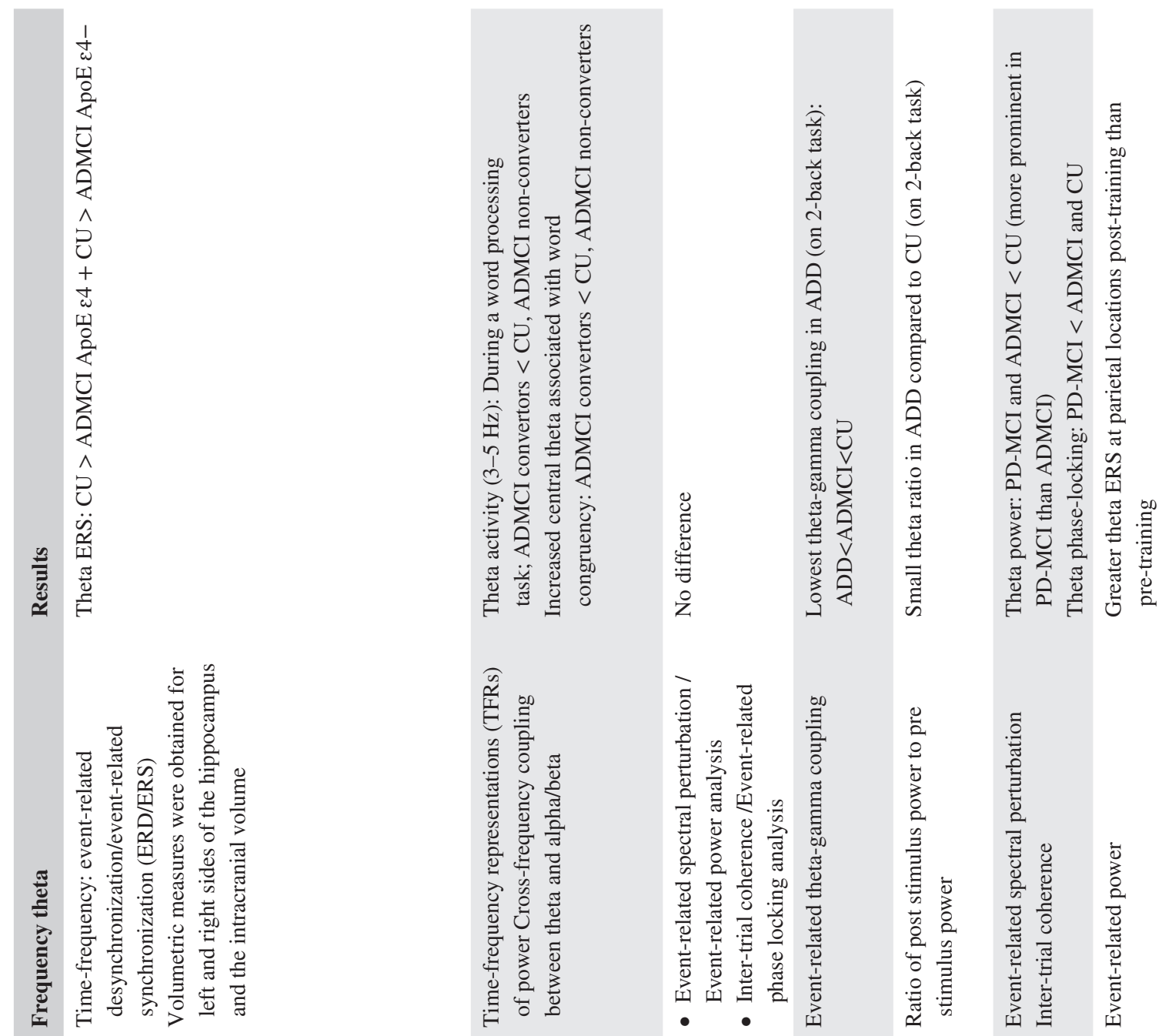

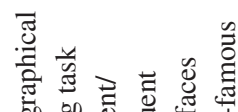

( ) क्ष
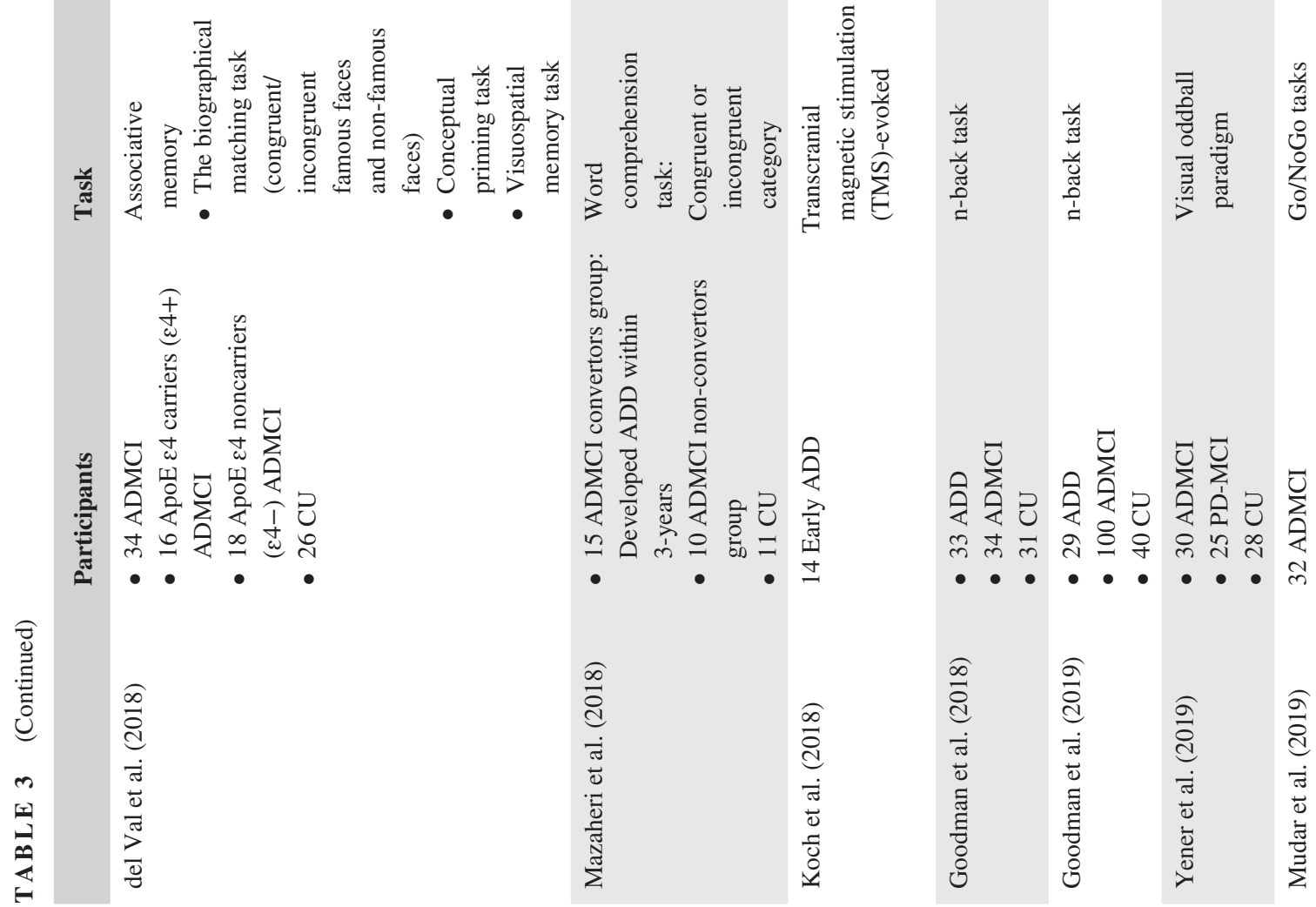
visual oddball task was lower in both ADMCI and PDMCI patients compared to $\mathrm{CU}$ adults. Furthermore, theta phaselocking was lower in PDMCI but not ADMCI patients when compared to controls (Yener et al., 2019). Rosenblum et al. (2020) showed that event-related theta power and phase-locking during a visual (but not auditory) oddball task was lower in LBD patients than in CU participants. Yener et al. (2019) reported that event-related theta power during a visual oddball task was lower in PDMCI than in ADMCI patients and lower in all patients than in $\mathrm{CU}$ participants. Furthermore, theta phase-locking was lower in PDMCI (but not ADMCI) than in CU participants (Yener et al., 2019). Similarly, Güntekin et al. (2020) reported that event-related theta power and phase locking during a visual and auditory oddball tasks were lower in PDD than PDMCI patients and lower in PDMCI patients than PD patients without cognitive deficits and controls.

Concerning cerebrovascular disease, Xu et al. (2015) reported that event-related measures of interdependence of theta rhythms at parieto-occipital electrode pairs during a visual oddball paradigm were lower in major VCI patients as compared to $\mathrm{CU}$ adults. Furthermore, the topology of the interdependence as indexed by graph theory markers showed a lower clustering coefficient in the theta band as compared to CU controls (Wang et al., 2014, 2016).

Table 2 summarizes the results for the event-related theta responses during cognitive tasks in patients with non-AD dementias. In general, event-related delta and theta power, phase-locking, and coherence during cognitive tasks were increased in CU participants (Başar et al., 2001; Cavanagh \& Frank, 2014; Cohen \& Cavanagh, 2011; Gevins et al., 1997; Gruber et al., 2018; Hsieh \& Ranganath, 2014; Jensen \& Tesche, 2002; Klimesch, 1999; Sauseng et al., 2010). Furthermore, some markers of event-related theta responses (particularly event-related power) were lower in ADMCI and ADD patients compared to CU adults (Başar et al., 2010; Caravaglios et al., 2010; Güntekin et al., 2008; Tülay et al., 2020; Yener et al., 2007). However, these effects may be non-specific as similar changes were observed in PDMCI (Güntekin et al., 2020; Yener et al., 2019), PDD (Güntekin et al., 2020), LBD (Rosenblum et al., 2020), and major VCI patients (Lou et al., 2011; Wang et al., 2016; Xu et al., 2011, 2015). Future comprehensive EEG experiments are therefore needed to compare event-related delta and theta responses among patients with different dementias at different levels of cognitive deficits.

\section{5 | Event-related alpha responses in ADMCI and ADD patients}

Since the first discovery of EEG recordings (Berger, 1929), alpha rhythms $(8-13 \mathrm{~Hz})$ have been considered as the 
dominant posterior oscillatory cortical activity observed in adults resting in quiet vigilance (Babiloni, Barry, et al., 2020). During development, the alpha frequency peak is observed at $5-10 \mathrm{~Hz}$ in infants and at 9-11 Hz in adolescents (Marcuse et al., 2008; Stroganova et al., 1999). During later life, alpha rhythms show lower amplitude and slower frequency peak (Babiloni et al., 2006; Hashemi et al., 2016; Ishii et al., 2017; Klass and Brenner, 1995; Klimesch, 1999). These effects are even more pronounced during pathological brain aging in dementia (Babiloni et al., 2004; Babiloni, Frisoni, et al., 2009; Babiloni, Ferri, et al., 2009; Babiloni, Pascarelli, et al., 2020; Dunkin et al., 1994; Leuchter et al., 1987; Locatelli et al., 1998; Rossini et al., 2007; Rossini et al., 2020).

Previous studies have shown mixed effects of aging on event-related alpha responses. On the one hand, several studies reported greater event-related alpha phase locking (Kolev et al., 2002; Yordanova et al., 1998) and power density (Aktürk et al., 2020; Babiloni et al., 2004; Karrasch et al., 2004; Schmiedt-Fehr et al., 2016; Strunk et al., 2017) during auditory and visual tasks in older compared to younger CU adults. Furthermore, Dushanova and Christov (2014) showed that stimulus-evoked alpha responses were greater in older compared to younger CU adults, while the opposite was true for event-related alpha responses during cognitive demands. Moreover, other studies have reported delayed eventrelated alpha responses in older relative to younger $\mathrm{CU}$ adults (Deiber et al., 2010; Nguyen et al., 2020; Zanto et al., 2010). On the other hand, several studies found no significant aging effects on event-related alpha responses raising the issue of reliability of such measures (Kober et al., 2016; Mishra et al., 2013; Schmiedt-Fehr et al., 2009).

Similarly, previous studies have yielded mixed findings regarding event-related alpha responses in ADMCI patients. On the one hand, some studies reported significant effects. For example, Karrasch et al. (2006) showed alpha ERS during a Sternberg short-term memory paradigm in CU participants but not ADMCI patients. Furthermore, Mazaheri et al. (2018) reported that the alpha ERD during a word processing task diminished during each repetition of the words in CU participants but not ADMCI patients. Caravaglios et al. (2015) also found that post-stimulus alpha ERS during an attention task was lower in ADMCI patients than in CU participants. Along the same line, Deiber et al. (2015) showed that event-related alpha phase-locking during a 2-back working memory task was lower in ADMCI patients compared to controls. In contrast, Yener et al. (2019) found no differences in event-related alpha responses during a visual oddball paradigm between ADMCI and CU groups. Tülay et al. (2020) also found no difference in event-related alpha responses during a visual oddball paradigm among groups of ADMCI, ADD, and CU participants.

Concerning disease prediction, Michalopoulos et al. (2012) reported that event-related alpha power and phase-locking during a 0-back task were lower in ADMCI patients progressing to dementia over those who were clinically stable. Similarly, Del Val et al. (2016) showed that alpha ERD during a face memory task was lower in the former than the latter group.

Previous studies have also produced mixed findings on event-related alpha responses in ADD patients. Specifically, Güntekin et al. (2019) showed that event-related alpha responses (right hemisphere) during the detection of facial expressions was lower in ADD patients than in CU controls. Along the same line, Karrasch et al. (2006) showed lower ERD alpha responses during an auditory-verbal Sternberg task in ADD patients relative to CU controls. Similar effects were also observed by Fraga et al. (2017) during an Nback task. On the contrary, Babiloni et al. (2005) reported that alpha ERD responses during a short-term memory task were greater and temporally delayed in ADD patients relative to CU participants. Furthermore, several studies found no differences in event-related alpha responses during cognitive tasks between ADD and CU groups (Cespon et al., 2019; Goodman et al., 2019; Güntekin et al., 2019; Koch et al., 2018; Tülay et al., 2020; Yener et al., 2009).

Table 4 reports the above findings.

\section{6 | Event-related alpha responses in patients with non-AD dementias}

Findings regarding event-related alpha responses in patients with dementia not due to AD have also been mixed.

Concerning brain diseases due to $\alpha$-synucleopathy, Yener et al. (2019) showed that event-related alpha power and alpha phase-locking during a visual oddball paradigm were lower in PDMCI patients relative to ADMCI patients and CU controls. Furthermore, Pugnetti et al. (2010) reported alpha responses during $12-\mathrm{Hz}$ intermittent photic stimulations in $\mathrm{CU}$ participants but not in PDD patients. Finally, Rosenblum et al. (2020) showed that alpha responses in the 300-700 ms post-stimulus were reduced in LBD patients relative to $\mathrm{CU}$ controls during visual and auditory oddball paradigms.

Abnormal event-related alpha responses have also been observed in VCI patients, though the methodological approaches and findings have been varied. In one study, Babiloni et al. (2005) showed that, like ADD patients, major VCI patients had greater and delayed alpha ERD responses during a short-term memory task when compared with CU controls. In two separate studies, Wang et al. $(2014,2016)$ showed that major VCI patients were characterized by a lower clustering coefficient in the event-related alpha responses recorded during a visual oddball task, relative to controls,. Notably, Wang et al. (2016) analyzed the event-related responses with graph theory methodology and showed abnormal alpha responses in major VCI patients compared to controls. 

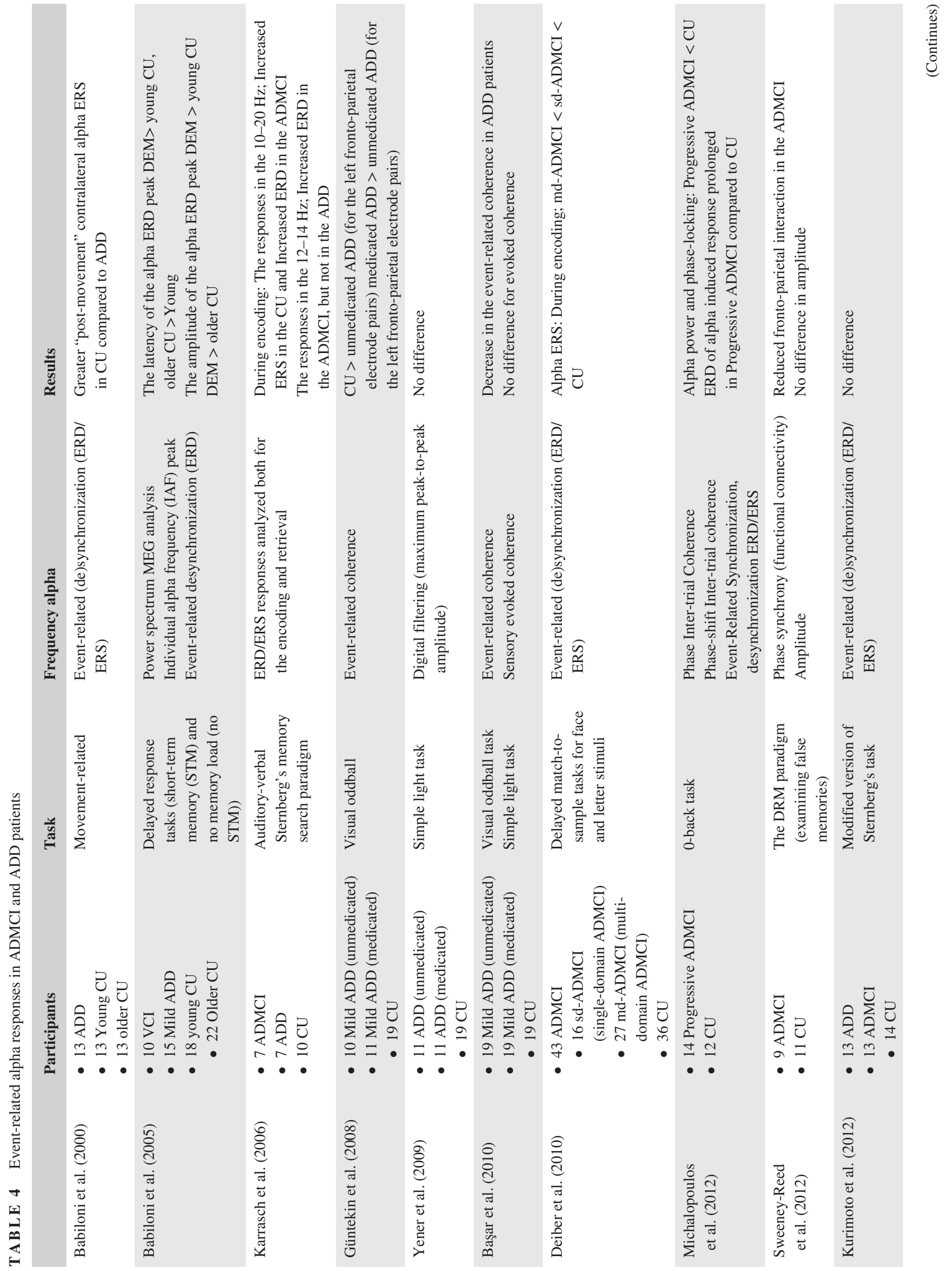

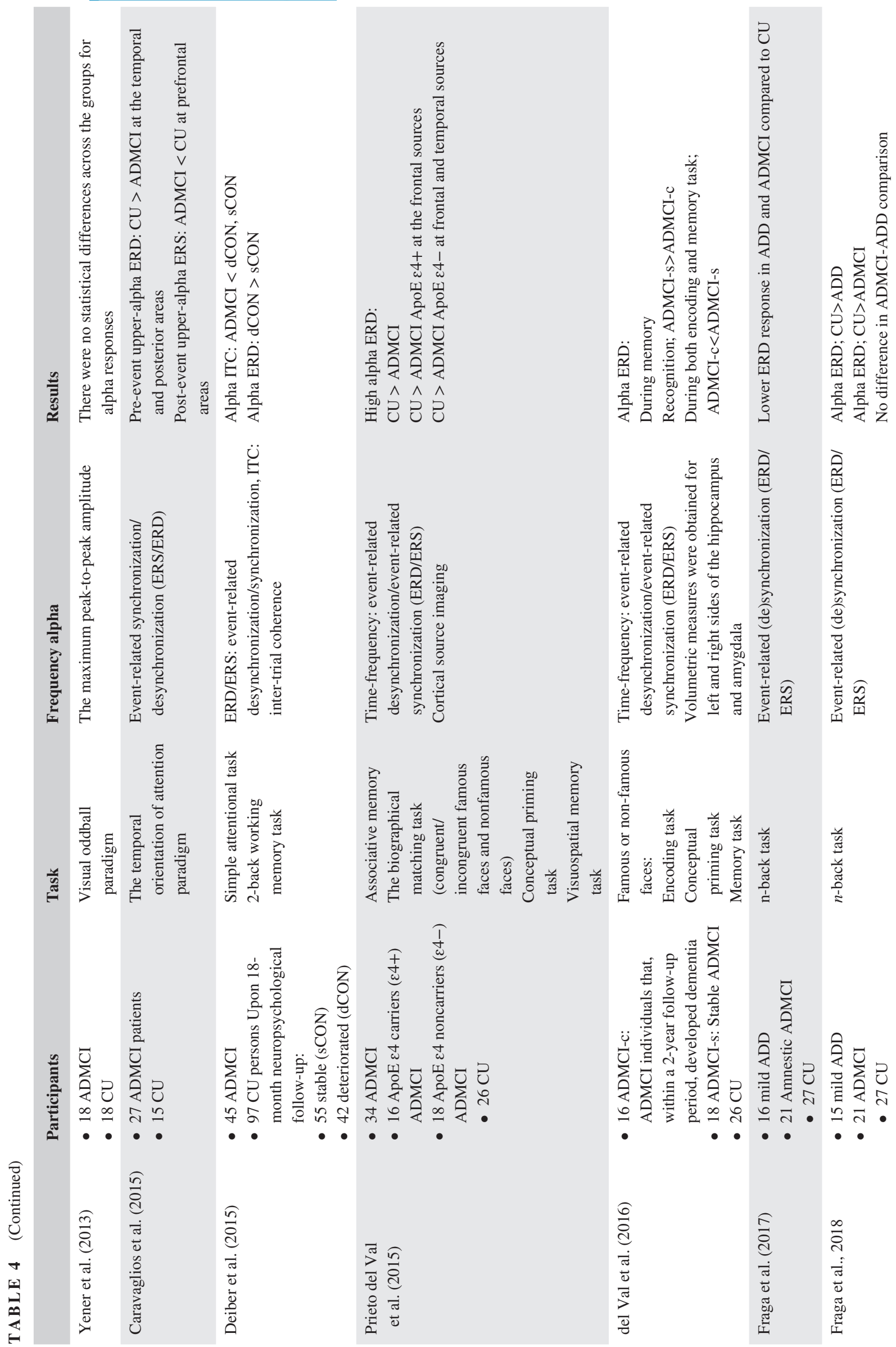

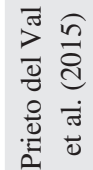

0
0
0
$\frac{d}{\sigma}$
$\frac{\pi}{0}$
$\frac{\pi}{\pi}$
$\frac{\pi}{0}$

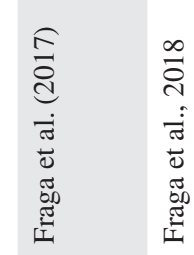



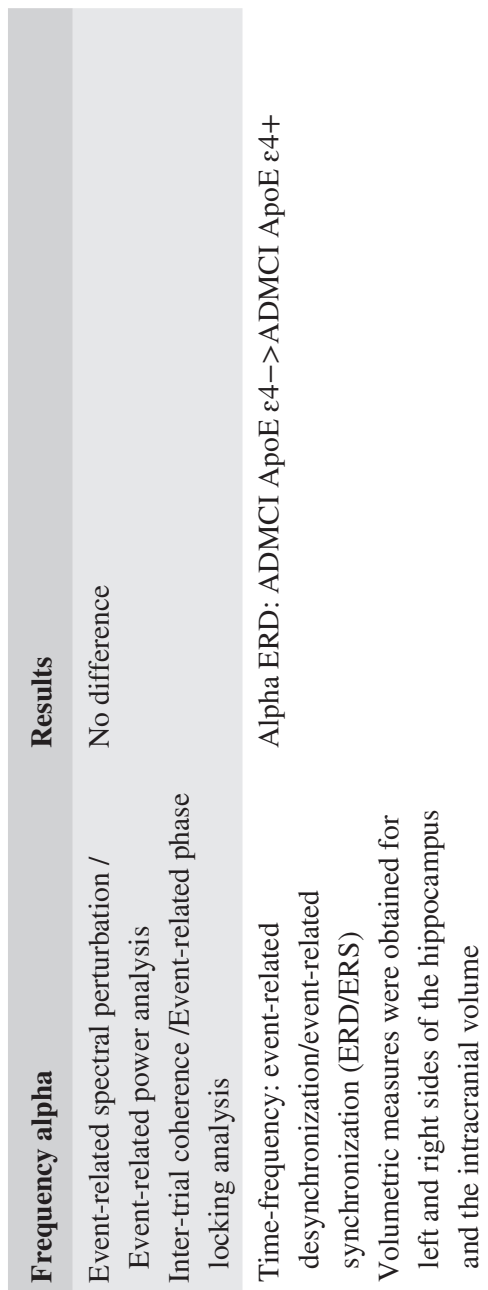
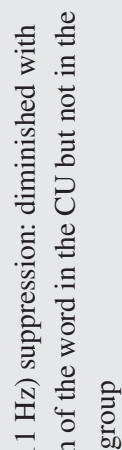

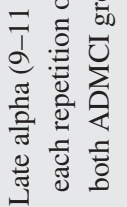

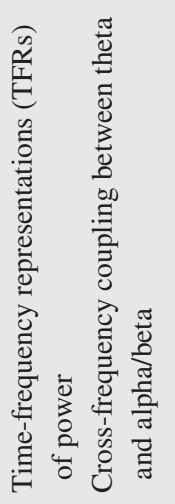

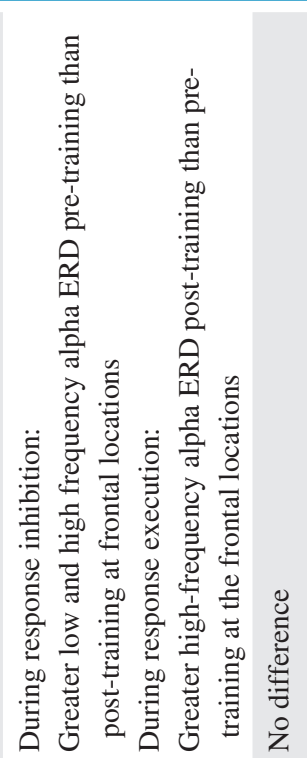

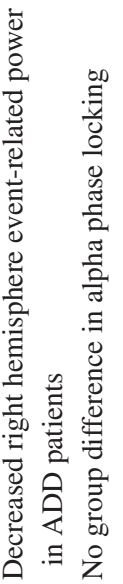

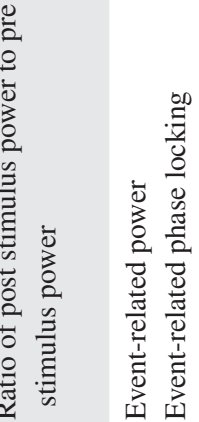
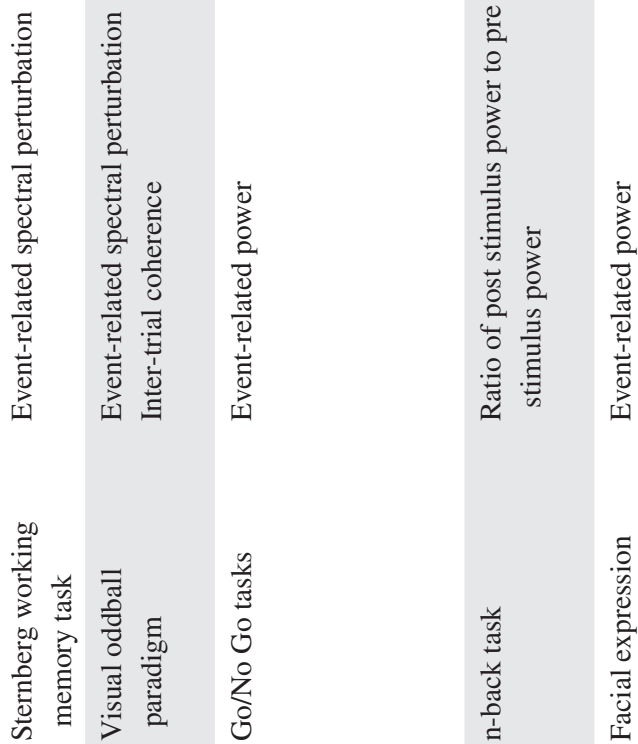

苨 害

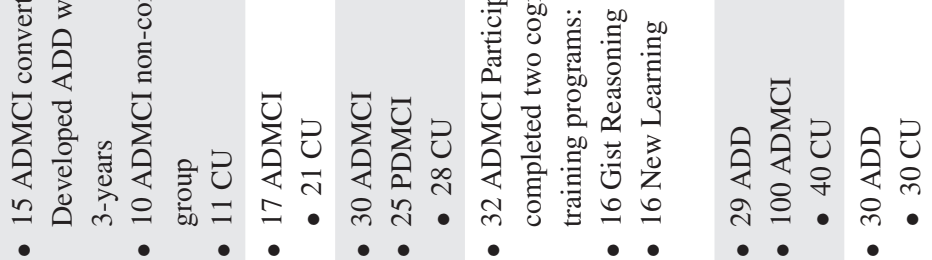

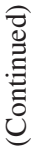
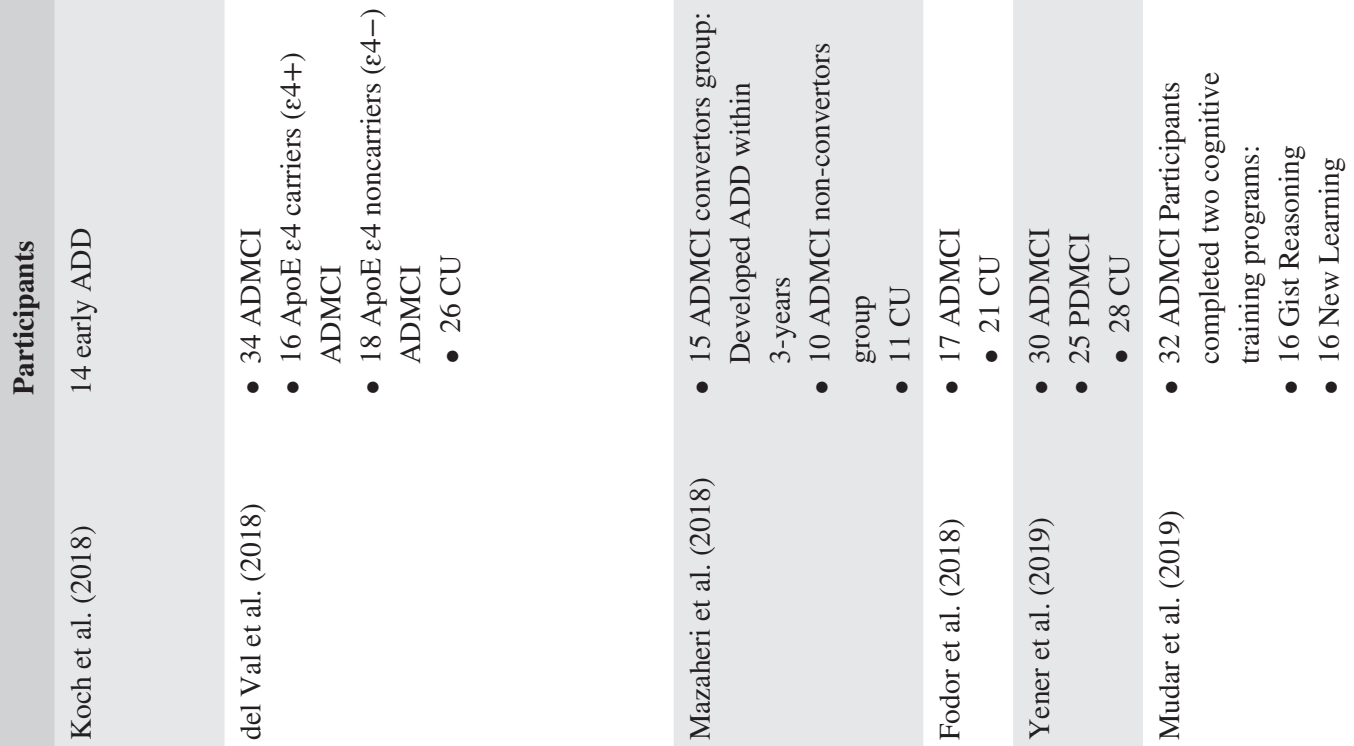


\subsection{Event-related beta responses in ADMCI and ADD patients}

Multiple studies showed a strong relationship between cortical beta rhythms and voluntary movements in humans (Engel \& Fries, 2010; Neuper et al., 2009; Pfurtscheller et al., 1996). Changes in cortical beta rhythms were also related to increased attention, working memory, emotional arousal, and other cognitive processes (Engel \& Fries, 2010; Güntekin and Basar, 2007, 2010; Güntekin et al., 2013; Wróbel, 2000). Evidence also suggests that event-related beta responses during cognitive tasks may change across the lifespan. Wiesmann and Wilson (2019) reported that beta responses during a visuospatial discrimination task were negatively correlated with age, particularly over the somatomotor area. Furthermore, Wang et al. (2017) showed greater interrelatedness of beta rhythms during an audiovisual task in older relative to younger $\mathrm{CU}$ individuals.

Findings regarding event-related beta responses in ADMCI and ADD patients have been mixed. On the one hand, beta responses during cognitive tasks increased with cognitive load in CU participants but not ADMCI patients (Deiber et al., 2015; Güntekin et al., 2013; Missonnier et al., 2007). For example, Missonier et al. (2007) investigated event-related beta responses during an N-back task in ADMCI, ADD, and $\mathrm{CU}$ groups. Results showed that ADMCI patients who later progressed to dementia had lower beta responses compared to $\mathrm{CU}$ and stable ADMCI groups. Furthermore, Güntekin et al. (2013) reported that CU participants (but not ADMCI patients) exhibited higher beta responses during oddball targets in comparison to non-target stimuli. In the same vein, Deiber et al. (2015) showed lower beta phase locking during a 2-back working memory task in ADMCI patients relative to cognitively stable CU participants.

On the other hand, Caravaglios et al. (2018) presented greater beta phase locking in ADMCI patients compared to CU participants during a task using omitted stimuli. In the same study, beta power was found to be lower in the ADMCI group than in CU group. Furthermore, del Val et al. (2016) showed lower ERD during a memory task in ADMCI patients relative to CU participants. Fraga et al. (2017) reported the same effect during an N-back task. In contrast, Mazaheri et al. (2018) found increased beta ERD in ADMCI patients relative to $\mathrm{CU}$ participants during a word comprehension task. Furthermore, Tülay et al. (2020) found no differences in total and evoked beta power between ADMCI and CU groups during a visual oddball task.

Mixed results were also reported for event-related beta responses even in studies focused on ADD patients. Specifically, Missonnier et al. (2007) reported that beta ERS were similarly lower in ADMCI patients (who progressed to dementia) and ADD patients than in CU participants during an N-back task. Furthermore, there were no differences 
between ADMCI patients who progressed to dementia and ADD patients (Missonnier et al., 2007). Along the same line, Fraga et al. (2017) reported lower beta ERD for both ADMCI and ADD patients during the N-back task, as compared to CU controls.

In contrast, Babiloni et al. (2000) showed greater beta ERD during voluntary movements and lower post-movement beta ERS in ADD patients relative to CU controls. Similarly, Koch et al. (2018) reported that repetitive TMS (rTMS) over the precuneus induced greater beta power and phaselocking in ADD patients than in controls. In addition, several studies found no difference in event-related beta responses between ADD patients and controls. For example, no beta differences were reported by Yener et al. (2009) using a simple sensory visual task (digital filtering of ERP responses), Tülay et al. (2020) using a visual oddball task (total and evoked power), Başar et al. (2010) using visual sensory and oddball tasks (event-related coherence analysis) or Cespon et al. (2019) using an N-back task. Table 5 summarizes the results of event-related beta responses in ADMCI and ADD patients.

\subsection{Event-related beta responses in patients with non-AD dementias}

Mixed results have also been reported for event-related beta responses in patients with $\mathrm{MCI}$ and dementia not due to $\mathrm{AD}$. In one study, Rosenblum et al. (2020) showed an increase of beta power during auditory and visual oddball paradigms in LBD patients as compared to CU controls. Using graph theory, Wang et al. (2016) showed abnormal indexes in major VCI patients compared to controls at delta, theta, alpha, and beta frequency bands. In relation to the $\mathrm{CU}$ group, major VCI patients were characterized by a lower graph clustering coefficient at the beta and other bands (Wang et al., 2016).

Keeping in mind the above results, event-related beta responses may be abnormal in AD, LBD, and VCI patients, but further studies are needed to define optimal experimental conditions to obtain repeatable and clinically significant results.

\section{9 | Event-related gamma responses in ADMCI and ADD patients}

Gamma responses have been associated with multiple functional roles, similar to the other frequency bands. Earlier studies showed the role of event-related gamma responses in sensory information processing in hedgehogs (Adrian, 1942), rabbits (Freeman, 1975), and cats (Başar et al., 1975), while Gray and Singer (1989) defined the role of gamma responses as binding. More recently, many reviews have extended the functional role of event-related gamma in the human brain (Başar, 2013; Başar et al., 2001; BaşarEroglu et al., 1996; Herrmann et al., ,2004, 2010; Herrmann \& Knight, 2001; Jensen et al., 2007; Singer, 1999; TallonBaudry \& Bertrand, 1999). More specifically, gamma responses have been linked to episodic memory processes (Başar-Eroglu \& Başar, 1991; Debener et al., 2003; Gruber et al., 2002; Herrmann et al., 2004; Kaiser et al., 2003; Karakaş et al., 2000; Miltner et al., 1999; Tallon-Baudry et al., 1998) and the elaboration of emotional valence of stimuli (Balconi \& Lucchiari, 2008; Güntekin \& Tülay, 2014; Keil et al., 1999, 2001, 2007; Luo et al., 2007, 2009; Martini et al., 2012; Müller et al., 1999; Sato et al., 2011). In addition, the causal role of brain systems generating gamma was highlighted in a recent review on the beneficial effects of interventions targeting gamma responses in patients with neuropsychiatric diseases (Struber and Herrmann, 2020).

Like other frequency bands, event-related gamma responses are affected by physiological aging (Arif et al., 2020; Barr et al., 2014; Böttger et al., 2002; Christov \& Dushanova, 2016; Gaetz et al., 2012; Goossens et al., 2016; Herrmann \& Demiralp, 2005; Hogan et al., 2011; Murty et al., 2020; Ross et al., 2010; Ross et al., 2020; Wiesmann and Wilson, 2019). For example, Böttger et al. (2002) showed lower phase-locked frontal gamma responses during a visual discrimination task in older CU participants.

Regional event-related gamma responses are also affected by pathological aging; however, findings vary according to the methodological approach used. On the one hand, Park et al. (2012) showed that mid-frontal gamma ERD during a spatial delayed match to sample task was lower in ADMCI compared to $\mathrm{CU}$ participants. Furthermore, Kurimoto et al. (2012) found that frontal and parietal gamma ERD during a modified Sternberg's task was lower in ADD relative to ADMCI patients. Another study by Fraga et al. (2018) showed that $\mathrm{CU}$ adults presented temporal and temporalparietal gamma ERS during an N-back task, whereas ADMCI patients were characterized by temporal-parietal gamma ERD.

On the other hand, Osipova et al. (2006) showed that auditory $40 \mathrm{~Hz}$ steady state stimuli induced greater primary auditory cortex gamma power in ADD patients than $\mathrm{CU}$ participants. This effect was confirmed later in ADMCI patients (Van Deursen et al., 2011). Furthermore, Van Deursen et al. (2008) showed that gamma power during a checkerboard reversal task was greater in ADD than ADMCI patients and $\mathrm{CU}$ adults.

Başar, Emek-Savaş et al. (2016) showed that event-related posterior gamma responses during a visual oddball task were lower in ADD compared to CU participants in the early post-stimulus period (0-200 ms), with the opposite pattern observed later (400-600 ms). Furthermore, event-related gamma coherence during the same task was greater in ADD 

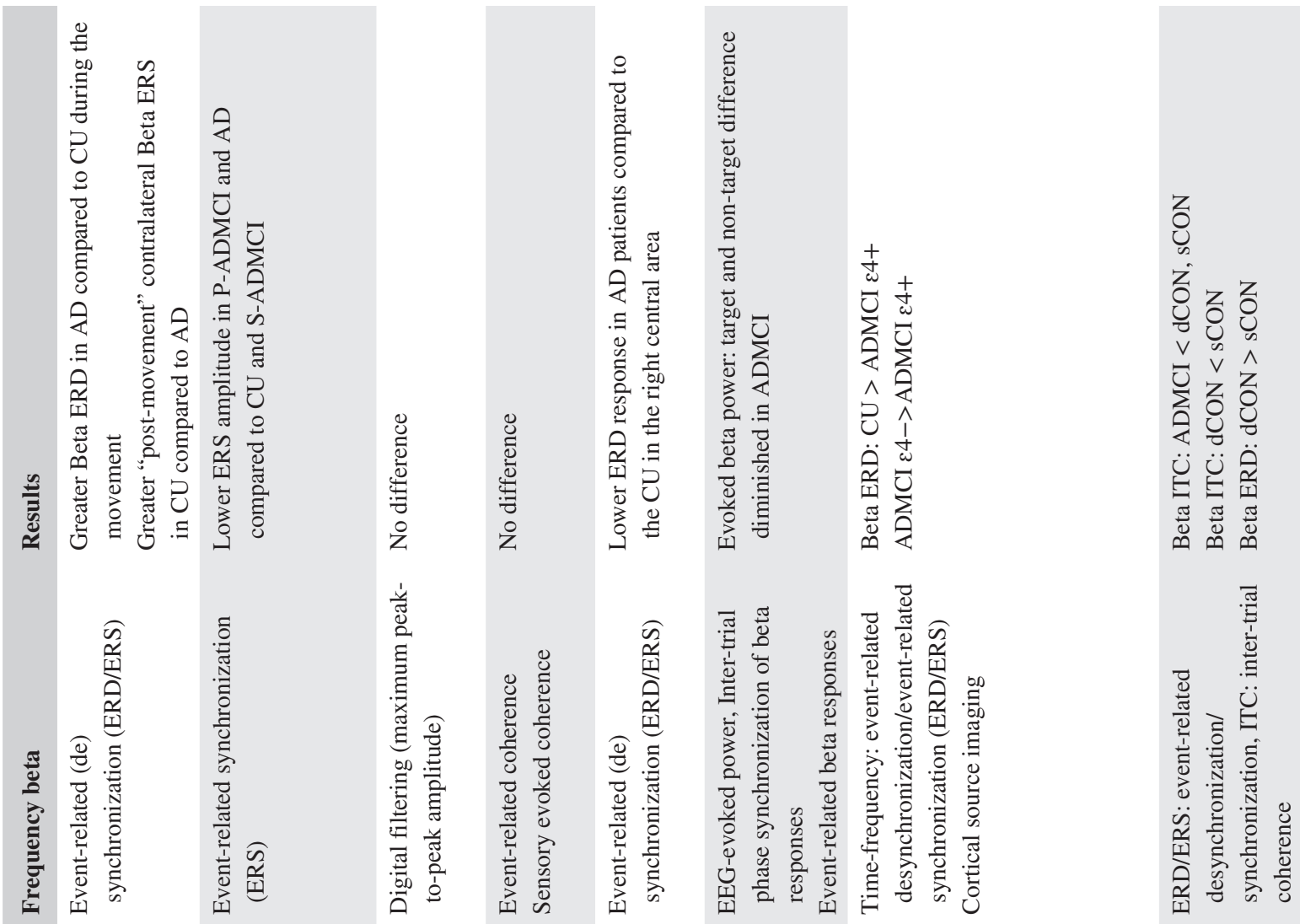

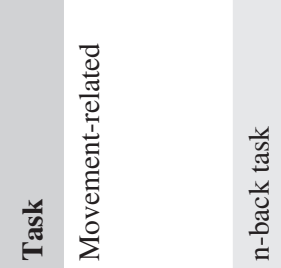
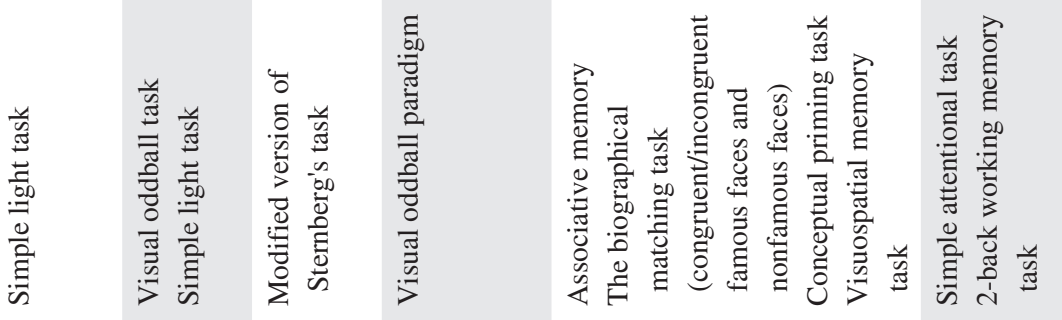

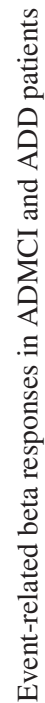
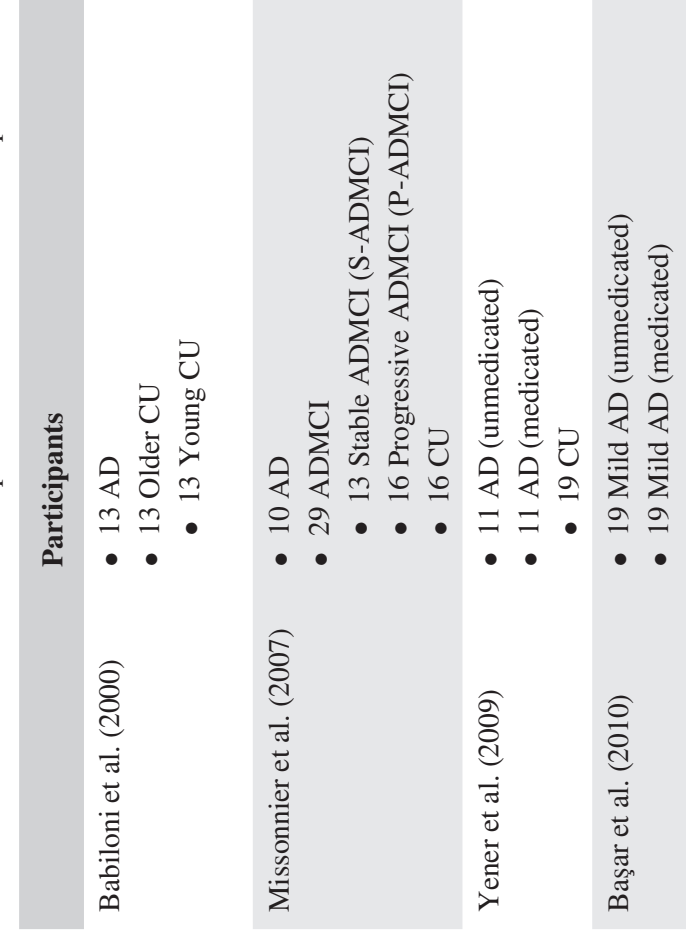

完
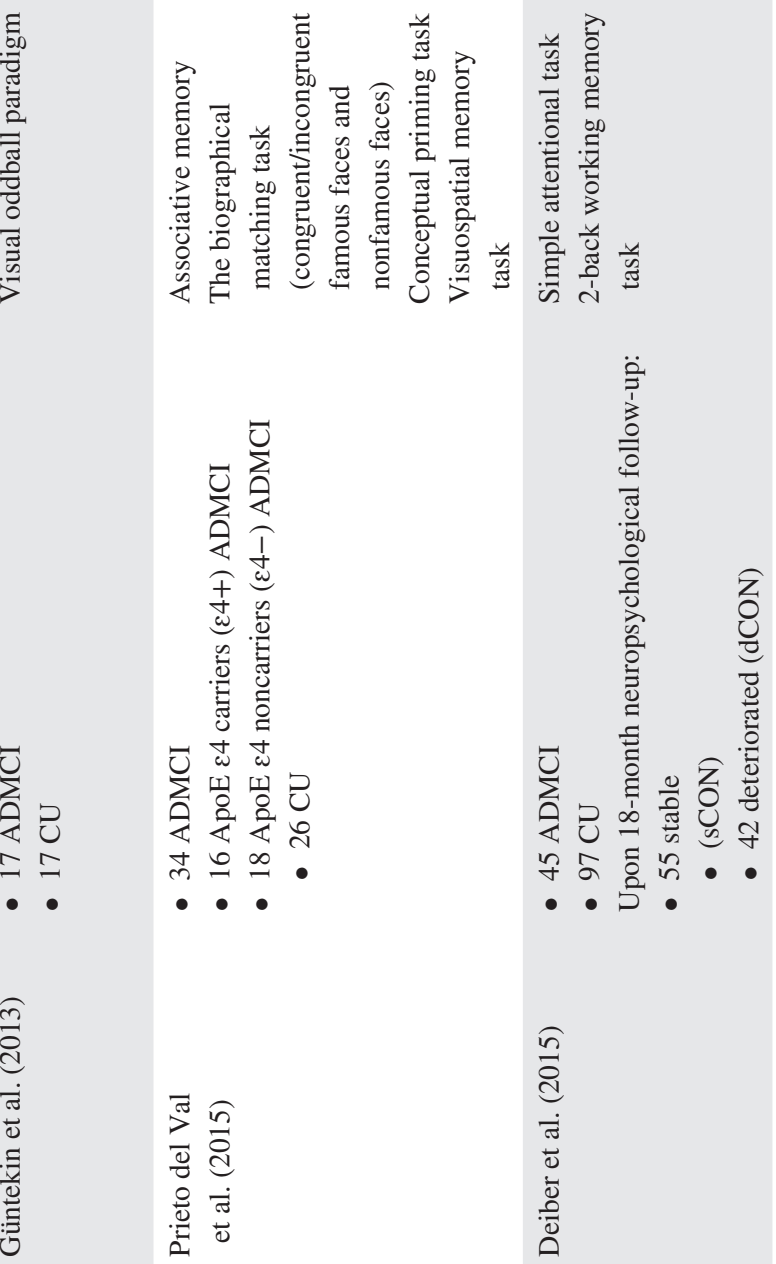

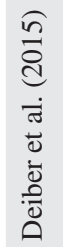



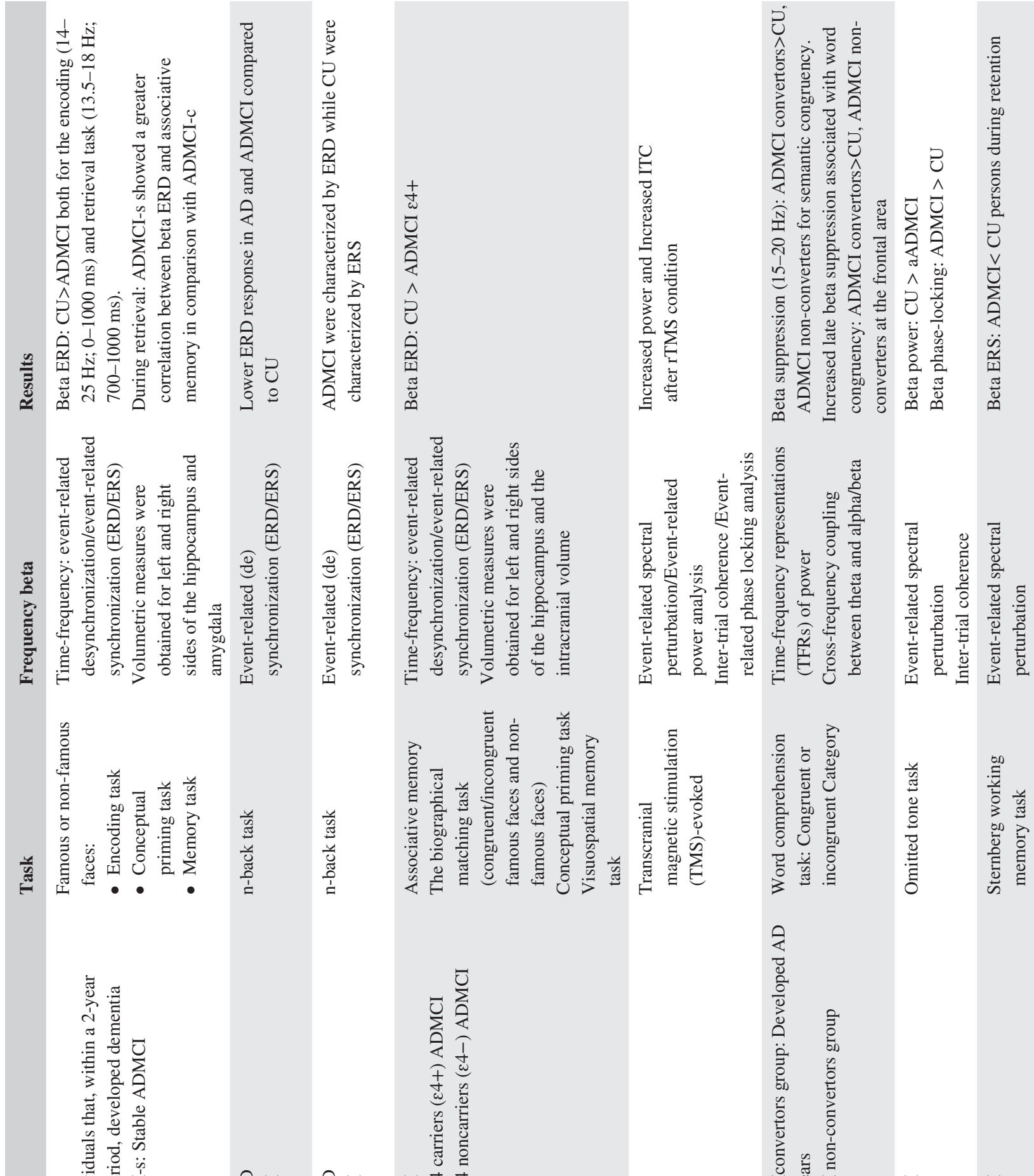

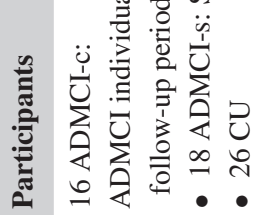
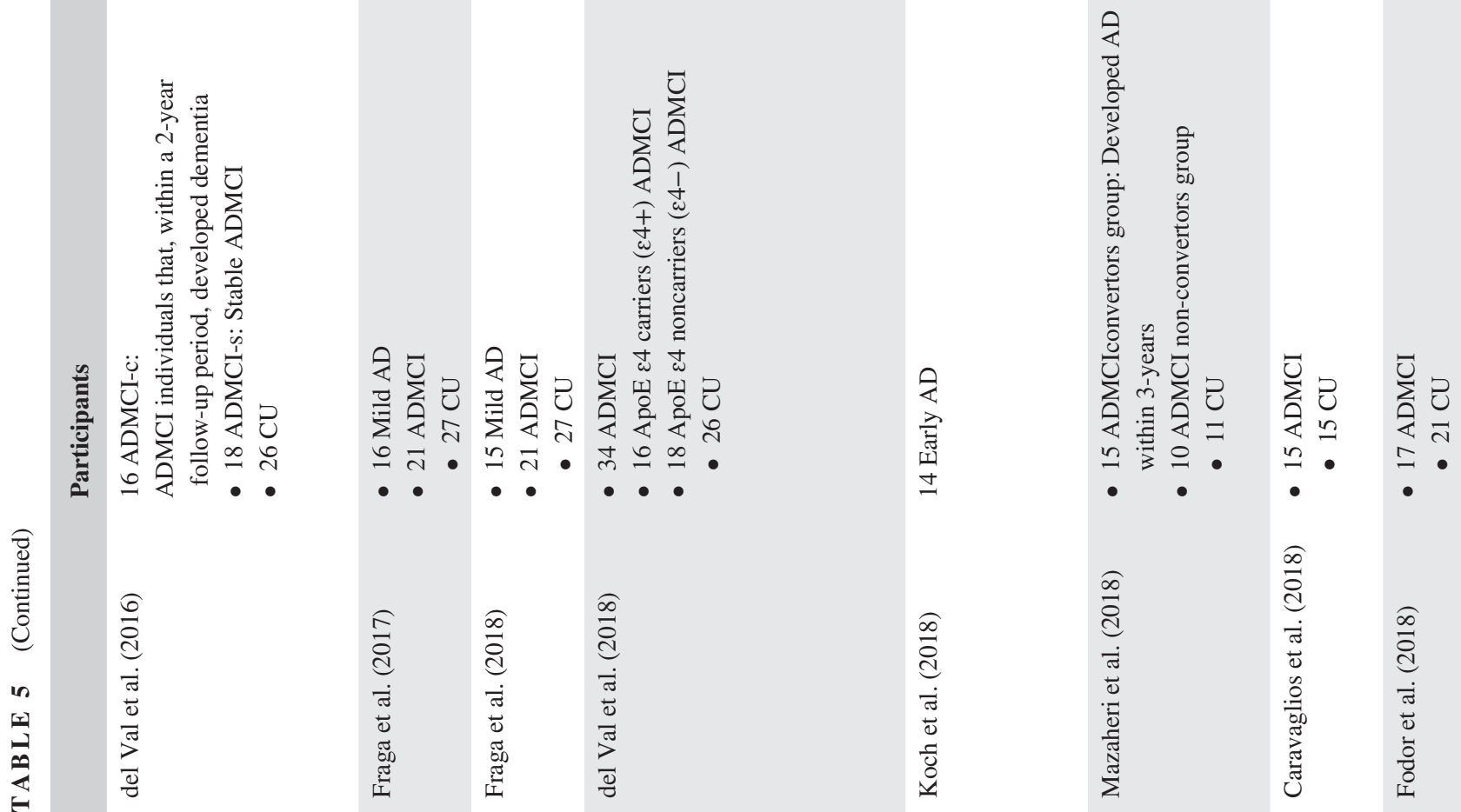
(especially when patients had not undergone cholinergic therapy) compared to CU participants (Başar et al., 2017). Other studies found no differences in event-related gamma responses during cognitive tasks between $\mathrm{ADD}$ and $\mathrm{CU}$ controls (Koch et al., 2018; Tülay et al., 2020; Yener et al., 2009). Table 6 summarizes the results of event-related gamma responses in ADMCI and AD patients. The explored literature was insufficient for an evaluation of event-related gamma responses during cognitive tasks in patients with MCI and dementia not due to $\mathrm{AD}$.

\section{5 | DISCUSSION AND RECOMMENDATIONS}

In this article, a multidisciplinary panel of experts reviewed the field literature and reached consensus about the eventrelated EEG oscillations during cognitive tasks more consistently found to be abnormal in ADMCI and ADD patients when compared to $\mathrm{CU}$ individuals and patients with $\mathrm{MCI}$ and dementia due to PD, LB, and VCI.

Previous EEG studies from independent research teams have consistently demonstrated reduced event-related delta and theta power in ADMCI and ADD patients during oddball tasks at the group level, relative to $\mathrm{CU}$ controls (Başar et al., 2010; Caravaglios et al., 2008, 2013; Cummins et al., 2008; Deiber et al., 2015; Güntekin et al., 2008, 2019; Karrasch et al., 2006; Michalopoulos et al., 2012; Tülay et al., 2020; Yener et al., 2008, 2012). Notably, these effects were not demonstrated at the individual level. Furthermore, they may be disease unspecific as similar abnormalities were observed in PDMCI (Güntekin et al., 2020; Yener et al., 2019), PDD (Güntekin et al., 2020), LBD (Rosenblum et al., 2020), and major VCI patients (Lou et al., 2011; Wang et al., 2016; Xu et al., 2011, 2015). Keeping the above data in mind, the present Expert Panel recommends that eventrelated delta and theta power during oddball tasks may be used in future clinical trials carried out in ADMCI and ADD patients for analyses at the group level. Their use for diagnostic purposes is not recommended.

Specifically, event-related delta and theta measures may be tested as prognostic biomarkers and endpoints of pharmacological and non-pharmacological interventions targeting the cognitive processes underpinning oddball paradigms, such as focused attention, decision making, and working memory (Donchin et al., 1973; O'connell et al., 2012; Polich \& Kok, 1995). Indeed, considering the diagnosis of ADMCI and ADD based on clinical and standard diagnostic criteria for research (Jack et al., 2018), AD patients with the greatest alterations of event-related delta and theta power during oddball tasks may present the fastest clinical decline over time. Furthermore, AD patients with the smallest alterations in these EEG measures (i.e., the most preserved 

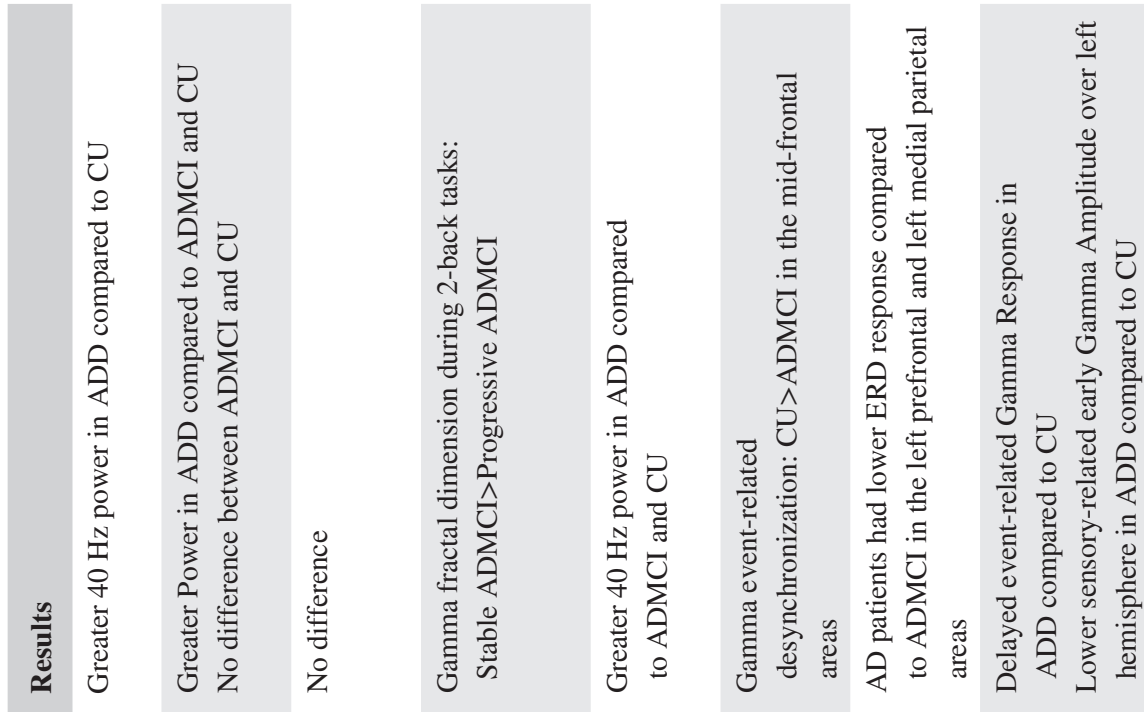

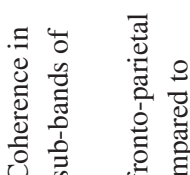

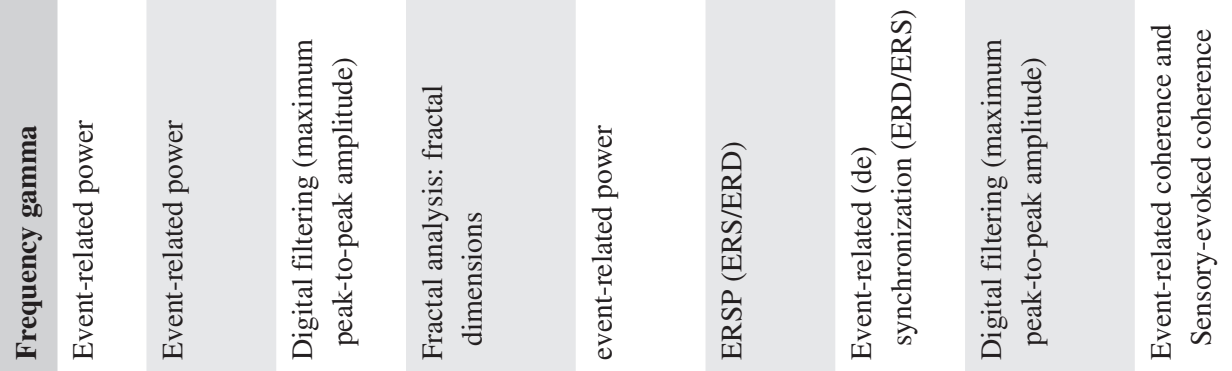
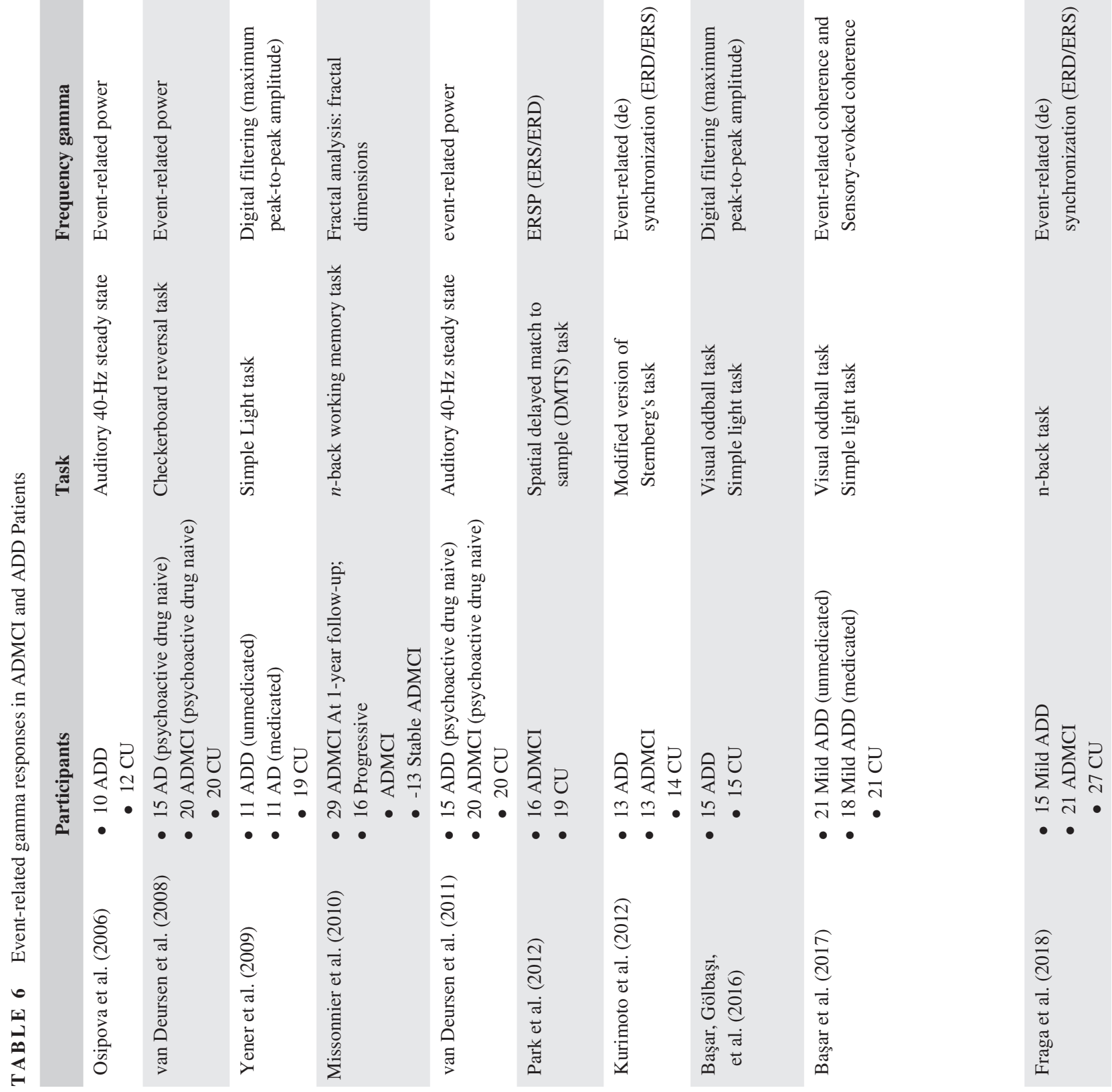
neurophysiological cognitive systems) may yield the greatest benefit most from interventions targeting the neural underpinnings of focused attention, decision making, and working memory.

The above-mentioned EEG measures may also provide a functionally-specific complement to the measures derived from resting state condition. Notably, several commercial and open-access WEB-based EEG platforms (e.g., among others, see EEGlab at https://sccn.ucsd.edu/eeglab/index.php, LORETA at https://www.uzh.ch/keyinst/loreta.htmand, and Fieldtrip at https://www.fieldtriptoolbox.org/) are available for this purpose.

Figure 2 shows a schematic representation of the event related oscillatory abnormalities in ADMCI and ADD patients.

Previous EEG studies by independent research teams repeatedly showed that non-phase locked alpha and beta ERD/ $E R S$ in ADMCI and ADD patients were lower in magnitude than CU controls during cognitive tasks at the group level (Deiber et al., 2015; Fraga et al., 2017; Güntekin et al., 2019; Karrasch et al., 2006; Mazaheri et al., 2018; Michalopoulos et al., 2012; del Val et al., 2016). Similarly, some studies showed that ADMCI and ADD patients pointed to lower event-related beta power and phase-locking during cognitive tasks at the group level (Deiber et al., 2015; Güntekin et al., 2013; Missonnier et al., 2007). Finally, event-related gamma power and coherence during cognitive tasks were higher in ADD patients than CU controls at the group level, as a function of the post-stimulus period and frequencies considered (Başar, Emek-Savaş, et al., 2016; Başar et al., 2017; van Deursen et al., 2008, 2011). However, the EEG methodologies (i.e., alpha and beta ERD/ERS) and the cognitive tasks used (oddball, N-back, word recognition, etc.) were heterogeneous across the reviewed studies, which may limit the interpretation of findings. Furthermore, other studies showed contrasting evidence. Therefore, the present Expert Panel recommends further clinical research before the use of event-related EEG oscillations at alpha, beta, and gamma frequency bands in clinical trials investigating $A D D$ and ADMCI patients. More research is also needed to systematically compare these measures across AD, PD, LBD, and VCI patient groups.

\section{6 | LONGITUDINAL STUDIES USING EVENT-RELATED EEG RESPONSES FOR THE PREDICTION OF COGNITIVE DECLINE IN PEOPLE WITH AD AND PEOPLE WITH MCI OR OTHER DEMENTIA}

Previous longitudinal studies have investigated eventrelated EEG responses in relation to cognitive decline in people with $\mathrm{AD}$ and people with $\mathrm{MCI}$ or dementia. 


\section{Oddball Event-Related Oscillations in ADMCI and ADD Patients}
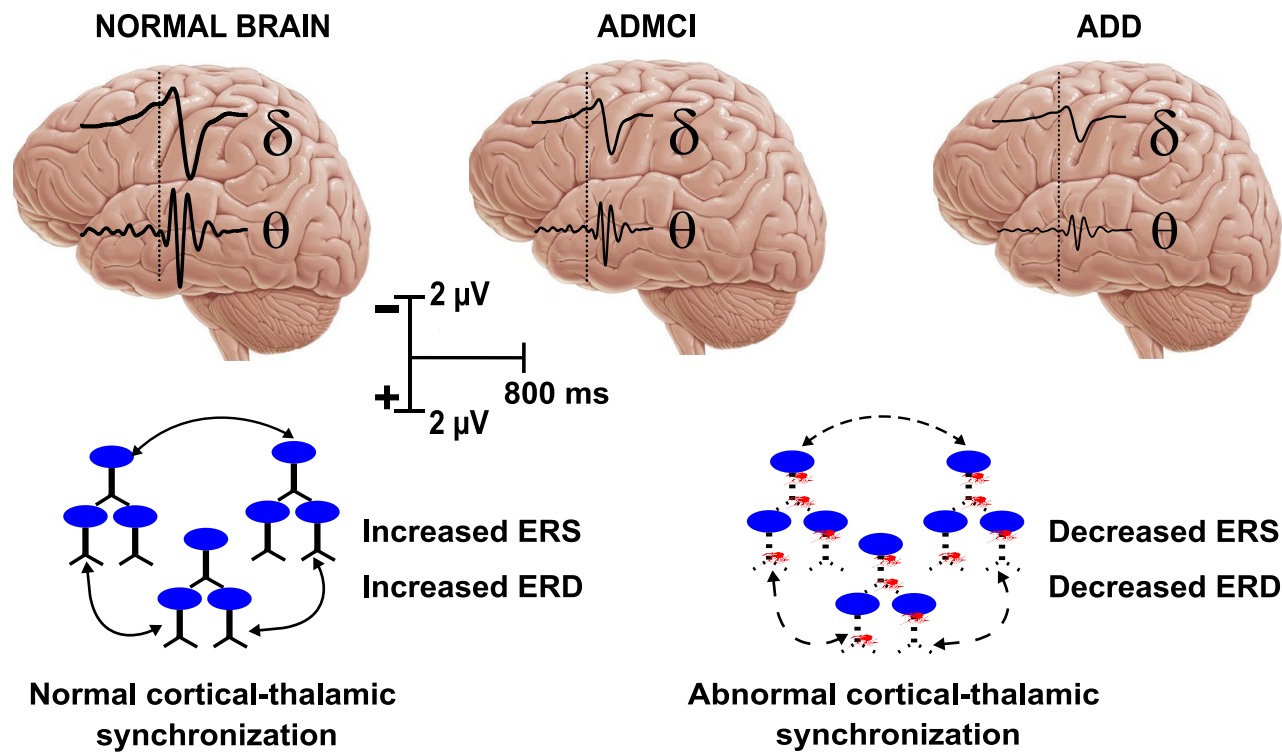

Abnormal cortical-thalamic synchronization

F I G U R E 2 Schematic description of event-related alpha synchronization and desynchronization in cognitively unimpaired adults and ADD patients. In general, alpha ERS and ERD were both reduced in ADD patients

Concerning AD patients, Missonnier et al. (2006) showed reduced event-related theta power during an n-back working memory task in progressive ADMCI patients as compared to stable ADMCI patients and CU participants at one-year follow-up. Deiber et al. (2009) confirmed these results in a similar study investigating event-related EEG responses during an n-back task. They reported reduced frontal eventrelated theta power in progressive ADMCI patients as compared to stable ADMCI patients and CU participants. The same group (Deiber et al., 2015) carried out another study in which ADMCI patients and CU adults were clinically followed for 18 months. Based on clinical status at follow up, CU participants were divided into two groups: stable and deteriorated. At baseline, event-related theta responses during a 2-back working memory task were lower in the ADMCI patients than the stable $\mathrm{CU}$ group but there was no difference between the stable $\mathrm{CU}$ and deteriorated $\mathrm{CU}$ groups. In another study, Mazaheri et al. (2018) clinically followed ADMCI patients for three years. They reported that eventrelated theta power during a word comprehension task was lower in the progressive ADMCI patients (i.e., those who progressed to ADD), as compared to the stable ADMCI patients and the $\mathrm{CU}$ participants. Overall, the above findings confirm that reduced event-related theta responses during cognitive tasks not only reflect cognitive status in AD patients but they may also predict or monitor disease progression at the group level.

To our knowledge, only one study has investigated eventrelated EEG delta responses in ADMCI patients longitudinally. Emek-Savaş et al. (2016) showed that ADMCI patients who progressed to ADD after one year were characterized by poor event-related delta responses during a visual oddball task at the baseline recording session. Furthermore, as compared to $\mathrm{CU}$ participants and stable ADMCI patients, ADMCI patients progressing to ADD showed reduced eventrelated delta responses at 1-year follow-up. Though more research is needed in this area, current evidence suggests that event-related delta and theta responses may predict $\mathrm{AD}$ progression at the group level.

Longitudinal studies have also examined if alpha and beta event-related responses during cognitive tasks may predict or reflect AD progression. Prieto del Val et al. (2016) reported that ADMCI patients who progressed to ADD showed reduced alpha ERD during a memory encoding task as compared to $\mathrm{CU}$ participants and stable ADMCI patients. Mazaheri et al. (2018) tested ERD/ERS at various frequency bands during a verbal memory task in stable and progressive ADMCI patients (follow-up at three years). They showed that late alpha ERD diminished with repeated presentation of words in the CU group but not in stable and progressive ADMCI patients, thus indicating that such an EEG biomarker may reflect cognitive status but not AD progression.

In another longitudinal study, Missonnier et al. (2007) reported that baseline beta ERS recorded during an nback task was lower in progressive (follow-up at one year) than stable ADMCI patients. Similarly, Prieto del Val et al. (2016) reported that progressive ADMCI patients (follow-up at two year) showed lower beta ERD during memory encoding at baseline as compared to stable ADMCI patients. In contrast, Mazaheri et al. (2018) found that beta ERD during a word comprehension task 
at baseline was greater in progressive (follow-up at three year) than stable ADMCI patients. Finally, Deiber et al. (2015) showed that beta phase-locking during a 2back working memory task at baseline was higher in the stable CU group compared to the deteriorated CU group (follow-up at 18 months).

The mixed results for alpha and beta frequencies may be due to a number of factors including the different EEG variables, time periods, and cognitive paradigms used. Overall, at baseline, beta ERS/ERD and phase-locking were generally lower in $\mathrm{CU}$ participants and $\mathrm{AD}$ patients who showed diminished cognitive status at follow-up (one year or later). Further longitudinal studies are needed, however, to reach conclusive recommendations about these frequencies.

Longitudinal studies examining event-related gamma responses in $\mathrm{AD}$ patients during cognitive tasks are also lacking. To our knowledge, there is only one study in the literature, conducted by Missonnier et al. (2010). The authors investigated gamma fractal dimensions of event-related EEG responses during a 2-back task; results showed that progressive ADMCI patients (follow-up at one year) were characterized by higher gamma fractal dimensions as compared to stable ADMCI patients, possibly reflecting reduced complexity of the EEG signal (Missonnier et al., 2010). Notably, mapping event-related gamma responses during cognitive tasks may help to inform potential treatments for AD patients based on neuromodulation of gamma, which is an emerging field. More specifically, both animal (Adaikkan et al., 2019; Iaccarino et al., 2016; Martorell et al., 2019) and human studies (Benussi et al., 2021; Ismail et al., 2018; Jones et al., 2019; Zibrandtsen et al., 2020) have shown potentially beneficial effects of electromagnetic or sensory stimulation at gamma frequencies in rodent models of AD and AD patients. Thus, event-related gamma responses during cognitive tasks may represent an informative intervention endpoint.

To our knowledge, there are no longitudinal studies investigating event-related delta, theta, alpha, beta, and gamma responses during cognitive tasks in non-AD older adults with MCI or dementia.

Considering the above review, the present Expert Panel recommends that significant efforts be made to develop longitudinal studies investigating event-related EEG responses during cognitive tasks in older people with MCI and dementia due to Alzheimer's and related neurodegenerative disorders. Such studies will dramatically improve our understanding of the extent to which EEG responses (including gamma) may provide heuristic measures of the natural deterioration of cognitive systems during disease progression, as well as sensitive biomarkers to demonstrate potential benefits of future smart drugs, cognitive training, and/or brain stimulation.

\section{7 | MULTIMODAL STUDIES USING CSF, NEUROIMAGING, AND EVENT-RELATED EEG RESPONSES IN PEOPLE WITH AD AND PEOPLE WITH MCI OR OTHER DEMENTIA}

Multimodal studies using CSF, neuroimaging, and eventrelated EEG responses during cognitive tasks are sparse in $\mathrm{AD}$ and non-AD patients with MCI or dementia. Results from existing studies are summarized in the following section.

In AD research, Prieto del Val et al. (2015) investigated event-related EEG responses during an episodic memory task in CU people and ADMCI patients (Prieto del Val et al., 2015). ADMCI patients with the most significant genetic risk factor of sporadic AD (i.e., ApoE ع4) showed reduced alpha ERD in temporal sources and less beta ERD in frontal sources, relative to $\mathrm{CU}$ people and ADMCI patients without ApoE $\varepsilon 4$, thus suggesting reduced efficiency and capacity of memory-related information processing in the former group (Prieto del Val et al., 2015). In another study (del Val et al., 2018), the authors showed that in ADMCI patients with ApoE ع4, hippocampal damage affected episodic memory through temporal cortical thickness, event-related theta responses, and frontal alpha/ beta ERD. In those ADMCI patients, the authors evaluated the predictive value of event-related EEG responses during an episodic memory task (del Val et al., 2016). As compared to $\mathrm{CU}$ and stable ADMCI groups, progressive ADMCI patients showed lower associative memory scores, larger atrophy of the medial temporal lobe, and lower capacity to recruit alpha oscillatory cortical networks (del Val et al., 2016). Interestingly, accuracy in predicting progression from MCI to dementia was higher using the encoding-induced abnormal alpha ERD in posterior cingulate sources at baseline compared to neuroimaging biomarkers of amygdala atrophy (del Val et al., 2016). When both neuroimaging and EEG biomarkers were used as an input, the best accuracy (about 80\%) was reached (del Val et al., 2016). These findings extended previous magnetoencephalographic (MEG) evidence indicating that as compared to stable ADMCI patients, progressive ADMCI patients are characterized by lower episodic and semantic memory scores, larger atrophy of entorhinal cortex, and higher interdependence of source activity between anterior cingulate and temporo-occipital at alpha frequencies (López et al., 2014). Notably, this higher interdependence was associated with greater medial temporal atrophy and worse cognitive performance (López et al., 2014).

In another multimodal study, Fodor et al. (2018) investigated alpha-beta ERS/ERD during a Sternberg working memory task in ADMCI patients and CU participants. Structural MRIs were also carried out. Relative to the CU group, ADMCI patients showed reduced alpha and beta ERS 
(Fodor et al., 2018). Furthermore, EEG source estimates showed that ADMCI patients were characterized by reduced beta ERS in inferior and middle temporal gyrus, fusiform gyrus, and cuneus. Furthermore, the correlation between EEG and structural MRI measures showed that beta ERS was correlated with the size of hippocampus, entorhinal cortex, and parahippocampal gyrus.

Serrano et al. (2020) investigated event-related theta, alpha, and beta (MEG) responses during a working memory task in ADMCI patients, those with subjective memory complaints, and CU participants. As compared to people with subjective memory complaints and those who were CU, ADMCI patients showed reduced theta, alpha, and beta power. Furthermore, ADMCI patients had lower hippocampal volume, with no differences between subjective memory complaints and $\mathrm{CU}$ groups. The authors also found significant positive correlations between theta-alpha power derived from EEG data and biomarkers of right precuneus and supramarginal gyrus as well as bilateral cingulate cortex, fusiform gyrus, and medial temporal lobe.

In a final study, Yener et al. (2016) investigated eventrelated EEG responses during an oddball task in $\mathrm{CU}$ and ADMCI groups. Structural MRIs were also carried out. Results showed that both event-related delta responses to the target stimuli and frontal volume were reduced in the ADMCI relative to the $\mathrm{CU}$ group. Additionally, the authors reported a linear reduction in frontal event-related delta responses and frontal lobe atrophy for $\mathrm{CU}$ and ADMCI participants as a whole group.

The results of this section support the idea that established multimodal fluid and neuroimaging biomarkers of $\mathrm{AD}$ are significantly associated with event-related EEG responses during attention and memory tasks. However, further crossvalidation studies are needed to confirm the direct effects of AD-related amyloidosis, tauopathy, and neurodegeneration and their association with topography-specific event-related EEG responses. Confirming that association may lend further support to the use of EEG responses in the assessment of cognitive systems in $\mathrm{AD}$ patients.

Finally, the present Expert Panel recommends the use of EEG source estimation techniques in the analysis of eventrelated delta and theta responses during oddball tasks in older people with MCI and dementia due to Alzheimer's and related neurodegenerative disorders. Ideally, future EEG studies should use $>48$ scalp electrodes to mitigate spatial blurring of rsEEG source estimates (Babiloni, Barry, et al., 2020). In such studies, the exact location of electrode placement over the scalp can be digitized and integrated into realistic head models based on individual structural MRIs to enhance the spatial accuracy of rsEEG source estimates (Babiloni, Barry, et al., 2020). Estimated EEG source solutions may be especially suitable in multimodal studies in patients with MCI and dementia using neuroimaging techniques to map cerebrovascular lesions, core neuropathology, and neurodegeneration. Within a common brain space constructed by realistic MRI-based head models, abnormalities in EEG source solutions may be correlated with core neuropathology and neurodegeneration, as revealed by structural MRIs and PET or singlephoton emission computerized tomography (SPECT), as well as clinical manifestations. Correlations between EEG biomarkers and specific features of Alzheimer's and related neurodegenerative disorders may elucidate the neurophysiological correlates of those disorders in the cognitively unimpaired brain.

\section{8 | INTERNATIONAL INITIATIVES FOR RESEARCH ON RSEEG MEASURES IN AD}

In general, the findings reviewed in the present article raise the need for international consensus initiatives to develop or refine a multicenter standardization of instructions to patients, EEG recordings during oddball tasks, and selection of artifact-free rsEEG periods in line with the standards of clinical trials in AD. First attempts can be found in initiatives of the International Federation of Clinical Neurophysiology (Babiloni, Barry, et al., 2020; Rossini et al., 2020) as well those of the Electrophysiology Professional Interest Area of ISTAART.

The present Expert Panel recommends the development of comprehensive EEG experiments comparing eventrelated delta and theta responses during oddball tasks among groups of patients MCI and dementia due to AD, $P D, L B$, and VCI. A key feature of those future studies may be the longitudinal multicenter enrollment of patients and use of standard methods for the computation of phaselocked EROs at delta and theta bands. Two interesting examples are shown in Colclough et al. (2016) and Mahjoory et al. (2017).

Despite several evidence-based reviews (Lejko et al., 2020; Yener \& Başar, 2010, 2013), no substantial study has been reported testing the discriminative power of eventrelated EEG oscillatory responses during cognitive tasks at the individual level in $\mathrm{AD}, \mathrm{PD}, \mathrm{LBD}$, and VCI patients. Therefore, while these measures are not yet suitably validated for diagnostic, screening and progression tracking use-cases, we recommend machine learning and other discriminative analyses be applied both to future studies, and retrospectively to some of the high-quality data sets already collected. When performing these analyses, we also recommend that hypothesis driven approaches to data characterization (e.g., functional connectivity and other graph-related measures) be applied, alongside deep learning and other feature discovery approaches. 


\section{9 | CONCLUSIONS}

How should we frame event-related EEG oscillations in the theory of AD biomarkers? It is well know that the Working Group of the National Institute of Aging and Alzheimer's Association (NIA-AA) Research Framework (Jack et al., 2018) proposed two classes of biomarkers for $\mathrm{AD}$ research: (i) diagnostic Alzheimer's disease biomarkers, measuring cerebral amyloidosis (i.e., "A" biomarkers) and phospho-tau (i.e., "T" biomarkers) by CSF or PET techniques and (ii) neurodegenerative/progression biomarkers (i.e., "N" biomarkers), measuring total tau by CSF sampling, FDG-PET hypometabolism, and structural MRI markers of brain atrophy. Keeping in mind the above theoretical qualification of AD biomarkers, the present Expert Panel posits the introduction of another class of biomarkers in the instrumental assessment of $\mathrm{AD}$ patients. These biomarkers may probe the vulnerability or resilience of subcortical and thalamocortical neural (de)synchronization mechanisms in relation to $\mathrm{AD}$ processes. For the purposes of the present study, the biomarkers of event-related EEG oscillations may be represented by the mentioned event-related delta and theta power during oddball tasks. Keeping in mind the neurophysiological meaning of these EEG biomarkers, the term neural synchronization or physiological biomarker (i.e., "P" biomarker) may be introduced in the above A-T-N Research Framework (Jack et al., 2018).

\section{ACKNOWLEDGMENTS}

This manuscript wasfacilitated by the Alzheimer's Association International Society to Advance Alzheimer's Research and Treatment (ISTAART), through the Electrophysiology Professional Interest Area (PIA). The views and opinions expressed by the authors in this publication represent those of the authors and do not necessarily reflect those of the PIA membership, ISTAART or the Alzheimer's Association. The EPIA is committed to exploiting biomarkers for (1) improving the understanding of neurophysiological mechanisms underlying Alzheimer's disease and other dementias at micro, meso, and macro spatial scales and (2) promoting clinical applications and international initiatives. EPIA members believe that quantitative EEG techniques and biomarkers are an important resource for brain research and clinical applications in neurologic and psychiatric diseases, especially in lower- and middle-income countries.

\section{CONFLICTS OF INTEREST}

There are no relevant conflicts of interest for the co-authors in the present article.

\section{AUTHOR CONTRIBUTIONS}

Conceptualization; Investigation; Methodology; Project administration; Supervision; Visualization; Writingoriginal draft; Writing-review \& editing: Bahar Guntekin.
Investigation; Methodology; Visualization; Writing-original draft; Writing-review \& editing: Tuba Aktürk. Investigation; Methodology; Writing-original draft: Xianghong Arakaki. Investigation; Methodology; Writing-original draft: Laura Bonanni. Investigation; Methodology; Writing-original draft: Claudio Delpercio. Investigation; Methodology; Writing-original draft: Rebecca Edelmayer. Investigation; Methodology; Writing-original draft: Francesca Farina. Investigation; Methodology; Writing-original draft: Raffaele Ferri. Investigation; Methodology; Writing-original draft: Lütfü Hanoğlu. Investigation; Methodology; Writingoriginal draft: Sanjeev Kumar. Investigation; Methodology; Writing-original draft: Roberta Lizio. Investigation; Methodology; Writing-original draft: Susanna Lopez. Investigation; Methodology; Writing-original draft: Brian Murphy. Investigation; Methodology; Writing-original draft: Giuseppe Noce. Investigation; Methodology; Writingoriginal draft: Fiona Randall. Investigation; Methodology; Writing-original draft: Alexander T. Sack. Investigation; Methodology; Writing-original draft: Fabrizio Stocchi. Investigation; Methodology; Writing-original draft: Görsev Yener. Investigation; Methodology; Visualization; Writingoriginal draft; Writing-review \& editing: Ebru Yıldırım. Conceptualization; Investigation; Methodology; Project administration; Supervision; Visualization; Writing-original draft; Writing-review \& editing: Claudio Babiloni.

\section{ORCID}

Bahar Güntekin (iD https://orcid.org/0000-0002-0860-0524 Tuba Aktürk (iD) https://orcid.org/0000-0002-7555-3801 Ebru Ylldırım (D) https://orcid.org/0000-0002-7715-3035 Claudio Babiloni (D) https://orcid.org/0000-0002-5245-9839

\section{REFERENCES}

Adaikkan, C., Middleton, S. J., Marco, A., Pao, P.-C., Mathys, H., Kim, D.-W., Gao, F., Young, J. Z., Suk, H.-J., Boyden, E. S., McHugh, T. J., \& Tsai, L.-H. (2019). Gamma entrainment binds higher-order brain regions and offers neuroprotection. Neuron, 102(5), 929-943. https://doi.org/10.1016/j.neuron.2019.04.011

Adrian, E. D. (1942). Olfactory reactions in the brain of the hedgehog. The Journal of Physiology, 100(4), 459. https://doi.org/10.1113/ jphysiol.1942.sp003955

Aktürk, T., İşoğlu-Alkaç, Ü., Hanoğlu, L., \& Güntekin, B. (2020). Age related differences in the recognition of facial expression: Evidence from EEG event-related brain oscillations. International Journal of Psychophysiology, 147, 244-256. https://doi.org/10.1016/j.ijpsy cho.2019.11.013

Albert, M. S., DeKosky, S. T., Dickson, D., Dubois, B., Feldman, H. H., Fox, N. C., Gamst, A., Holtzman, D. M., Jagust, W. J., Petersen, R. C., Snyder, P. J., Carrillo, M. C., Thies, B., \& Phelps, C. H. (2011). The diagnosis of mild cognitive impairment due to Alzheimer's disease: Recommendations from the National Institute on AgingAlzheimer's Association workgroups on diagnostic guidelines for Alzheimer's disease. Alzheimer's \& Dementia, 7(3), 270-279. https://doi.org/10.1016/j.jalz.2011.03.008 
Arif, Y., Spooner, R. K., Wiesman, A. I., Embury, C. M., Proskovec, A. L., \& Wilson, T. W. (2020). Modulation of attention networks serving reorientation in healthy aging. Aging (Albany NY), 12(13), 12582. https://doi.org/10.18632/aging.103515

Atagün, M. İ., Güntekin, B., Maşalı, B., Tülay, E., \& Başar, E. (2014). Decrease of event-related delta oscillations in euthymic patients with bipolar disorder. Psychiatry Research: Neuroimaging, 223(1), 43-48. https://doi.org/10.1016/j.pscychresns.2014.04.001

Babiloni, C., Arakaki, X., Azami, H., Bennys, K., Blinowska, K., Bonanni, L., Bujan, A., Carrillo, M. C., Cichocki, A., Frutos-Lucas, J., Del Percio, C., Dubois, B., Edelmayer, R., Egan, G., Epelbaum, S., Escudero, J., Evans, A., Farina, F., Fargo, K., ... Guntekin, B. (2021). Measures of resting state EEG rhythms for clinical trials in Alzheimer's disease: Recommendations of an expert panel. Alzheimer's \& Dementia, 2021, 1-26. http://dx.doi.org/10.1002/ alz. 12311

Babiloni, C., Babiloni, F., Carducci, F., Cincotti, F., Del Percio, C., De Pino, G., Maestrini, S., Priori, A., Tisei, P., Zanetti, O., \& Rossini, P. M. (2000). Movement-related electroencephalographic reactivity in Alzheimer disease. NeuroImage, 12(2), 139-146. https://doi. org/10.1006/nimg.2000.0602

Babiloni, C., Barry, R. J., Başar, E., Blinowska, K. J., Cichocki, A., Drinkenburg, W. H. I. M., Klimesch, W., Knight, R. T., Lopes da Silva, F., Nunez, P., Oostenveld, R., Jeong, J., Pascual-Marqui, R., Valdes-Sosa, P., \& Hallett, M. (2020). International federation of clinical neurophysiology (IFCN)-EEG research workgroup: Recommendations on frequency and topographic analysis of resting state EEG rhythms. Part 1: Applications in clinical research studies. Clinical Neurophysiology, 131(1), 285-307. https://doi. org/10.1016/j.clinph.2019.06.234

Babiloni, C., Binetti, G., Cassarino, A., Dal Forno, G., Del Percio, C., Ferreri, F., Ferri, R., Frisoni, G., Galderisi, S., Hirata, K., Lanuzza, B., Miniussi, C., Mucci, A., Nobili, F., Rodriguez, G., Luca Romani, G., \& Rossini, P. M. (2006). Sources of cortical rhythms in adults during physiological aging: A multicentric EEG study. Human Brain Mapping, 27(2), 162-172. https://doi.org/10.1002/hbm.20175

Babiloni, C., Binetti, G., Cassetta, E., Cerboneschi, D., Dal Forno, G., Del Percio, C., Ferreri, F., Ferri, R., Lanuzza, B., Miniussi, C., Moretti, D. V., Nobili, F., Pascual-Marqui, R. D., Rodriguez, G., Romani, G. L., Salinari, S., Tecchio, F., Vitali, P., Zanetti, O., ... Rossini, P. M. (2004). Mapping distributed sources of cortical rhythms in mild Alzheimer's disease. A Multicentric EEG Study. Neuroimage, 22(1), 57-67. https://doi.org/10.1016/j.neuroimage.2003.09.028

Babiloni, C., Blinowska, K., Bonanni, L., Cichocki, A., De Haan, W., Del Percio, C., Dubois, B., Escudero, J., Fernández, A., Frisoni, G., Guntekin, B., Hajos, M., Hampel, H., Ifeachor, E., Kilborn, K., Kumar, S., Johnsen, K., Johannsson, M., Jeong, J., ... Randall, F. (2020). What electrophysiology tells us about Alzheimer's disease: A window into the synchronization and connectivity of brain neurons. Neurobiology of Aging, 85, 58-73. https://doi.org/10.1016/j. neurobiolaging.2019.09.008

Babiloni, C., Cassetta, E., Chiovenda, P., Del Percio, C., Ercolani, M., Moretti, D. V., Moffa, F., Pasqualetti, P., Pizzella, V., Romani, G. L., Tecchio, F., Zappasodi, F., \& Rossini, P. M. (2005). Alpha rhythms in mild dements during visual delayed choice reaction time tasks: A MEG study. Brain Research Bulletin, 65(6), 457-470. https://doi. org/10.1016/j.brainresbull.2005.01.014

Babiloni, C., Ferri, R., Binetti, G., Vecchio, F., Frisoni, G. B., Lanuzza, B., Miniussi, C., Nobili, F., Rodriguez, G., Rundo, F., Cassarino, A., Infarinato, F., Cassetta, E., Salinari, S., Eusebi, F., \& Rossini,
P. M. (2009). Directionality of EEG synchronization in Alzheimer's disease subjects. Neurobiology of Aging, 30(1), 93-102. https://doi. org/10.1016/j.neurobiolaging.2007.05.007

Babiloni, C., Frisoni, G., Pievani, M., Vecchio, F., Lizio, R., Buttiglione, M., Geroldi, C., Fracassi, C., Eusebi, F., \& Ferri, R. (2009). Hippocampal volume and cortical sources of EEG alpha rhythms in mild cognitive impairment and Alzheimer disease. NeuroImage, 44(1), 123-135. https://doi.org/10.1016/j.neuroimage.2008.08.005

Babiloni, C., Pascarelli, M. T., Lizio, R., Noce, G., Lopez, S., Rizzo, M., Ferri, R., Soricelli, A., Nobili, F., Arnaldi, D., Famà, F., Orzi, F., Buttinelli, C., Giubilei, F., Salvetti, M., Cipollini, V., Bonanni, L., Franciotti, R., Onofrj, M., ... Del Percio, C. (2020). Abnormal cortical neural synchronization mechanisms in quiet wakefulness are related to motor deficits, cognitive symptoms, and visual hallucinations in Parkinson's disease patients: An electroencephalographic study. Neurobiology of Aging. 91, 88-111. https://doi.org/10.1016/j. neurobiolaging.2020.02.029

Bachman, M. D., \& Bernat, E. M. (2018). Independent contributions of theta and delta time-frequency activity to the visual oddball P3b. International Journal of Psychophysiology, 128, 70-80. https://doi. org/10.1016/j.ijpsycho.2018.03.010

Balconi, M., \& Lucchiari, C. (2008). Consciousness and arousal effects on emotional face processing as revealed by brain oscillations. A gamma band analysis. International Journal of Psychophysiology, 67(1), 41-46. https://doi.org/10.1016/j.ijpsycho.2007.10.002

Barr, M. S., Radhu, N., Guglietti, C. L., Zomorrodi, R., Rajji, T. K., Ritvo, P., \& Daskalakis, Z. J. (2014). Age-related differences in working memory evoked gamma oscillations. Brain Research, 1576, 43-51. https://doi.org/10.1016/j.brainres.2014.05.043

Başar, E. (1972). A study of the time and frequency characteristics of the potentials evoked in the acoustical cortex. Kybernetik, 10(2), 6164. https://doi.org/10.1007/BF00292231

Başar, E. (2013). A review of gamma oscillations in healthy subjects and in cognitive impairment. International Journal of Psychophysiology, 90(2), 99-117. https://doi.org/10.1016/j.ijpsycho.2013.07.005

Başar, E., Başar-Eroglu, C., Karakaş, S., \& Schürmann, M. (2001). Gamma, alpha, delta, and theta oscillations govern cognitive processes. International Journal of Psychophysiology, 39(2-3), 241248. https://doi.org/10.1016/S0167-8760(00)00145-8

Başar, E., Başar-Eroglu, C., Parnefjord, R., Rahn, E., \& Schürmann, M. (1992). Evoked potentials: Ensembles of brain induced rhythmicities in the alpha, theta and gamma ranges. In E. Başar \& T. Bullock (Eds.), Induced rhythms in the brain (pp. 155-181). Birkhäuser.

Basar, E., Demiralp, T., Schürmann, M., Basar-Eroglu, C., \& Ademoglu, A. (1999). Oscillatory brain dynamics, wavelet analysis, and cognition. Brain and Language, 66(1), 146-183. https://doi.org/10.1006/ brln.1998.2029

Başar, E., Emek-Savaş, D. D., Güntekin, B., \& Yener, G. G. (2016). Delay of cognitive gamma responses in Alzheimer's disease. NeuroImage: Clinical, 11, 106-115. https://doi.org/10.1016/j. nicl.2016.01.015

Başar, E., Femir, B., Emek-Savaş, D. D., Güntekin, B., \& Yener, G. G. (2017). Increased long distance event-related gamma band connectivity in Alzheimer's disease. NeuroImage: Clinical, 14, 580-590. https://doi.org/10.1016/j.nicl.2017.02.021

Başar, E., Gölbaşı, B. T., Tülay, E., Aydın, S., \& Başar-Eroğlu, C. (2016). Best method for analysis of brain oscillations in healthy subjects and neuropsychiatric diseases. International Journal of Psychophysiology, 103, 22-42. https://doi.org/10.1016/j.ijpsy cho.2015.02.017 
Başar, E., Gönder, A., Ozesmi, C., \& Ungan, P. (1975). Dynamics of brain rhythmic and evoked potentials. II. Studies in the auditory pathway, reticular formation, and hippocampus during the waking stage. Biological Cybernetics, 20(3-4), 145-160. https://doi. org/10.1007/BF00342635

Başar, E., Güntekin, B., Tülay, E., \& Yener, G. G. (2010). Evoked and event related coherence of Alzheimer patients manifest differentiation of sensory-cognitive networks. Brain Research, 1357, 79-90. https://doi.org/10.1016/j.brainres.2010.08.054

Basar, E., \& Stampfer, H. G. (1985). Important associations among EEG-dynamics, event-related potentials, short-term memory and learning. International Journal of Neuroscience, 26(3-4), 161-180. https://doi.org/10.3109/00207458508985615

Başar-Eroglu, C., \& Başar, E. (1991). A compound P300-40Hz response of the cat hippocampus. International Journal of Neuroscience, 60(3-4), 227-237. https://doi.org/10.3109/00207459109167035

Başar-Eroglu, C., Strüber, D., Schürmann, M., Stadler, M., \& Başar, E. (1996). Gamma-band responses in the brain: A short review of psychophysiological correlates and functional significance. International Journal of Psychophysiology, 24(1-2), 101-112. https://doi.org/10.1016/S0167-8760(96)00051-7

Bates, A. T., Kiehl, K. A., Laurens, K. R., \& Liddle, P. F. (2009). Lowfrequency EEG oscillations associated with information processing in schizophrenia. Schizophrenia Research, 115(2-3), 222-230. https://doi.org/10.1016/j.schres.2009.09.036

Benussi, A., Cantoni, V., Cotelli, M. S., Cotelli, M., Brattini, C., Datta, A., Thomas, C., Santarnecchi, E., Pascual-Leone, A., \& Borroni, B. (2021). Exposure to gamma tACS in Alzheimer's disease: A randomized, double-blind, sham-controlled, crossover, pilot study. Brain Stimulation, 14(3), 531-540. https://doi.org/10.1016/j. brs.2021.03.007

Berger, H. (1929). Über das Elektrenkephalogramm des Menschen. I. Bericht. Archiv Für Psychiatrie Und Nervenkrankheiten, 87, 527570. https://doi.org/10.1007/BF01797193

Bobes, M. A., García, Y. F., Lopera, F., Quiroz, Y. T., Galán, L., Vega, M., Trujillo, N., Valdes-Sosa, M., \& Valdes-Sosa, P. (2010). ERP generator anomalies in presymptomatic carriers of the Alzheimer's disease E280APS-1mutation. Human Brain Mapping, 31(2), 247265. http://dx.doi.org/10.1002/hbm.20861

Böttger, D., Herrmann, C. S., \& von Cramon, D. Y. (2002). Amplitude differences of evoked alpha and gamma oscillations in two different age groups. International Journal of Psychophysiology, 45(3), 245251. https://doi.org/10.1016/S0167-8760(02)00031-4

Bruns, A., Eckhorn, R., Jokeit, H., \& Ebner, A. (2000). Amplitude envelope correlation detects coupling among incoherent brain signals. NeuroReport, 11(7), 1509-1514. https://doi.org/10.1097/00001756200005150-00029

Canolty, R. T., Edwards, E., Dalal, S. S., Soltani, M., Nagarajan, S. S., Kirsch, H. E., Berger, M. S., Barbaro, N. M., \& Knight, R. T. (2006). High gamma power is phase-locked to theta oscillations in human neocortex. Science, 313(5793), 1626-1628. https://doi.org/10.1126/ science. 1128115

Canolty, R. T., \& Knight, R. T. (2010). The functional role of crossfrequency coupling. Trends in Cognitive Sciences, 14(11), 506-515. https://doi.org/10.1016/j.tics.2010.09.001

Caravaglios, G., Castro, G., Costanzo, E., Di Maria, G., Mancuso, D., \& Muscoso, E. G. (2010). Theta power responses in mild Alzheimer's disease during an auditory oddball paradigm: Lack of theta enhancement during stimulus processing. Journal of Neural Transmission, 117(10), 1195-1208. https://doi.org/10.1007/s00702-010-0488-2
Caravaglios, G., Castro, G., Muscoso, E. G., Crivelli, D., \& Balconi, M. (2018). Beta responses in healthy elderly and in patients with amnestic mild cognitive impairment during a task of temporal orientation of attention. Clinical EEG and Neuroscience, 49(4), 258-271. https://doi.org/10.1177/1550059416676144

Caravaglios, G., Costanzo, E., Palermo, F., \& Muscoso, E. G. (2008). Decreased amplitude of auditory event-related delta responses in Alzheimer's disease. International Journal of Psychophysiology, 70(1), 23-32. https://doi.org/10.1016/j.ijpsycho.2008.04.004

Caravaglios, G., Muscoso, E. G., Di Maria, G., \& Costanzo, E. (2013). Theta responses are abnormal in mild cognitive impairment: Evidence from analysis of theta event-related synchronization during a temporal expectancy task. Journal of Neural Transmission, 120(7), 1093-1107. https://doi.org/10.1007/s00702-012-0921-9

Caravaglios, G., Muscoso, E. G., Di Maria, G., \& Costanzo, E. (2015). Patients with mild cognitive impairment have an abnormal upperalpha event-related desynchronization/synchronization (ERD/ERS) during a task of temporal attention. Journal of Neural Transmission, 122(3), 441-453. https://doi.org/10.1007/s00702-014-1262-7

Cavanagh, J. F., \& Frank, M. J. (2014). Frontal theta as a mechanism for cognitive control. Trends in Cognitive Sciences, 18(8), 414-421. https://doi.org/10.1016/j.tics.2014.04.012

Cespon, J., Rodella, C., Miniussi, C., \& Pellicciari, M. C. (2019). Behavioural and electrophysiological modulations induced by transcranial direct current stimulation in healthy elderly and Alzheimer's disease patients: A pilot study. Clinical Neurophysiology, 130(11), 2038-2052. https://doi.org/10.1016/j.clinph.2019.08.016

Christov, M., \& Dushanova, J. (2016). Functional correlates of brain aging: Beta and gamma components of event-related band responses. Acta Neurobiologiae Experimentalis, 76(2), 98-109. https://doi.org/10.21307/ane-2017-009

Cohen, M. X. (2008). Assessing transient cross-frequency coupling in EEG data. Journal of Neuroscience Methods, 168(2), 494-499. https://doi.org/10.1016/j.jneumeth.2007.10.012

Cohen, M. X. (2014). Analyzing neural time series data: Theory and practice. MIT press.

Cohen, M. X., \& Cavanagh, J. F. (2011). Single-trial regression elucidates the role of prefrontal theta oscillations in response conflict. Frontiers in Psychology, 2, 30. https://doi.org/10.3389/ fpsyg.2011.00030

Colclough, G. L., Woolrich, M. W., Tewarie, P. K., Brookes, M. J., Quinn, A. J., \& Smith, S. M. (2016). How reliable are MEG restingstate connectivity metrics? NeuroImage, 138, 284-293. https://doi. org/10.1016/j.neuroimage.2016.05.070

Crunelli, V., David, F., Lőrincz, M. L., \& Hughes, S. W. (2015). The thalamocortical network as a single slow wave-generating unit. Current Opinion in Neurobiology, 31, 72-80. https://doi.org/10.1016/j. conb.2014.09.001

Cummins, T. D., Broughton, M., \& Finnigan, S. (2008). Theta oscillations are affected by amnestic mild cognitive impairment and cognitive load. International Journal of Psychophysiology, 70(1), 75-81. https://doi.org/10.1016/j.ijpsycho.2008.06.002

Cummins, T. D., \& Finnigan, S. (2007). Theta power is reduced in healthy cognitive aging. International Journal of Psychophysiology, 66(1), 10-17. https://doi.org/10.1016/j.ijpsycho.2007.05.008

de Haan, W., Pijnenburg, Y. A., Strijers, R. L., van der Made, Y., van der Flier, W. M., Scheltens, P., \& Stam, C. J. (2009). Functional neural network analysis in frontotemporal dementia and Alzheimer's disease using EEG and graph theory. BMC Neuroscience, 10(1), 1-12. https://doi.org/10.1186/1471-2202-10-101 
Debener, S., Herrmann, C. S., Kranczioch, C., Gembris, D., \& Engel, A. K. (2003). Top-down attentional processing enhances auditory evoked gamma band activity. NeuroReport, 14(5), 683-686. https:// doi.org/10.1097/00001756-200304150-00005

Deiber, M. P., Ibañez, V., Missonnier, P., Herrmann, F., Fazio-Costa, L., Gold, G., \& Giannakopoulos, P. (2009). Abnormal-induced theta activity supports early directed-attention network deficits in progressive MCI. Neurobiology of Aging, 30(9), 1444-1452. https:// doi.org/10.1016/j.neurobiolaging.2007.11.021

Deiber, M.-P., Meziane, H. B., Hasler, R., Rodriguez, C., Toma, S., Ackermann, M., Herrmann, F., \& Giannakopoulos, P. (2015). Attention and working memory-related EEG markers of subtle cognitive deterioration in healthy elderly individuals. Journal of Alzheimer's Disease, 47(2), 335-349. https://doi.org/10.3233/JAD-150111

Deiber, M.-P., Rodriguez, C., Jaques, D., Missonnier, P., Emch, J., Millet, P., Gold, G., Giannakopoulos, P., \& Ibañez, V. (2010). Aging effects on selective attention-related electroencephalographic patterns during face encoding. Neuroscience, 171(1), 173-186. https:// doi.org/10.1016/j.neuroscience.2010.08.051

del Val, L. P., Cantero, J. L., \& Atienza, M. (2016). Atrophy of amygdala and abnormal memory-related alpha oscillations over posterior cingulate predict conversion to Alzheimer's disease. Scientific Reports, 6, 31859. https://doi.org/10.1038/srep31859

Del Val, L. P., Cantero, J. L., Baena, D., \& Atienza, M. (2018). Damage of the temporal lobe and APOE status determine neural compensation in mild cognitive impairment. Cortex, 101, 136-153. https:// doi.org/10.1016/j.cortex.2018.01.018

Delorme, A., \& Makeig, S. (2004). EEGLAB: An open source toolbox for analysis of single-trial EEG dynamics including independent component analysis. Journal of Neuroscience Methods, 134(1), 921. https://doi.org/10.1016/j.jneumeth.2003.10.009

Demiralp, T., Ademoglu, A., Istefanopulos, Y., Başar-Eroglu, C., \& Başar, E. (2001). Wavelet analysis of oddball P300. International Journal of Psychophysiology, 39(2-3), 221-227. https://doi. org/10.1016/S0167-8760(00)00143-4

Doege, K., Jansen, M., Mallikarjun, P., Liddle, E. B., \& Liddle, P. F. (2010). How much does phase resetting contribute to event-related EEG abnormalities in schizophrenia? Neuroscience Letters, 481(1), 1-5. https://doi.org/10.1016/j.neulet.2010.06.008

Doege, K., Kumar, M., Bates, A. T., Das, D., Boks, M. P. M., \& Liddle, P. F. (2010). Time and frequency domain event-related electrical activity associated with response control in schizophrenia. Clinical Neurophysiology, 121(10), 1760-1771. https://doi.org/10.1016/j. clinph.2010.03.049

Donchin, E., Kubovy, M., Kutas, M., Johnson, R., \& Tterning, R. I. (1973). Graded changes in evoked response (P300) amplitude as a function of cognitive activity. Perception \& Psychophysics, 14(2), 319-324. https://doi.org/10.3758/BF03212398

Drinkenburg, W. H., Ruigt, G. S., \& Ahnaou, A. (2015). PharmacoEEG studies in animals: An overview of contemporary translational applications. Neuropsychobiology, 72(3-4), 151-164. https://doi. org/10.1159/000442210

Dunkin, J. J., Leuchter, A. F., Newton, T. F., \& Cook, I. A. (1994). Reduced EEG coherence in dementia: State or trait marker? Biological Psychiatry, 35(11), 870-879. https://doi. org/10.1016/0006-3223(94)90023-X

Dushanova, J., \& Christov, M. (2014). The effect of aging on EEG brain oscillations related to sensory and sensorimotor functions. Advances in Medical Sciences, 59(1), 61-67. https://doi.org/10.1016/j. advms.2013.08.002
Emek-Savaş, D. D., Güntekin, B., Yener, G. G., \& Başar, E. (2016). Decrease of delta oscillatory responses is associated with increased age in healthy elderly. International Journal of Psychophysiology, 103, 103-109. https://doi.org/10.1016/j.jpsycho.2015.02.006

Emek-Savaş, D. D., Özmüş, G., Güntekin, B., Dönmez Çolakoğlu, B., Çakmur, R., Başar, E., \& Yener, G. G. (2017). Decrease of delta oscillatory responses in cognitively normal Parkinson's disease. Clinical EEG and Neuroscience, 48(5), 355-364. https://doi. org/10.1177/1550059416666718

Engel, A. K., \& Fries, P. (2010). Beta-band oscillations-signalling the status quo? Current Opinion in Neurobiology, 20(2), 156-165. https://doi.org/10.1016/j.conb.2010.02.015

Ergen, M., Marbach, S., Brand, A., Başar-Eroğlu, C., \& Demiralp, T. (2008). P3 and delta band responses in visual oddball paradigm in schizophrenia. Neuroscience Letters, 440(3), 304-308. https://doi. org/10.1016/j.neulet.2008.05.054

Fodor, Z., Sirály, E., Horváth, A., Salacz, P., Hidasi, Z., Csibri, É., Szabó, Á., \& Csukly, G. (2018). Decreased event-related beta synchronization during memory maintenance marks early cognitive decline in mild cognitive impairment. Journal of Alzheimer's Disease, 63(2), 489-502. https://doi.org/10.3233/JAD-171079

Ford, J. M., Roach, B. J., Hoffman, R. S., \& Mathalon, D. H. (2008). The dependence of P300 amplitude on gamma synchrony breaks down in schizophrenia. Brain Research, 1235, 133-142. https://doi. org/10.1016/j.brainres.2008.06.048

Fraga, F. J., Ferreira, L. A., Falk, T. H., Johns, E., \& Phillips, N. D. (2017, March). Event-related synchronisation responses to Nback memory tasks discriminate between healthy ageing, mild cognitive impairment, and mild Alzheimer's disease. In 2017 IEEE International Conference on Acoustics, Speech and Signal Processing (ICASSP) (pp. 964-968). IEEE. https://doi.org/10.1109/ ICASSP.2017.7952299

Fraga, F. J., Mamani, G. Q., Johns, E., Tavares, G., Falk, T. H., \& Phillips, N. A. (2018). Early diagnosis of mild cognitive impairment and Alzheimer's with event-related potentials and event-related desynchronization in N-back working memory tasks. Computer Methods and Programs in Biomedicine, 164, 1-13. https://doi. org/10.1016/j.cmpb.2018.06.011

Freeman, W. J. (1975). Mass action in the nervous system (Vol. 2004). Academic Press.

Friston, K. J. (1997). Another neural code? NeuroImage, 5(3), 213-220. https://doi.org/10.1006/nimg.1997.0260

Gaetz, W., Roberts, T. P., Singh, K. D., \& Muthukumaraswamy, S. D. (2012). Functional and structural correlates of the aging brain: Relating visual cortex (V1) gamma band responses to age-related structural change. Human Brain Mapping, 33(9), 2035-2046. https://doi.org/10.1002/hbm.21339

Gevins, A., Smith, M. E., McEvoy, L., \& Yu, D. (1997). Highresolution EEG mapping of cortical activation related to working memory: Effects of task difficulty, type of processing, and practice. Cerebral Cortex (New York, NY: 1991), 7(4), 374-385. https://doi. org/10.1093/cercor/7.4.374

Golob, E. J., Irimajiri, R., \& Starr, A. (2007). Auditory cortical activity in amnestic mild cognitive impairment: Relationship to subtype and conversion to dementia. Brain, 130(3), 740-752. https://doi. org/10.1093/brain/awl375

Goodman, M. S., Kumar, S., Zomorrodi, R., Ghazala, Z., Cheam, A. S. M., Barr, M. S., Daskalakis, Z. J., Blumberger, D. M., Fischer, C., Flint, A., Mah, L., Herrmann, N., Bowie, C. R., Mulsant, B. H., \& Rajji, T. K. (2018). Theta-gamma coupling and working 
memory in Alzheimer's dementia and mild cognitive impairment. Frontiers in Aging Neuroscience, 10, 101. http://dx.doi.org/10.3389/ fnagi.2018.00101

Goodman, M. S., Zomorrodi, R., Kumar, S., Barr, M. S., Daskalakis, Z. J., Blumberger, D. M., Fischer, C. E., Flint, A., Mah, L., Herrmann, N., Pollock, B. G., Bowie, C. R., Mulsant, B. H., \& Rajji, T. K. (2019). Changes in theta but not alpha modulation are associated with impairment in working memory in Alzheimer's disease and mild cognitive impairment. Journal of Alzheimer's Disease, 68(3), 1085-1094. https://doi.org/10.3233/JAD-181195

Goossens, T., Vercammen, C., Wouters, J., \& Wieringen, A. V. (2016). Aging affects neural synchronization to speech-related acoustic modulations. Frontiers in Aging Neuroscience, 8, 133. https://doi. org/10.3389/fnagi.2016.00133

Grace, A. A. (1995). The tonic/phasic model of dopamine system regulation: Its relevance for understanding how stimulant abuse can alter basal ganglia function. Drug and Alcohol Dependence, 37(2), 111129. https://doi.org/10.1016/0376-8716(94)01066-T

Gray, C. M., \& Singer, W. (1989). Stimulus-specific neuronal oscillations in orientation columns of cat visual cortex. Proceedings of the National Academy of Sciences, 86(5), 1698-1702. https://doi. org/10.1073/pnas.86.5.1698

Gruber, M. J., Hsieh, L. T., Staresina, B. P., Elger, C. E., Fell, J., Axmacher, N., \& Ranganath, C. (2018). Theta phase synchronization between the human hippocampus and pre- frontal cortex increases during encoding of unexpected information: A case study. Journal of Cognitive Neuroscience, 30(11), 1646-1656. https://doi. org/10.1162/jocn_a_01302

Gruber, T., Müller, M. M., \& Keil, A. (2002). Modulation of induced gamma band responses in a perceptual learning task in the human EEG. Journal of Cognitive Neuroscience, 14(5), 732-744. https:// doi.org/10.1162/08989290260138636

Güntekin, B., Aktürk, T., Yıldırım, E., Yılmaz, N. H., Hanoğlu, L., \& Yener, G. (2020). Abnormalities in auditory and visual cognitive processes are differentiated with theta responses in patients with Parkinson's disease with and without dementia. International Journal of Psychophysiology, 153, 65-79. https://doi.org/10.1016/j. ijpsycho.2020.04.016

Güntekin, B., \& Basar, E. (2007). Emotional face expressions are differentiated with brain oscillations. International Journal of Psychophysiology, 64(1), 91-100. https://doi.org/10.1016/j.jpsycho.2006.07.003

Güntekin, B., \& Başar, E. (2009). Facial affect manifested by multiple oscillations. International Journal of Psychophysiology, 71(1), 3136. https://doi.org/10.1016/j.ijpsycho.2008.07.019

Güntekin, B., \& Başar, E. (2010). Event-related beta oscillations are affected by emotional eliciting stimuli. Neuroscience Letters, 483(3), 173-178. https://doi.org/10.1016/j.neulet.2010.08.002

Güntekin, B., \& Başar, E. (2016). Review of evoked and eventrelated delta responses in the human brain. International Journal of Psychophysiology, 103, 43-52. https://doi.org/10.1016/j.ijpsy cho.2015.02.001

Güntekin, B., \& Emek-Savaş, D. D. (2019). Fonksiyon Değerlendirme ve Görüntüleme Teknikleri, Elektroensefalografi ve Beyin Osilasyonları: Farklı Fonksiyonel ve Kognitif Durumların Analizi. In H. Biçeroğlu (Ed.), Fonksiyonun Cerrahi Anatomisi (pp. 11111133). Istanbul, Turkey: Us Akademi.

Güntekin, B., Emek-Savaş, D. D., Kurt, P., Yener, G. G., \& Başar, E. (2013). Beta oscillatory responses in healthy subjects and subjects with mild cognitive impairment. NeuroImage: Clinical, 3, 39-46. https://doi.org/10.1016/j.nicl.2013.07.003
Güntekin, B., Hanoğlu, L., Aktürk, T., Fide, E., Emek-Savaş, D. D., Ruşen, E., Yıldırım, E., \& Yener, G. G. (2019). Impairment in recognition of emotional facial expressions in Alzheimer's disease is represented by EEG theta and alpha responses. Psychophysiology, 56(11), e13434. https://doi.org/10.1111/psyp.13434

Güntekin, B., Hanoğlu, L., Güner, D., Yılmaz, N. H., Çadırcı, F., Mantar, N., Aktürk, T., Emek-Savaş, D. D., Özer, F. F., Yener, G., \& Başar, E. (2018). Cognitive impairment in Parkinson's disease is reflected with gradual decrease of EEG delta responses during auditory discrimination. Frontiers in Psychology, 9, 170. https://doi. org/10.3389/fpsyg.2018.00170

Güntekin, B., Saatçi, E., \& Yener, G. (2008). Decrease of evoked delta, theta and alpha coherences in Alzheimer patients during a visual oddball paradigm. Brain Research, 1235, 109-116. https://doi. org/10.1016/j.brainres.2008.06.028

Güntekin, B., \& Tülay, E. (2014). Event related beta and gamma oscillatory responses during perception of affective pictures. Brain Research, 1577, 45-56. https://doi.org/10.1016/j.brain res.2014.06.029

Hashemi, A., Pino, L. J., Moffat, G., Mathewson, K. J., Aimone, C., Bennett, P. J., Schmidt, L. A., \& Sekuler, A. B. (2016). Characterizing population EEG dynamics throughout adulthood. Eneuro, 3(6), 113. https://doi.org/10.1523/ENEURO.0275-16.2016

Haufe, S., Nikulin, V. V., Müller, K. R., \& Nolte, G. (2013). A critical assessment of connectivity measures for EEG data: A simulation study. NeuroImage, 64, 120-133. https://doi.org/10.1016/j.neuro image.2012.09.036

Helfrich, R. F., \& Knight, R. T. (2019). Cognitive neurophysiology: Event-related potentials. Handbook of Clinical Neurology, 160, 543-558. https://doi.org/10.1016/B978-0-444-64032-1.00036-9

Herrmann, C. S., \& Demiralp, T. (2005). Human EEG gamma oscillations in neuropsychiatric disorders. Clinical Neurophysiology, 116(12), 2719-2733. https://doi.org/10.1016/j.clinph.2005.07.007

Herrmann, C. S., Fründ, I., \& Lenz, D. (2010). Human gamma-band activity: A review on cognitive and behavioral correlates and network models. Neuroscience \& Biobehavioral Reviews, 34(7), 981-992. https://doi.org/10.1016/j.neubiorev.2009.09.001

Herrmann, C. S., \& Knight, R. T. (2001). Mechanisms of human attention: Event-related potentials and oscillations. Neuroscience \& Biobehavioral Reviews, 25(6), 465-476. https://doi.org/10.1016/ S0149-7634(01)00027-6

Herrmann, C. S., Munk, M. H., \& Engel, A. K. (2004). Cognitive functions of gamma-band activity: Memory match and utilization. Trends in Cognitive Sciences, 8(8), 347-355. https://doi.org/10.1016/j. tics.2004.06.006

Herrmann, C. S., Rach, S., Vosskuhl, J., \& Strüber, D. (2014). Timefrequency analysis of event-related potentials: A brief tutorial. Brain Topography, 27(4), 438-450. https://doi.org/10.1007/s1054 8-013-0327-5

Hogan, M., Collins, P., Keane, M., Kilmartin, L., Kaiser, J., Kenney, J., Lai, R., \& Upton, N. (2011). Electroencephalographic coherence, aging, and memory: Distinct responses to background context and stimulus repetition in younger, older, and older declined groups. Experimental Brain Research, 212(2), 241-255. https://doi. org/10.1007/s00221-011-2726-8

Hogan, M. J., Swanwick, G. R., Kaiser, J., Rowan, M., \& Lawlor, B. (2003). Memory-related EEG power and coherence reductions in mild Alzheimer's disease. International Journal of Psychophysiology, 49(2), 147-163. https://doi.org/10.1016/S0167 $-8760(03) 00118-1$ 
Horvath, A., Szucs, A., Csukly, G., Sakovics, A., Stefanics, G., \& Kamondi, A. (2018). EEG and ERP biomarkers of Alzheimer's disease: A critical review. Frontiers in Bioscience (Landmark edition), 23, 183-220. https://doi.org/10.2741/4587

Hsieh, L. T., \& Ranganath, C. (2014). Frontal midline theta oscillations during working memory maintenance and episodic encoding and retrieval. NeuroImage, 85, 721-729. https://doi.org/10.1016/j.neuro image.2013.08.003

Iaccarino, H. F., Singer, A. C., Martorell, A. J., Rudenko, A., Gao, F., Gillingham, T. Z., Mathys, H., Seo, J., Kritskiy, O., Abdurrob, F., Adaikkan, C., Canter, R. G., Rueda, R., Brown, E. N., Boyden, E. S., \& Tsai, L.-H. (2016). Gamma frequency entrainment attenuates amyloid load and modifies microglia. Nature, 540(7632), 230-235. https://doi.org/10.1038/nature20587

Ishii, R., Canuet, L., Aoki, Y., Hata, M., Iwase, M., Ikeda, S., Nishida, K., \& Ikeda, M. (2017). Healthy and pathological brain aging: From the perspective of oscillations, functional connectivity, and signal complexity. Neuropsychobiology, 75(4), 151-161. https://doi. org/10.1159/000486870

Ismail, R., Hansen, A. K., Parbo, P., Brændgaard, H., Gottrup, H., Brooks, D. J., \& Borghammer, P. (2018). The effect of 40-Hz light therapy on amyloid load in patients with prodromal and clinical Alzheimer's disease. International Journal of Alzheimer's Disease, 2018, 6852303. https://doi.org/10.1155/2018/6852303

Jack, C. R., Bennett, D. A., Blennow, K., Carrillo, M. C., Dunn, B., Haeberlein, S. B., Holtzman, D. M., Jagust, W., Jessen, F., Karlawish, J., Liu, E., Molinuevo, J. L., Montine, T., Phelps, C., Rankin, K. P., Rowe, C. C., Scheltens, P., Siemers, E., Snyder, H. M., ... Silverberg, N. (2018). NIA-AA research framework: Toward a biological definition of Alzheimer's disease. Alzheimer's \& Dementia, 14(4), 535562. https://doi.org/10.1016/j.jalz.2018.02.018

Jensen, O., Kaiser, J., \& Lachaux, J. P. (2007). Human gamma-frequency oscillations associated with attention and memory. Trends in Neurosciences, 30(7), 317-324. https://doi.org/10.1016/j.tins.2007.05.001

Jensen, O., \& Tesche, C. D. (2002). Frontal theta activity in humans increases with memory load in a working memory task. European Journal of Neuroscience, 15(8), 1395-1399. https://doi. org/10.1046/j.1460-9568.2002.01975.x

Jones, K. A., Porjesz, B., Chorlian, D., Rangaswamy, M., Kamarajan, C., Padmanabhapillai, A., Stimus, A., \& Begleiter, H. (2006). Stransform time-frequency analysis of P300 reveals deficits in individuals diagnosed with alcoholism. Clinical Neurophysiology, 117(10), 2128-2143. https://doi.org/10.1016/j.clinph.2006.02.028

Jones, M., McDermott, B., Oliveira, B. L., O’Brien, A., Coogan, D., Lang, M., Moriarty, N., Dowd, E., Quinlan, L., Mc Ginley, B., Dunne, E., Newell, D., Porter, E., Elahi, M. A., O' Halloran, M., \& Shahzad, A. (2019). Gamma band light stimulation in human case studies: Groundwork for potential Alzheimer's disease treatment. Journal of Alzheimer's Disease, 70(1), 171-185. https://doi. org/10.3233/JAD-190299

Kaiser, J., Ripper, B., Birbaumer, N., \& Lutzenberger, W. (2003). Dynamics of gamma-band activity in human magnetoencephalogram during auditory pattern working memory. NeuroImage, 20(2), 816-827. https://doi.org/10.1016/S1053-8119(03)00350-1

Kamarajan, C., Porjesz, B., Jones, K. A., Choi, K., Chorlian, D. B., Padmanabhapillai, A., Rangaswamy, M., Stimus, A. T., \& Begleiter, H. (2004). The role of brain oscillations as functional correlates of cognitive systems: A study of frontal inhibitory control in alcoholism. International Journal of Psychophysiology, 51(2), 155-180. https://doi.org/10.1016/j.ijpsycho.2003.09.004
Karakaş, S., Erzengin, Ö. U., \& Başar, E. (2000). A new strategy involving multiple cognitive paradigms demonstrates that ERP components are determined by the superposition of oscillatory responses. Clinical Neurophysiology, 111(10), 1719-1732. https:// doi.org/10.1016/S1388-2457(00)00418-1

Karamacoska, D., Barry, R. J., Steiner, G. Z., Coleman, E. P., \& Wilson, E. J. (2018). Intrinsic EEG and task-related changes in EEG affect Go/NoGo task performance. International Journal of Psychophysiology, 125, 17-28. https://doi.org/10.1016/j.ijpsy cho.2018.01.015

Kardos, Z., Tóth, B., Boha, R., File, B., \& Molnár, M. (2014). Agerelated changes of frontal-midline theta is predictive of efficient memory maintenance. Neuroscience, 273, 152-162. https://doi. org/10.1016/j.neuroscience.2014.04.071

Karrasch, M., Laine, M., Rapinoja, P., \& Krause, C. M. (2004). Effects of normal aging on event-related desynchronization/synchronization during a memory task in humans. Neuroscience Letters, 366(1), 1823. https://doi.org/10.1016/j.neulet.2004.05.010

Karrasch, M., Laine, M., Rinne, J. O., Rapinoja, P., Sinervä, E., \& Krause, C. M. (2006). Brain oscillatory responses to an auditoryverbal working memory task in mild cognitive impairment and Alzheimer's disease. International Journal of Psychophysiology, 59(2), 168-178. https://doi.org/10.1016/j.ijpsycho.2005.04.006

Keil, A., Müller, M. M., Gruber, T., Wienbruch, C., Stolarova, M., \& Elbert, T. (2001). Effects of emotional arousal in the cerebral hemispheres: A study of oscillatory brain activity and event-related potentials. Clinical Neurophysiology, 112(11), 2057-2068. https://doi. org/10.1016/S1388-2457(01)00654-X

Keil, A., Müller, M. M., Ray, W. J., Gruber, T., \& Elbert, T. (1999). Human gamma band activity and perception of a gestalt. Journal of Neuroscience, 19(16), 7152-7161. https://doi.org/10.1523/JNEUR OSCI.19-16-07152.1999

Keil, A., Stolarova, M., Moratti, S., \& Ray, W. J. (2007). Adaptation in human visual cortex as a mechanism for rapid discrimination of aversive stimuli. NeuroImage, 36(2), 472-479. https://doi.org/10.1016/j. neuroimage.2007.02.048

Klass, D. W., \& Brenner, R. P. (1995). Electroencephalography of the elderly. Journal of Clinical Neurophysiology, 12(2), 116-131. https:// doi.org/10.1097/00004691-199503000-00002

Klimesch, W. (1999). EEG alpha and theta oscillations reflect cognitive and memory performance: A review and analysis. Brain Research Reviews, 29(2-3), 169-195. https://doi.org/10.1016/S0165-0173(98)00056-3

Kober, S. E., Reichert, J. L., Neuper, C., \& Wood, G. (2016). Interactive effects of age and gender on EEG power and coherence during a short-term memory task in middle-aged adults. Neurobiology of Aging, 40, 127-137. https://doi.org/10.1016/j.neurobiola ging.2016.01.015

Koch, G., Bonnì, S., Pellicciari, M. C., Casula, E. P., Mancini, M., Esposito, R., Ponzo, V., Picazio, S., Di Lorenzo, F., Serra, L., Motta, C., Maiella, M., Marra, C., Cercignani, M., Martorana, A., Caltagirone, C., \& Bozzali, M. (2018). Transcranial magnetic stimulation of the precuneus enhances memory and neural activity in prodromal Alzheimer's disease. NeuroImage, 169, 302-311. https:// doi.org/10.1016/j.neuroimage.2017.12.048

Kolev, V., Beste, C., Falkenstein, M., \& Yordanova, J. (2009). Errorrelated oscillations: Effects of aging on neural systems for behavioral monitoring. Journal of Psychophysiology, 23(4), 216-223. https://doi.org/10.1027/0269-8803.23.4.216

Kolev, V., Yordanova, J., Basar-Eroglu, C., \& Basar, E. (2002). Age effects on visual EEG responses reveal distinct frontal alpha networks. 
Clinical Neurophysiology, 113(6), 901-910. https://doi.org/10.1016/ S1388-2457(02)00106-2

Kurimoto, R., Ishii, R., Canuet, L., Ikezawa, K., Iwase, M., Azechi, M., Aoki, Y., Ikeda, S., Yoshida, T., Takahashi, H., Nakahachi, T., Kazui, H., \& Takeda, M. (2012). Induced oscillatory responses during the Sternberg's visual memory task in patients with Alzheimer's disease and mild cognitive impairment. Neurolmage, 59(4), 4132-4140. https://doi.org/10.1016/j.neuroimage.2011.10.061

Kurt, P., Emek-Savaş, D. D., Batum, K., Turp, B., Güntekin, B., Karşıdağ, S., \& Yener, G. G. (2014). Patients with mild cognitive impairment display reduced auditory event-related delta oscillatory responses. Behavioural Neurology, 2014, 1-11. https://doi. org/10.1155/2014/268967

Lambertz, M., \& Langhorst, P. (1998). Simultaneous changes of rhythmic organization in brainstem neurons, respiration, cardiovascular system and EEG between $0.05 \mathrm{~Hz}$ and $0.5 \mathrm{~Hz}$. Journal of the Autonomic Nervous System, 68(1-2), 58-77. https://doi. org/10.1016/s0165-1838(97)00126-4

Lavin, A., \& Grace, A. A. (1996). Physiological properties of rat ventral pallidal neurons recorded intracellularly in vivo. Journal of Neurophysiology, 75(4), 1432-1443. https://doi.org/10.1152/ jn.1996.75.4.1432

Lejko, N., Larabi, D. I., Herrmann, C. S., Aleman, A., \& Curcic-Blake, B. (2020). Alpha power and functional connectivity in cognitive decline: A systematic review and meta-analysis. Journal of Alzheimer's Disease, 78, 1047-1088. https://doi.org/10.3233/JAD-200962

Leuchter, A. F., Spar, J. E., Walter, D. O., \& Weiner, H. (1987). Electroencephalographic spectra and coherence in the diagnosis of Alzheimer's-type and multi-infarct dementia: A pilot study. Archives of General Psychiatry, 44(11), 993-998. https://doi.org/10.1001/ archpsyc.1987.01800230073012

Leung, L. S., \& Yim, C. C. (1993). Rhythmic delta-frequency activities in the nucleus accumbens of anesthetized and freely moving rats. Canadian Journal of Physiology and Pharmacology, 71(5-6), 311320. https://doi.org/10.1139/y93-049

Liu, C.-J., Huang, C.-F., Chou, C.-Y., Kuo, W.-J., Lin, Y.-T., Hung, C.M., Chen, T.-C., \& Ho, M.-C. (2012). Age-and disease-related features of task-related brain oscillations by using mutual information. Brain and Behavior, 2(6), 754-762. https://doi.org/10.1002/brb3.93

Locatelli, T., Cursi, M., Liberati, D., Franceschi, M., \& Comi, G. (1998). EEG coherence in Alzheimer's disease. Electroencephalography and Clinical Neurophysiology, 106(3), 229-237. https://doi. org/10.1016/S0013-4694(97)00129-6

Lopez, M. E., Bruna, R., Aurtenetxe, S., Pineda-Pardo, J. A., Marcos, A., Arrazola, J., Reinoso, A. I., Montejo, P., Bajo, R., \& Maestu, F. (2014). Alpha-band hypersynchronization in progressive mild cognitive impairment: A magnetoencephalography study. Journal of Neuroscience, 34(44), 14551-14559. https://doi.org/10.1523/ JNEUROSCI.0964-14.2014

Lou, W., Xu, J., Sheng, H., \& Zhao, S. (2011). Multichannel linear descriptors analysis for event-related EEG of vascular dementia patients during visual detection task. Clinical Neurophysiology, 122(11), 2151-2156. https://doi.org/10.1016/j.clinph.2011.03.021

Luck, S. J. (2014). An introduction to the event-related potential technique. MIT press.

Lundin, N. B., Bartolomeo, L. A., O’Donnell, B. F., \& Hetrick, W. P. (2018). Reduced EEG responses to standard and target auditory stimuli in bipolar disorder and the impact of psychotic features: Analysis of ERPs, spectral power, and inter-trial coherence. Bipolar Disorders, 20(1), 49. https://doi.org/10.1111/bdi.12561
Luo, Q., Holroyd, T., Jones, M., Hendler, T., \& Blair, J. (2007). Neural dynamics for facial threat processing as revealed by gamma band synchronization using MEG. NeuroImage, 34(2), 839-847. https:// doi.org/10.1016/j.neuroimage.2006.09.023

Luo, Q., Mitchell, D., Cheng, X., Mondillo, K., Mccaffrey, D., Holroyd, T., Carver, F., Coppola, R., \& Blair, J. (2009). Visual awareness, emotion, and gamma band synchronization. Cerebral Cortex, 19(8), 1896-1904. https://doi.org/10.1093/cercor/bhn216

Maffei, A. (2020). Spectrally resolved EEG intersubject correlation reveals distinct cortical oscillatory patterns during free-viewing of affective scenes. Psychophysiology, 57(11), e13652. https://doi. org/10.1111/psyp.13652

Mahjoory, K., Nikulin, V. V., Botrel, L., Linkenkaer-Hansen, K., Fato, M. M., \& Haufe, S. (2017). Consistency of EEG source localization and connectivity estimates. NeuroImage, 152, 590-601. https://doi. org/10.1016/j.neuroimage.2017.02.076

Marcuse, L. V., Schneider, M., Mortati, K. A., Donnelly, K. M., Arnedo, V., \& Grant, A. C. (2008). Quantitative analysis of the EEG posterior-dominant rhythm in healthy adolescents. Clinical Neurophysiology, 119(8), 1778-1781. https://doi.org/10.1016/j. clinph.2008.02.023

Martínez-Cancino, R., Heng, J., Delorme, A., Kreutz-Delgado, K., Sotero, R. C., \& Makeig, S. (2019). Measuring transient phaseamplitude coupling using local mutual information. NeuroImage, 185, 361-378. https://doi.org/10.1016/j.neuroimage.2018.10.034

Martini, N., Menicucci, D., Sebastiani, L., Bedini, R., Pingitore, A., Vanello, N., Milanesi, M., Landini, L., \& Gemignani, A. (2012). The dynamics of EEG gamma responses to unpleasant visual stimuli: From local activity to functional connectivity. NeuroImage, 60(2), 922-932. https://doi.org/10.1016/j.neuroimage.2012.01.060

Martorell, A. J., Paulson, A. L., Suk, H.-J., Abdurrob, F., Drummond, G. T., Guan, W., Young, J. Z., Kim, D.-W., Kritskiy, O., Barker, S. J., Mangena, V., Prince, S. M., Brown, E. N., Chung, K., Boyden, E. S., Singer, A. C., \& Tsai, L.-H. (2019). Multi-sensory gamma stimulation ameliorates Alzheimer's-associated pathology and improves cognition. Cell, 177(2), 256-271. https://doi.org/10.1016/j. cell.2019.02.014

Mazaheri, A., Segaert, K., Olichney, J., Yang, J. C., Niu, Y. Q., Shapiro, K., \& Bowman, H. (2018). EEG oscillations during word processing predict MCI conversion to Alzheimer's disease. NeuroImage: Clinical, 17, 188-197. https://doi.org/10.1016/j.nicl.2017.10.009

McKhann, G. M., Knopman, D. S., Chertkow, H., Hyman, B. T., Jack, C. R., Kawas, C. H., Klunk, W. E., Koroshetz, W. J., Manly, J. J., Mayeux, R., Mohs, R. C., Morris, J. C., Rossor, M. N., Scheltens, P., Carrillo, M. C., Thies, B., Weintraub, S., \& Phelps, C. H. (2011). The diagnosis of dementia due to Alzheimer's disease: Recommendations from the National Institute on AgingAlzheimer's Association workgroups on diagnostic guidelines for Alzheimer's disease. Alzheimer's \& Dementia, 7(3), 263-269. https://doi.org/10.1016/j.jalz.2011.03.005

Michalopoulos, K., Zervakis, M., Bourbakis, N., Giannakopoulos, P., \& Deiber, M. P. (2012, November). Decomposition and evaluation of activity in multiple event-related trials. In 2012 IEEE 12th International Conference on Bioinformatics \& Bioengineering (BIBE) (pp. 374-379). IEEE. https://doi. org/10.1109/BIBE.2012.6399653

Miltner, W. H., Braun, C., Arnold, M., Witte, H., \& Taub, E. (1999). Coherence of gamma-band EEG activity as a basis for associative learning. Nature, 397(6718), 434-436. https://doi. org/10.1038/17126 
Mishra, J., Zanto, T., Nilakantan, A., \& Gazzaley, A. (2013). Comparable mechanisms of working memory interference by auditory and visual motion in youth and aging. Neuropsychologia, 51(10), 1896-1906. https://doi.org/10.1016/j.neuropsychologia. 2013.06.011

Missonnier, P., Deiber, M.-P., Gold, G., Herrmann, F. R., Millet, P., Michon, A., Fazio-Costa, L., Ibañez, V., \& Giannakopoulos, P. (2007). Working memory load-related electroencephalographic parameters can differentiate progressive from stable mild cognitive impairment. Neuroscience, 150(2), 346-356. https://doi.org/10.1016/j. neuroscience.2007.09.009

Missonnier, P., Gold, G., Herrmann, F. R., Fazio-Costa, L., Michel, J.-P., Deiber, M.-P., Michon, A., \& Giannakopoulos, P. (2006). Decreased theta event-related synchronization during working memory activation is associated with progressive mild cognitive impairment. Dementia and Geriatric Cognitive Disorders, 22(3), 250-259. https://doi.org/10.1159/000094974

Missonnier, P., Herrmann, F. R., Michon, A., Fazio-Costa, L., Gold, G., \& Giannakopoulos, P. (2010). Early disturbances of gamma band dynamics in mild cognitive impairment. Journal of Neural Transmission, 117(4), 489-498. https://doi.org/10.1007/s0070 2-010-0384-9

Miyake, A., Friedman, N. P., Emerson, M. J., Witzki, A. H., Howerter, A., \& Wager, T. D. (2000). The unity and diversity of executive functions and their contributions to complex "frontal lobe" tasks: A latent variable analysis. Cognitive Psychology, 41(1), 49-100. https://doi.org/10.1006/cogp.1999.0734

Mudar, R. A., Nguyen, L. T., Eroh, J., Chiang, H. S., Rackley, A., \& Chapman, S. B. (2019). Event-related neural oscillation changes following reasoning training in individuals with mild cognitive impairment. Brain Research, 1704, 229-240. https://doi.org/10.1016/j. brainres.2018.10.017

Müller, M. M., Keil, A., Gruber, T., \& Elbert, T. (1999). Processing of affective pictures modulates right-hemispheric gamma band EEG activity. Clinical Neurophysiology, 110(11), 1913-1920. https://doi. org/10.1016/S1388-2457(99)00151-0

Müller, V., Gruber, W., Klimesch, W., \& Lindenberger, U. (2009). Lifespan differences in cortical dynamics of auditory perception. Developmental Science, 12(6), 839-853. https://doi. org/10.1111/j.1467-7687.2009.00834.x

Murty, D. V. P. S., Manikandan, K., Kumar, W. S., Ramesh, R. G., Purokayastha, S., Javali, M., Rao, N. P., \& Ray, S. (2020). Gamma oscillations weaken with age in healthy elderly in human EEG. NeuroImage, 215, 116826. https://doi.org/10.1016/j.neuro image.2020.116826

Neuper, C., \& Klimesch, W. (Eds.). (2006). Event-related dynamics of brain oscillations. Elsevier.

Neuper, C., Scherer, R., Wriessnegger, S., \& Pfurtscheller, G. (2009). Motor imagery and action observation: Modulation of sensorimotor brain rhythms during mental control of a brain-computer interface. Clinical Neurophysiology, 120(2), 239-247. https://doi. org/10.1016/j.clinph.2008.11.015

Nguyen, L. T., Marini, F., Shende, S. A., Llano, D. A., \& Mudar, R. A. (2020). Investigating EEG theta and alpha oscillations as measures of value-directed strategic processing in cognitively normal younger and older adults. Behavioural Brain Research, 391, 112702. https:// doi.org/10.1016/j.bbr.2020.112702

O'Connell, R. G., Balsters, J. H., Kilcullen, S. M., Campbell, W., Bokde, A. W., Lai, R., Upton, N., \& Robertson, I. H. (2012). A simultaneous ERP/fMRI investigation of the P300 aging effect. Neurobiology of Aging, 33(10), 2448-2461. https://doi.org/10.1016/j.neurobiola ging.2011.12.021

Olichney, J. M., Iragui, V. J., Salmon, D. P., Riggins, B. R., Morris, S. K., \& Kutas, M. (2006). Absent event-related potential (ERP) word repetition effects in mild Alzheimer's disease. Clinical Neurophysiology, 117(6), 1319-1330. https://doi.org/10.1016/j. clinph.2006.02.022

Olichney, J. M., Morris, S. K., Ochoa, C., Salmon, D. P., Thal, L. J., Kutas, M., \& Iragui, V. J. (2002). Abnormal verbal event related potentials in mild cognitive impairment and incipient Alzheimer's disease. Journal of Neurology, Neurosurgery \& Psychiatry, 73(4), 377-384. https://doi.org/10.1136/jnnp.73.4.377

Olichney, J. M., Yang, J. C., Taylor, J., \& Kutas, M. (2011). Cognitive event-related potentials: Biomarkers of synaptic dysfunction across the stages of Alzheimer's disease. Journal of Alzheimer's Disease, 26(s3), 215-228. https://doi.org/10.3233/JAD-2011-0047

Osipova, D., Pekkonen, E., \& Ahveninen, J. (2006). Enhanced magnetic auditory steady-state response in early Alzheimer's disease. Clinical Neurophysiology, 117(9), 1990-1995. https://doi.org/10.1016/j. clinph.2006.05.034

Park, J. Y., Lee, K. S., An, S. K., Lee, J., Kim, J. J., Kim, K. H., \& Namkoong, K. (2012). Gamma oscillatory activity in relation to memory ability in older adults. International Journal of Psychophysiology, 86(1), 58-65. https://doi.org/10.1016/j.ijpsy cho.2012.08.002

Penny, W. D., Duzel, E., Miller, K. J., \& Ojemann, J. G. (2008). Testing for nested oscillation. Journal of Neuroscience Methods, 174(1), 50-61. https://doi.org/10.1016/j.jneumeth.2008.06.035

Pfurtscheller, G., \& Andrew, C. (1999). Event-related changes of band power and coherence: Methodology and interpretation. Journal of Clinical Neurophysiology, 16(6), 512. https://doi.org/10.1097/00004 691-199911000-00003

Pfurtscheller, G., \& Da Silva, F. L. (1999). Event-related EEG/MEG synchronization and desynchronization: Basic principles. Clinical Neurophysiology, 110(11), 1842-1857. https://doi.org/10.1016/ S1388-2457(99)00141-8

Pfurtscheller, G., Stancak, A. Jr, \& Neuper, C. (1996). Post-movement beta synchronization. A correlate of an idling motor area? Electroencephalography and Clinical Neurophysiology, 98(4), 281293. https://doi.org/10.1016/0013-4694(95)00258-8

Pievani, M., de Haan, W., Wu, T., Seeley, W. W., \& Frisoni, G. B. (2011). Functional network disruption in the degenerative dementias. The Lancet Neurology, 10(9), 829-843. https://doi.org/10.1016/S14744422(11)70158-2

Polich, J., \& Corey-Bloom, J. (2005). Alzheimer's disease and P300: Review and evaluation of task and modality. Current Alzheimer Research, 2(5), 515-525. https://doi.org/10.2174/1567205057 74932214

Polich, J., \& Kok, A. (1995). Cognitive and biological determinants of P300: An integrative review. Biological Psychology, 41(2), 103146. https://doi.org/10.1016/0301-0511(95)05130-9

Prieto del Val, L., Cantero, J. L., \& Atienza, M. (2015). APOE $\varepsilon 4$ constrains engagement of encoding-related compensatory networks in amnestic mild cognitive impairment. Hippocampus, 25(9), 9931007. https://doi.org/10.1002/hipo.22422

Pugnetti, L., Baglio, F., Farina, E., Alberoni, M., Calabrese, E., Gambini, A., Di Bella, E., Garegnani, M., Deleonardis, L., \& Nemni, R. (2010). EEG evidence of posterior cortical disconnection in PD and related dementias. International Journal of Neuroscience, 120(2), 88-98. https://doi.org/10.3109/00207450903436346 
Quiroz, Y. T., Ally, B. A., Celone K., McKeever, J., Ruiz-Rizzo, A. L., Lopera, F., Stern, C. E., \& Budson, A. E. (2011). Event-related potential markers of brain changes in preclinical familial Alzheimer disease. Neurology, 77(5), 469-475. http://dx.doi.org/10.1212/ wnl.0b013e318227b1b0

Rangaswamy, M., Jones, K. A., Porjesz, B., Chorlian, D. B., Padmanabhapillai, A., Kamarajan, C., Kuperman, S., Rohrbaugh, J., O'Connor, S. J., Bauer, L. O., Schuckit, M. A., \& Begleiter, H. (2007). Delta and theta oscillations as risk markers in adolescent offspring of alcoholics. International Journal of Psychophysiology, 63(1), 3-15. https://doi.org/10.1016/j.ijpsycho.2006.10.003

Röschke, J., \& Fell, J. (1997). Spectral analysis of P300 generation in depression and schizophrenia. Neuropsychobiology, 35(2), 108114. https://doi.org/10.1159/000119400

Rosenblum, Y., Maidan, I., Fahoum, F., Giladi, N., Bregman, N., Shiner, T., \& Mirelman, A. (2020). Differential changes in visual and auditory event-related oscillations in dementia with Lewy bodies. Clinical Neurophysiology, 131(10), 2357-2366. https://doi. org/10.1016/j.clinph.2020.06.029

Ross, B., Schneider, B., Snyder, J. S., \& Alain, C. (2010). Biological markers of auditory gap detection in young, middle-aged, and older adults. PLoS One, 5(4), e10101. https://doi.org/10.1371/journ al.pone.0010101

Ross, B., Tremblay, K. L., \& Alain, C. (2020). Simultaneous EEG and MEG recordings reveal vocal pitch elicited cortical gamma oscillations in young and older adults. NeuroImage, 204, 116253. https:// doi.org/10.1016/j.neuroimage.2019.116253

Rossini, P. M., Di Iorio, R., Vecchio, F., Anfossi, M., Babiloni, C., Bozzali, M., Bruni, A. C., Cappa, S. F., Escudero, J., Fraga, F. J., Giannakopoulos, P., Guntekin, B., Logroscino, G., Marra, C., Miraglia, F., Panza, F., Tecchio, F., Pascual-Leone, A., \& Dubois, B. (2020). Early diagnosis of Alzheimer's disease: The role of biomarkers including advanced EEG signal analysis. Report from the IFCN-sponsored panel of experts. Clinical Neurophysiology, 131(6), 1287-1310. https://doi.org/10.1016/j.clinph.2020.03.003

Rossini, P. M., Rossi, S., Babiloni, C., \& Polich, J. (2007). Clinical neurophysiology of aging brain: From normal aging to neurodegeneration. Progress in Neurobiology, 83(6), 375-400. https://doi. org/10.1016/j.pneurobio.2007.07.010

Ruiz-Gómez, S. J., Hornero, R., Poza, J., Maturana-Candelas, A., Pinto, N., \& Gómez, C. (2019). Computational modeling of the effects of EEG volume conduction on functional connectivity metrics. Application to Alzheimer's disease continuum. Journal of Neural Engineering, 16(6), 066019. https://doi.org/10.1088/1741-2552/ ab4024

Sato, W., Kochiyama, T., Uono, S., Matsuda, K., Usui, K., Inoue, Y., \& Toichi, M. (2011). Rapid amygdala gamma oscillations in response to fearful facial expressions. Neuropsychologia, 49(4), 612-617. https://doi.org/10.1016/j.neuropsychologia.2010.12.025

Sauseng, P., Griesmayr, B., Freunberger, R., \& Klimesch, W. (2010). Control mechanisms in working memory: A possible function of EEG theta oscillations. Neuroscience \& Biobehavioral Reviews, 34(7), 1015-1022. https://doi.org/10.1016/j.neubiorev.2009.12.006

Sauseng, P., Klimesch, W., Gruber, W. R., Hanslmayr, S., Freunberger, R., \& Doppelmayr, M. (2007). Are event-related potential components generated by phase resetting of brain oscillations? A Critical Discussion. Neuroscience, 146(4), 1435-1444. https://doi. org/10.1016/j.neuroscience.2007.03.014

Schmiedt-Fehr, C., \& Basar-Eroglu, C. (2011). Event-related delta and theta brain oscillations reflect age-related changes in both a general and a specific neuronal inhibitory mechanism. Clinical Neurophysiology, 122(6), 1156-1167. https://doi.org/10.1016/j. clinph.2010.10.045

Schmiedt-Fehr, C., Mathes, B., \& Basar-Eroglu, C. (2009). Alpha brain oscillations and inhibitory control: A partially preserved mechanism in healthy aging? Journal of Psychophysiology, 23(4), 208. https:// doi.org/10.1027/0269-8803.23.4.208

Schmiedt-Fehr, C., Mathes, B., Kedilaya, S., Krauss, J., \& Basar-Eroglu, C. (2016). Aging differentially affects alpha and beta sensorimotor rhythms in a go/nogo task. Clinical Neurophysiology, 127(10), 3234-3242. https://doi.org/10.1016/j.clinph.2016.07.008

Schmiedt-Fehr, C., Schwendemann, G., Herrmann, M., \& Basar-Eroglu, C. (2007). Parkinson's disease and age-related alterations in brain oscillations during a Simon task. NeuroReport, 18(3), 277-281. https://doi.org/10.1097/WNR.0b013e32801421e3

Serrano, N., López-Sanz, D., Bruña, R., Garcés, P., Rodríguez-Rojo, I. C., Marcos, A., Crespo, D. P., \& Maestú, F. (2020). Spatiotemporal oscillatory patterns during working memory maintenance in mild cognitive impairment and subjective cognitive decline. International Journal of Neural Systems, 30(1), 1950019. https://doi.org/10.1142/ S0129065719500199

Singer, W. (1999). Neuronal synchrony: A versatile code for the definition of relations? Neuron, 24(1), 49-65. https://doi.org/10.1016/ s0896-6273(00)80821-1

Stam, C. J., Nolte, G., \& Daffertshofer, A. (2007). Phase lag index: Assessment of functional connectivity from multi channel EEG and MEG with diminished bias from common sources. Human Brain Mapping, 28(11), 1178-1193. https://doi.org/10.1002/hbm.20346

Stampfer, H. G., \& Başar, E. (1985). Does frequency analysis lead to better understanding of human event related potentials. International Journal of Neuroscience, 26(3-4), 181-196. https:// doi.org/10.3109/00207458508985616

Steriade, M. (1993). Cellular substrates of brain rhythms. In E. Niedermeyer, \& F. Lopez Da Silva (Eds.), Electroencephalography: Basic principles, clinical application, and related fields (pp. 27-62). Williams, Wilkins.

Steriade, M., \& Buzsaki, G. (1990). Parallel activation of thalamic and cortical neurons by brainstem and basal forebrain cholinergic systems. In M. Steriade, \& D. Biesold (Eds.), Brain cholinergic systems (pp. 3-62). Oxford University Press.

Steriade, M., Gloor, P. L. R. R., Llinas, R. R., Da Silva, F. L., \& Mesulam, M. M. (1990). Basic mechanisms of cerebral rhythmic activities. Electroencephalography and Clinical Neurophysiology, 76(6), 481-508. https://doi.org/10.1016/0013-4694(90)90001-Z

Stroganova, T. A., Orekhova, E. V., \& Posikera, I. N. (1999). EEG alpha rhythm in infants. Clinical Neurophysiology, 110, 997-1012. https:// doi.org/10.1016/S1388-2457(98)00009-1

Strüber, D., \& Herrmann, C. S. (2020). Modulation of gamma oscillations as a possible therapeutic tool for neuropsychiatric diseases: A review and perspective. International Journal of Psychophysiology, 152, 15-25. https://doi.org/10.1016/j.ijpsycho.2020.03.003

Strunk, J., James, T., Arndt, J., \& Duarte, A. (2017). Age-related changes in neural oscillations supporting context memory retrieval. Cortex, 91, 40-55. https://doi.org/10.1016/j.cortex.2017.01.020

Sweeney-Reed, C. M., Riddell, P. M., Ellis, J. A., Freeman, J. E., \& Nasuto, S. J. (2012). Neural correlates of true and false memory in mild cognitive impairment. PLoS One, 7(10), e48357. https://doi. org/10.1371/journal.pone.0048357

Tafuro, A., Ambrosini, E., Puccioni, O., \& Vallesi, A. (2019). Brain oscillations in cognitive control: A cross-sectional study with a 
spatial stroop task. Neuropsychologia, 133, 107190. https://doi. org/10.1016/j.neuropsychologia.2019.107190

Tallon-Baudry, C., \& Bertrand, O. (1999). Oscillatory gamma activity in humans and its role in object representation. Trends in Cognitive Sciences, 3(4), 151-162. https://doi.org/10.1016/S1364 -6613(99)01299-1

Tallon-Baudry, C., Bertrand, O., Peronnet, F., \& Pernier, J. (1998). Induced $\gamma$-band activity during the delay of a visual short-term memory task in humans. Journal of Neuroscience, 18(11), 4244 4254. https://doi.org/10.1523/JNEUROSCI.18-11-04244.1998

Teipel, S., Grothe, M. J., Zhou, J., Sepulcre, J., Dyrba, M., Sorg, C., \& Babiloni, C. (2016). Measuring cortical connectivity in Alzheimer's disease as a brain neural network pathology: Toward clinical applications. Journal of the International Neuropsychological Society, 22(2), 138-163. https://doi. org/10.1017/S1355617715000995

Tort, A. B., Komorowski, R., Eichenbaum, H., \& Kopell, N. (2010). Measuring phase-amplitude coupling between neuronal oscillations of different frequencies. Journal of Neurophysiology, 104(2), 11951210. https://doi.org/10.1152/jn.00106.2010

Tülay, E. E., Güntekin, B., Yener, G., Bayram, A., Başar-Eroğlu, C., \& Demiralp, T. (2020). Evoked and induced EEG oscillations to visual targets reveal a differential pattern of change along the spectrum of cognitive decline in Alzheimer's disease. International Journal of Psychophysiology, 155, 41-48. https://doi.org/10.1016/j.ijpsy cho.2020.06.001

van de Vijver, I., Cohen, M. X., \& Ridderinkhof, K. R. (2014). Aging affects medial but not anterior frontal learning-related theta oscillations. Neurobiology of Aging, 35(3), 692-704. https://doi. org/10.1016/j.neurobiolaging.2013.09.006

Van Deursen, J. A., Vuurman, E. F. P. M., van Kranen-Mastenbroek, V. H. J. M., Verhey, F. R. J., \& Riedel, W. J. (2011). 40-Hz steady state response in Alzheimer's disease and mild cognitive impairment. Neurobiology of Aging, 32(1), 24-30. https://doi.org/10.1016/j. neurobiolaging.2009.01.002

Van Deursen, J. A., Vuurman, E. F. P. M., Verhey, F. R. J., van KranenMastenbroek, V. H. J. M., \& Riedel, W. J. (2008). Increased EEG gamma band activity in Alzheimer's disease and mild cognitive impairment. Journal of Neural Transmission, 115(9), 1301-1311. https://doi.org/10.1007/s00702-008-0083-y

Venturella, I., Crivelli, D., Fossati, M., Fiorillo, F., \& Balconi, M. (2019). EEG and autonomic responses to nociceptive stimulation in disorders of consciousness. Journal of Clinical Neuroscience, 60, 101-106. https://doi.org/10.1016/j.jocn.2018.09.020

Voytek, B., D'Esposito, M., Crone, N., \& Knight, R. T. (2013). A method for event-related phase/amplitude coupling. NeuroImage, 64, 416-424. https://doi.org/10.1016/j.neuroimage.2012.09.023

Wang, C., Xu, J., Lou, W., \& Zhao, S. (2014). Dynamic information flow analysis in vascular dementia patients during the performance of a visual oddball task. Neuroscience Letters, 580, 108-113. https:// doi.org/10.1016/j.neulet.2014.07.056

Wang, C., Xu, J., Zhao, S., \& Lou, W. (2016). Graph theoretical analysis of EEG effective connectivity in vascular dementia patients during a visual oddball task. Clinical Neurophysiology, 127(1), 324-334. https://doi.org/10.1016/j.clinph.2015.04.063

Wang, L., Wang, W., Yan, T., Song, J., Yang, W., Wang, B., Go, R., Huang, Q., \& Wu, J. (2017). Beta-band functional connectivity influences audiovisual integration in older age: An EEG study. Frontiers in Aging Neuroscience, 9, 239. https://doi.org/10.3389/ fnagi.2017.00239
Wiesman, A. I., \& Wilson, T. W. (2019). The impact of age and sex on the oscillatory dynamics of visuospatial processing. NeuroImage, 185, 513-520. https://doi.org/10.1016/j.neuroimage.2018.10.036

Wróbel, A. (2000). Beta activity: A carrier for visual attention. Acta Neurobiologiae Experimentalis, 60(2), 247-260.

Xu, J., Lou, W., Zhao, S., \& Wang, C. (2015). Altered directed connectivity in patients with early vascular dementia during a visual oddball task. Brain Topography, 28(2), 330-339. https://doi. org/10.1007/s10548-014-0385-3

Xu, J., Zhao, S., Zhang, H., \& Zheng, C. (2011). Decreased delta event-related synchronization in patients with early vascular dementia. Clinical EEG and Neuroscience, 42(1), 53-58. https://doi. org/10.1177/155005941104200111

Yener, G. G., \& Başar, E. (2010). Sensory evoked and event related oscillations in Alzheimer's disease: A short review. Cognitive Neurodynamics, 4(4), 263-274. https://doi.org/10.1007/s1157 1-010-9138-5

Yener, G. G., \& Başar, E. (2013). Biomarkers in Alzheimer's disease with a special emphasis on event-related oscillatory responses. In Supplements to clinical neurophysiology (Vol. 62, pp. 237-273). Elsevier. https://doi.org/10.1016/B978-0-70205307-8.00020-X

Yener, G. G., Emek-Savaş, D. D., Güntekin, B., \& Başar, E. (2014). The visual cognitive network, but not the visual sensory network, is affected in amnestic mild cognitive impairment: A study of brain oscillatory responses. Brain Research, 1585, 141-149. https://doi. org/10.1016/j.brainres.2014.08.038

Yener, G. G., Emek-Savaş, D. D., Lizio, R., Çavuşoğlu, B., Carducci, F., Ada, E., Güntekin, B., Babiloni, C. C., \& Başar, E. (2016). Frontal delta event-related oscillations relate to frontal volume in mild cognitive impairment and healthy controls. International Journal of Psychophysiology, 103, 110-117. https://doi.org/10.1016/j.ijpsy cho.2015.02.005

Yener, G. G., Fide, E., Özbek, Y., Emek-Savaş, D. D., Aktürk, T., Çakmur, R., \& Güntekin, B. (2019). The difference of mild cognitive impairment in Parkinson's disease from amnestic mild cognitive impairment: Deeper power decrement and no phase-locking in visual event-related responses. International Journal of Psychophysiology, 139, 48-58. https://doi.org/10.1016/j.ijpsycho.2019.03.002

Yener, G., Güntekin, B., \& Başar, E. (2008). Event-related delta oscillatory responses of Alzheimer patients. European Journal of Neurology, 15(6), 540-547. https://doi.org/10.1111/j.1468-1331.2008.02100.x

Yener, G. G., Güntekin, B., Öniz, A., \& Başar, E. (2007). Increased frontal phase-locking of event-related theta oscillations in Alzheimer patients treated with cholinesterase inhibitors. International Journal of Psychophysiology, 64(1), 46-52. https://doi.org/10.1016/j.ijpsy cho.2006.07.006

Yener, G. G., Güntekin, B., Örken, D. N., Tülay, E., Forta, H., \& Başar, E. (2012). Auditory delta event-related oscillatory responses are decreased in Alzheimer's disease. Behavioural Neurology, 25(1), 311. https://doi.org/10.3233/BEN-2012-0344

Yener, G. G., Güntekin, B., Tülay, E., \& Başar, E. (2009). A comparative analysis of sensory visual evoked oscillations with visual cognitive event related oscillations in Alzheimer's disease. Neuroscience Letters, 462(3), 193-197. https://doi.org/10.1016/j. neulet.2009.07.036

Yener, G. G., Kurt, P., Emek-Savaş, D. D., Güntekin, B., \& Başar, E. (2013). Reduced visual event-related delta oscillatory responses in amnestic mild cognitive impairment. Journal of Alzheimer's Disease, 37(4), 759-767. https://doi.org/10.3233/JAD-130569 
Yordanova, J. Y., Kolev, V. N., \& Başar, E. (1998). EEG theta and frontal alpha oscillations during auditory processing change with aging. Electroencephalography and Clinical Neurophysiology/Evoked Potentials Section, 108(5), 497-505. https://doi.org/10.1016/S01685597(98)00028-8

Yuvaraj, R., Murugappan, M., Acharya, U. R., Adeli, H., Ibrahim, N. M., \& Mesquita, E. (2016). Brain functional connectivity patterns for emotional state classification in Parkinson's disease patients without dementia. Behavioural Brain Research, 298, 248-260. https://doi.org/10.1016/j.bbr.2015.10.036

Zanto, T. P., Toy, B., \& Gazzaley, A. (2010). Delays in neural processing during working memory encoding in normal aging. Neuropsychologia, 48(1), 13-25. https://doi.org/10.1016/j.neuro psychologia.2009.08.003

Zibrandtsen, I. C., Agger, M., \& Kjaer, T. W. (2020). Gamma entrainment in a large retrospective cohort: implications for photic stimulation therapy for Alzheimer's disease. Journal of Alzheimer's Disease, 75(4), 1181-1190. https://doi.org/10.3233/JAD-200083

How to cite this article: Güntekin, B., Aktürk, T., Arakaki, X., Bonanni, L., Del Percio, C., Edelmayer, R., Farina, F., Ferri, R., Hanoğlu, L., Kumar, S., Lizio, R., Lopez, S., Murphy, B., Noce, G., Randall, F., Sack, A. T., Stocchi, F., Yener, G., Yıldırım, E., \& Babiloni, C. (2021). Are there consistent abnormalities in event-related EEG oscillations in patients with Alzheimer's disease compared to other diseases belonging to dementia? Psychophysiology, 00e1-42. https://doi.org/10.1111/psyp.13934 